\title{
Interference of Toxoplasma gondii with IFN- $\gamma$-regulated gene expression of its host cell
}

\author{
PhD Thesis
}

\author{
in partial fulfilment of the requirements \\ for the degree "Doctor of Philosophy (PhD)" \\ in the Molecular Biology Program \\ at the Georg-August-University Göttingen, \\ Faculty of Biology
}

submitted by
Christine Lang
born in

Göttingen 
The experimental part of this thesis was performed at the

\section{Centre for Hygiene and Human Genetics \\ Department of Medical Microbiology \\ Georg-August-University \\ Göttingen, Germany}

Members of the thesis committee:

Prof. Dr. Uwe Groß (1 ${ }^{\text {st }}$ Referee $)$

Prof. Dr. Wolfgang Engel ( $2^{\text {nd }}$ Referee)

Prof. Dr. Donna J. Arndt-Jovin

Date of submission of the PhD thesis: 31.3.2005 
for my parents 
Herewith I declare, that I prepared the PhD thesis "Interference of Toxoplasma gondii with IFN- $\gamma$-regulated gene expression of its host cell" on my own and with no other sources and aids than quoted.

Göttingen, 31.3.2005

Christine Lang 


\section{List of publications}

Original publications

Lüder, C. G., Lang, C., Giraldo-Velasquez, M., Algner, M., Gerdes, J. and Gross, U. (2003). "Toxoplasma gondii inhibits MHC class II expression in neural antigen-presenting cells by down-regulating the class II transactivator CIITA." J Neuroimmunol 134(1-2): 1224.

Lüder, C. G., Algner, M., Lang, C., Bleicher, N. and Gross, U. (2003). "Reduced expression of the inducible nitric oxide synthase after infection with Toxoplasma gondii facilitates parasite replication in activated murine macrophages." Int J Parasitol 33(8): 83344.

Lang, C., Algner, M., Groß, U., Lüder, C.G.K. (2005). "Diverse mechanisms of Toxoplasma gondii to inhibit IFN- $\gamma$-induced MHC class II gene expression". In preparation.

\section{$\underline{\text { Abstracts }}$}

Lüder, C.G.K., Lang, C., Giraldo-Velasquez, M., Gross, U.. "Suppression of MHC class II expression in neural antigen-presenting cells by Toxoplasma gondii is mediated via interference with the class II transactivator CIITA". International Journal of Medical Microbiology, Volume 292, September 2002.

Lüder, C., Algner, M., Lang, C., Bleicher, N., Gross, U.. "Partial down-regulation of activation-induced NO production by Toxoplasma gondii enables parasite replication in moderately, but not fully activated murine macrophages". $7^{\text {th }}$ International Congress on Toxoplasmosis, Tarrytown, NY, USA, 23-27.05.2003.

Lang, C., Gerdes, J., Algner, M., Gross, U., Lüder, C.G.K.. "Modulation of interferonregulated host cell functions by Toxoplasma gondii facilitates intracellular survival". International Journal of Medical Microbiology, Volume 293, September 2003. 
Christine Lang, Michaela Algner, Uwe Gross, Carsten G.K. Lüder."Diverse mechanisms of Toxoplasma gondii to interfere with the IFN-gamma-induced MHC class II expression in murine macrophages". International Journal of Medical Microbiology, Volume 293, March 2004

Christine Lang, Michaela Algner, Uwe Gross and Carsten G.K. Lüder. "Differential effects of Toxoplasma gondii and parasite lysate on GAS-containing promoters driving IFN- $\gamma$ responsive genes". International Journal of Medical Microbiology, Volume 294, September 2004

Christine Lang, Uwe Gross and Carsten G.K. Lüder. "Diverse mechanisms of Toxoplasma gondii to modulate IFN- $\gamma$-regulated gene expression of its host cell". $14^{\text {th }}$ Japanese-German Cooperative Symposium on Protozoan diseases Düsseldorf; 20.-24. September 2004. 


\section{Acknowledgements}

I want to thank my supervisor PD Dr. Carsten G. K. Lüder for the design of an interesting project, which I got the opportunity to work on. I am grateful for his patient supervision in the experimental work, his continuous and extensive support.

I would like to thank Prof. Dr. Uwe Groß for giving me the opportunity to complete my $\mathrm{PhD}$ thesis at the Centre for Hygiene and Human Genetics, Department of Medical Microbiology of the Georg-August-University in Göttingen, his continuous support and valuable suggestions for my work.

I would like to thank the members of my thesis committee, Prof. Wolfgang Engel for being my second referee for this thesis and for his valuable contributions during thesis committee meetings, and Prof. Donna J. Arndt-Jovin for her willingness to join my thesis committee, her support and fruitful discussions during committee meetings.

I would like to thank Prof. Eberhard Günther for being member of my thesis committee and his fruitful contribution during the thesis committee meetings.

For their excellent assistance in performing some experiments I would like to thank Michaela Algner and Nicole Beinert.

I would also like to thank Dr. Hassan Dihazi, Göttingen for performing the MALDI-Tof analysis.

I would like to thank Dr. Andrea Kröger, Braunschweig for providing the mutant NIH/3T3 cell line expressing IRF-1/hER fusion protein, Dr. Mario Köster, Braunschweig for providing the NIH/3T3 cell line expressing the Stat-GFP fusion protein and Dr. Joel Ernst, New York for providing the RAW 264.7 cell line transfected with the CIITA pomoter IV driving luciferase. Furthermore, I would like to thank Dr. Ulrich Steinhoff, Berlin for providing the IL-10 knock-out mice and Dr. Vern Carruthers, Baltimore for providing highly concentrated excretory/secretory antigen preparations of $T$. gondii. 
I would also like to thank the coordination office of the Molecular Biology program for helping out whenever help was needed.

I would like to thank the Georg Christoph Lichtenberg Stiftung and the DFG for their financial support.

I would like to thank my parents Bunny and Rainer and my whole family as well as my best friends Sonja, Lars and Tobias for their consequent and warm support, without which I would have never made it so far.

Last but not least, I would like to thank all the people in the lab for their consequent support, the nice atmosphere, the good advice and of course for making the whole work fun: Thank you Tobias F., Andrea G., Diana H., Philine K., Polya V., Frieder S., Maja R., Wolfgang B., Ahmad S., Jeanette W., Anne S., Raimond L., Nicole M., Sandra M., Pia K., Lars T., Silvia F., Mathias H., Özden D., Stefan G. and Nadine B.. 


\section{$\underline{\text { Table of content }}$}

List of figures $\quad$ I

List of tables $\quad$ V

$\begin{array}{lll}\text { Abbreviations } & \text { VI }\end{array}$

$\begin{array}{lll}\text { Abstract } & \text { IX }\end{array}$

\section{Introduction}

1.1 Toxoplasma gondii 1

1.2 Medical importance of Toxoplasma gondii 2

1.3 The immune response against $T$. gondii 3

1.4 The intracellular life style of T. gondii 4

1.5 Immune modulation by intracellular pathogens 5

$\begin{array}{ll}1.6 \text { The major histocompatibility complex } & 6\end{array}$

$\begin{array}{ll}1.7 \text { Regulation of MHC class II expression } & 7\end{array}$

$\begin{array}{ll}1.8 \text { Alteration of MHC class II expression by pathogens } & 10\end{array}$

$\begin{array}{ll}1.9 \text { Specific aims } & 11\end{array}$

\section{Material and Methods}

$\begin{array}{ll}2.1 \text { Material } & 12\end{array}$

2.1.1 Cell culture 12

$\begin{array}{ll}\text { 2.1.2 Enzymes } & 13\end{array}$

2.1.3. Kits and reagents for nucleic acid isolation and manipulation 14

2.1.4. Molecular weight markers and standards $\quad 14$

2.1.5. Membranes and filters 14

2.1.6. Oligonucleotides 15

2.1.7. Antibodies (Ab) 16

$\begin{array}{ll}2.2 \text { Methods } & 17\end{array}$

$\begin{array}{ll}\text { 2.2.1 Cell culture } & 17\end{array}$ 
2.2.2 Preparation of UV-irradiated and heat-inactivated T. gondii

2.2.3 Preparation of $T$. gondii-lysate 20

2.2.4 Preparation of excreted/secreted antigens (ESA's) of $T$.gondii 21

2.2.5 Transwell experiments 22

2.2.6 Isolation of RNA 22

2.2.7 Reverse transcription 23

2.2.8 Polymerase chain reaction (PCR) 23

2.2.9 Agarose gelelectrophoresis 24

2.2.10 Analysis of murine macrophages by fluorescence activated cell 24 sorting (FACS)

2.2.11 Double immunofluorescence staining and microscopy 25

2.2.12 Preparation of nuclear and cytosolic cell fractions 27

2.2.13 Preparation of complete host cell extracts 28

2.2.14 Precipitation of oligonucleotide-bound proteins 29

2.2.15 SDS-polyacrylamid gelelectrophoresis (PAGE) 30

2.2.16 Western blotting and immunostaining 31

2.2.17 Two-dimensional gelelectrophoresis 33

2.2.18 MALDI-Tof 35

2.2.19 Electrophoretic mobility shift assay (EMSA) 35

2.2.20 Transient transfection 37

2.2.21 Luciferase assay 37

2.2.22 IL-10 ELISA

2.2.23 Chromatin immunoprecipitaion (ChIP) 39

\section{Results}

3.1 Interference of $T$. gondii with IFN- $\gamma$-regulated gene expression

3.1.1 T. gondii interferes with the expression of MHC class II in RAW 264.7 cells

3.1.2 T. gondii tachyzoites differentially interfere with

IFN- $\gamma$-responsive genes 
3.2.1 Host cell invasion is required for $T$. gondii-mediated inhibition of MHC class II expression

3.2.2 A parasite lysate mimics the interference of viable

T. gondii with IFN- $\gamma$ induced MHC class II expression

3.2.3 The molecule within the $T$. gondii lysate mediating the interference with IFN- $\gamma$-induced MHC class II expression is pronase sensitive

3.2.4 Interference of $T$. gondii with IFN- $\gamma$-induced MHC class II expression appears to be mediated by excreted/secreted antigens

3.2.5 Different preparations of excreted/secreted antigens derived from $T$. gondii did not interfere with IFN- $\gamma$-induced MHC class II expression

\subsection{Mechanisms of T. gondii interfering with IFN- $\gamma$-regulated}

3.3.1 Viable parasites and T. gondii lysate do not inhibit nuclear translocation of activated Stat $1 \alpha$ in response to IFN- $\gamma$

3.3.2 T. gondii interfere with MHC class II expression in cells expressing an IRF-1/hER fusion protein after stimulation with estradiol

3.3.3 T. gondii and $T$. gondii lysate differentially interfere with IFN- $\gamma$-mediated signalling

3.3.4 T. gondii and parasite lysate interfere with transcriptional activation of the CIITA promoter IV

3.3.5 Only viable $T$. gondii are able to interfere with a minimal GAS-containing promoter

3.3.6 T. gondii lysate stimulate the secretion of IL-10 by bone marrow-derived macrophages 
3.3.7 Kinetics of $T$. gondii-mediated interference with

IFN- $\gamma$-mediated signalling

3.3.8 Viable $T$. gondii modulate DNA-binding of GAF but induce a second GAS-binding complex

3.3.9 Recruitment of $\beta$-actin to GAS-containing oligonucleotides is reduced in cells infected with $T$. gondii

3.3.10 T. gondii interferes with the acetylation of histone 4 on the CIITA promoter IV

\section{Discussion}

4.1 Immune evasion strategies of $T$. gondii and parasite-mediated interference with antigen presentation via inhibition MHC class II

4.2 T. gondii interfere with IFN- $\gamma$-induced MHC class II expression in different cell types

4.3 T. gondii-mediated interference with IFN- $\gamma$-responsive genes in murine macrophages

4.4 Parasite requirements for inhibition of IFN- $\gamma$-induced MHC class II expression

4.5 Possible involvement of ESA's in parasite-mediated inhibition of MHC class II expression

4.6 Interference of $T$. gondii with IFN- $\gamma$-mediated signalling

4.7 Inhibition of transcriptional activation of IFN- $\gamma$-responsive promoters mediated by $T$. gondii

4.8 Mechanism of $T$. gondii lysate-mediated interference with MHC class II expression

4.9 T. gondii-induced modulation of GAS-binding complexes 


\section{List of figures}

Figure 1: $\quad$ Life cycle of $T$. gondii

Figure 2: $\quad$ The Jak-Stat signalling cascade in response to IFN- $\gamma$

Figure 3: $\quad T$. gondii tachyzoites interfere with the expression of MHC class II molecules in the monocyte/macrophage cell line RAW 264.7

Figure 4: $\quad$ T. gondii differentially interferes with IFN- $\gamma$-responsive genes

Figure 5: $\quad$ Ability of UV-irradiated and heat-inactivated T. gondii for host cell invasion and intracellular replication

Figure 6: $\quad$ Interference of $T$. gondii with IFN- $\gamma$-induced up-regulation of MHC class II expression requires host cell invasion but not intracellular replication of the parasite

Figure 7: T. gondii lysate mimics the inhibition of IFN- $\gamma$-induced MHC class II expression mediated by viable parasites

Figure 8: T. gondii lysate interferes with the expression of MHC class II molecules on the cell surface of murine macrophages

Figure 9: $\quad T$. gondii lysate interferes with the MHC class II expression in RAW 264.7 cells

Figure 10: The molecule within the T. gondii lysate inhibiting the up-regulation of MHC class II transcripts in response to IFN- $\gamma$ is pronase sensitive 
Figure 11: Excretory/secretory antigens of T. gondii appear to be involved in the interference with IFN- $\gamma$-induced MHC class II expression in murine macrophages

Figure 12: Different preparations of $T$. gondii excretory/secretory antigens do not interfere with IFN- $\gamma$-induced MHC class II expression in murine macrophages

Figure 13: The IFN- $\gamma$-induced nuclear translocation of Stat $1 \alpha$ is not abrogated by $T$. gondii and parasite lysate as determined by subcellular fractionation of RAW 264.7 cells and Western blot analysis

Figure 14: T. gondii and parasite lysate do not abrogate the nuclear translocation of Stat $1 \alpha$ in response to IFN- $\gamma$

Figure 15: The nuclear translocation of Stat-GFP fusion proteins in response to IFN- $\gamma$ is not inhibited by viable $T$. gondii or T. gondii lysate

Figure 16: T. gondii interfere with expression of MHC class II in estradiol-activated NIH/3T3 expressing a IRF-1/hER fusion protein

Figure 17: Viable T. gondii and parasite lysate differentially interfere with IFN- $\gamma$-induced gene expression

Figure 18: Viable parasites and T. gondii lysate interfere with CIITA-promoter IV-driven luciferase activity

Figure 19: Viable T. gondii but not parasite lysate interfere with transcriptional activity of a minimal GAS-containing promoter 
Figure 20: $\quad T$. gondii lysate induces the secretion of IL-10 by murine macrophages

Figure 21: IL-10 secretion by BMM is not involved in interference of $T$. gondii lysate with IFN- $\gamma$-induced MHC class II expression

Figure 22: Kinetics of T. gondii-mediated interference with the Jak-Stat signalling cascade

Figure 23: Viable $T$. gondii modulate the DNA-binding activity of nuclear extracts to GAS-containing oligonulceotides

Figure 24: Characterization of GAS-binding complexes after activation of macrophages with IFN- $\gamma$ or after infection with $T$. gondii

Figure 25: The T. gondii-induced second GAS-binding complex does not contain other members of the Stat family

Figure 26: Two-dimensional gelelectrophoresis of proteins pulled-down from cell lysates of $T$. gondii-infected or non-infected RAW 264.7 cells using GAS-containing oligonucleotides

Figure 27: Two-dimensional electrophoresis and coomassie staining of proteins pulled-down from non-infected RAW 264.7 cells using GAS-containing oligonucleotides

Figure 28: $\quad T$. gondii diminishes recruitment of $\beta$-actin to GAS-containing oligonucleotides

Figure 29: $\quad$ Subcellular distribution of $\beta$-actin is not changed after infection with $T$. gondii 
Figure 30: T. gondii interferes with IFN- $\gamma$-induced acetylation of histone 4 on the CIITA promoter IV 
List of tables

Table 1: $\quad$ Primary and secondary antibodies used for

FACS analysis

Table 2: $\quad$ Primary and secondary antibodies used for immunofluorescence staining

Table 3: $\quad$ Primary and secondary antibodies used for immunolabeling of Western blots

Table 4: $\quad$ Antibodies for supershift analysis in EMSA

Table 5: $\quad$ Results from MALDI-Tof analysis 


\section{$\underline{\text { Abbreviations }}$}

2D

two-dimensional

$\mathrm{Ab}$

antibody

AIDS acquired immunodeficiancy syndrom

APC antigen presenting cell

BMM bone marrow-derived macrophages

bp base pairs

BSA bovine serum albumin

cDNA complementary DNA

CIITA class II transactivator

CLIP class II-associated Ii chain peptide

CNS central nervous system

Cy 3 indocarbocyanin

Cy 5 indodicarbocyanin

Da dalton

dd $\mathrm{H}_{2} \mathrm{O}$ didestilled water

DEPC diethylenpyrocarbonate

DMEM Dulbecc`s MEM

DMSO dimethylsulfoxid

DNA desoxyribonucleic acid

DTT dithiothreitol

EBSS Earles Balanced Salt Solution

EBV Ebstein-Barr virus

EDTA ethylendiamintetraacidic acid

EMSA electrophoretic mobility shift assay

ER endoplasmatic reticulum

ESA's excreted/secreted antigens

$\mathrm{EtBr} \quad$ ethidiumbromid

FACS fluorescence-activated cell sorting

Fc $\gamma \mathrm{R} 1 \quad$ IgG Fc receptor type 1

FCS fetal calf serum

GAF gamma activated factor 
GAPDH glyceraldehyde-3-phosphate dehydrogenase

GAS gamma-interferon activated sites

GFP green fluorescence protein

HCMV human cytomegalovirus

HEPES 2-[4-(2-hydroxyethyl)-1-piperazinyl]-ethansulforacid

hER human estrogen recepetor

HRP horse raddish peroxidase

ICAM-1 intracellular adhesion molecule-1

IEF isoelectric focussing

IFN- $\gamma \quad$ interferon gamma

IgG immunoglobulin class $\mathrm{G}$

IGTP interferon-inducible GTP-binding protein

Ii invariant chain

IL interleukin

INDO indolamine 2,3-dioxygenase

iNOS inducible nitric oxide synthase

IRF interferon regulatory factor

ISGF3 interferon-stimulated genes factor 3

JAK Janus kinase

MALDI-tof Matrix Associated Laser Desorbtion Ionization-Time of flight

MHC major histocompatibility complex

mRNA messanger RNA

NK natural killer cells

PBS phosphate buffered saline

PCR polymerase chain reaction

PE phycoerythrin

$\mathrm{PGE}_{2} \quad$ prostaglandin $\mathrm{E}_{2}$

PMSF phenylmethylsulfonylfluorid

PTD protein transduction domain

PV parasitophorous vacuole

PVM parasitophorous vacuole membrane

r recombinant

RNA ribonucleic acid 
RNase ribonuclease

RPMI Roswell Park Memorial Institute Medium

RT reverse transcription

SDS sodiumdodecylsulfate

SH-2 src homology 2

STAT signal transducer and activator of transcription

TAE Tris, acidic acid, EDTA

TCR T cell receptor

Tris Tris(hydroxymethyl)-aminomethan

U unit

USF-1 upstream stimulatory factor 1

UV ultraviolet

X2BP $\quad$ X2 box binding protein 


\section{$\underline{\text { Abstract }}$}

Toxoplasma gondii is an obligate intracellular parasite that is able to persist within its host for the host's life span. The parasite has evolved multiple strategies in order to establish and maintain this persistence. One such strategy is the inhibition of IFN- $\gamma$-induced MHC class II expression via interference with IFN- $\gamma$-mediated signalling. In this study, it could be shown that viable $T$. gondii inhibit IFN- $\gamma$-induced MHC class II expression in the monocyte/macrophage cell line RAW 264.7. More importantly, analysis of the effect of $T$. gondii on a number of other IFN- $\gamma$-responsive genes revealed that the parasite interferes with mRNA levels of most but not all of the genes analysed so far. Parasite requirements for inhibition of IFN- $\gamma$-induced MHC class II up-regulation were analysed and the mechanisms involved on the host cell level were then further elucidated. It is shown that invasion of the host cell but not intracellular replication is required to enable the parasite to interfere with IFN- $\gamma$-induced MHC class II expression in murine macrophages. Furthermore, a T. gondii lysate was found to mimic the effect of viable parasites on MHC class II expression, suggesting that a parasite-derived factor rather than the process of host cell invasion itself is involved. However, analyses of the underlying cell-biological mechanisms revealed that viable parasites and $T$. gondii lysate differentially interfere with IFN- $\gamma$-mediated MHC class II expression. Thus, $T$. gondii exert diverse effects on those processes leading to MHC class II expression. The molecule within the parasite lysate mediating the inhibition of MHC class II is partially sensitive to pronase treatment indicating the involvement of a protein. Furthermore, it appears to be released by extracellular parasites, since $T$. gondii separated from the host cells by a semipermeable membrane also inhibit MHC class II expression of non-infected macrophages. However, different preparations of $T$. gondii-derived excretory/secretory (ES) antigens from the three specific ES organelles of the parasite did not interfere with IFN- $\gamma$-regulated MHC class II expression. Analyses of the mechanisms of the T. gondii-mediated abrogation of MHC class II expression on the host cell level revealed that viable parasite and the parasite lysate differentially interfere with the IFN- $\gamma$-induced signalling. Viable $T$. gondii and the parasite lysate do not abrogate the IFN- $\gamma$-induced nuclear translocation of Stat $1 \alpha$, but both interfere with the expression of the class II transactivator (CIITA). However, only viable parasites inhibit the transcript levels of interferon regulatory factor 1 (IRF-1). In addition, both parasite lysate and viable $T$. gondii abrogate the IFN- $\gamma$-induced transcriptional activity of the CIITA promoter IV while only viable $T$. gondii are also able to interfere with a 
minimal GAS-containing promoter as determined by luciferase reporter assays. This suggests the importance of the GAS-sequence and Stat $1 \alpha$ for interference of viable parasites with the transcriptional activation of IFN- $\gamma$-responsive genes. Furthermore, DNAbinding studies by EMSA revealed, that $T$. gondii lysate does not alter the DNA-binding activity of Stat $1 \alpha$ to the GAS-sequence. In contrast, viable parasites clearly diminish the formation of the IFN- $\gamma$-induced GAS-Stat $1 \alpha$-Stat $1 \alpha$ complex but instead induce the formation of a modified GAS-binding complex of lower electromobility, which was found to contain Stat1 $\alpha$. Precipitation with oligonucleotides containing the GAS-sequence, 2Dgelelectrophoresis and MALDI-Tof analyses revealed, that $T$. gondii interferes with the association of $\beta$-actin to GAS-containing DNA, which is independent of stimulation with IFN- $\gamma$ and of Stat $1 \alpha$-binding to GAS. Furthermore, viable parasites abrogate the acetylation of histone 4 on the CIITA promoter IV, further indicating that $T$. gondii interferes with the assembly of the basal transcription machinery. In conclusion, $T$. gondii alter the IFN- $\gamma$-induced chromatin remodelling at the CIITA promoter IV and diminish the recruitment of $\beta$-actin to the basal transcriptional machinery. This may then abrogate IFN$\gamma$-induced expression of MHC class II genes and possibly other IFN- $\gamma$-triggered immune responses facilitating intracellular survival of the parasite and its ability to establish persistent infections. 


\section{Introduction}

\subsection{Toxoplasma gondii}

Toxoplasma gondii was first discovered in 1908 by Nicolle and Manceaux in the North african rodent Ctenodactylus gundi (Nicolle and Manceaux, 1909). It belongs to the phylum Apicomplexa, a group of obligate intracellular protozoan parasites. A defining characteristic of the Apicomplexa is the so-called apical complex, a group of organelles including the excretory/secretory organelles, namely the micronemes, the rhoptries and the dense granules, as well as the polar ring and the conoid. These organelles are localized at the apical end of the organism and play an important role during host cell invasion. Other clinical relevant members of the group of Apicomplexa are Plasmodium spec., the causing agent of malaria.

As for most Apicomplexa, the lifecycle of $T$. gondii is complex (Figure 1) and was only fully understood in 1970 (Frenkel et al., 1970). T. gondii is able to infect a broad range of warm-blooded hosts including humans and lifestock animals and also a wide range of cell types within the host. The definitive hosts of $T$. gondii are members of the family Felideae, predominantly domestic cats, in which the sexual part of the parasites' life cycle can take place (Tenter et al., 2000). After taking up tissue cysts of $T$. gondii by eating infected bait, the parasite infects the epithelial cells of the small intestine of cats. Here, $T$. gondii differentiates into micro- and macrogametes, which fuse to form oocysts. These are excreted with the faeces of the cat and sporolate to highly resistant and infectious sporozoites, which are eventually taken up by the intermediate host (Dubey et al., 1998; Tenter et al., 2000). In addition to infection of the intermediate host by sporozoites, $T$. gondii can also be transmitted by two other main routes: ingestion of tissue cyst by eating raw or undercooked meat from infected intermediate hosts or via vertical transmission through the placenta from the mother to the foetus (Tenter et al., 2000). Oral uptake of the parasite by the intermediate host is followed by differentiation of $T$. gondii into the fast replicating tachyzoites in epithelial cells of the intestine. Tachyzoites replicate asexually in the host cell by dividing within the mother cell by endodyogeny. After six to seven divisions, the parasite is released from the dying host cell and is now able to infect new cells. During this acute phase of infection parasites disseminate into different organs, mainly the liver, the lymph nodes and the lung (Frenkel et al., 1988). In immunocompetent hosts, the acute phase of the $T$. gondii infection is successfully controlled by the immune system. The stress applied by the immune response drives the parasite to differentiate into 
slow replicating and tissue cyst forming bradyzoites. Compared to tachyzoites, bradyzoites have a reduced metabolic activity (Bohne et al., 1999) and are able to persist intracellularly for the hosts lifespan. These parasite containing tissue cysts are mainly found in the brain and in muscle tissue (Dubey et al., 1998). When infected intermediate hosts, e.g. rodents and birds are ingested by members of the felideae family, the life cycle of the parasite is completed.

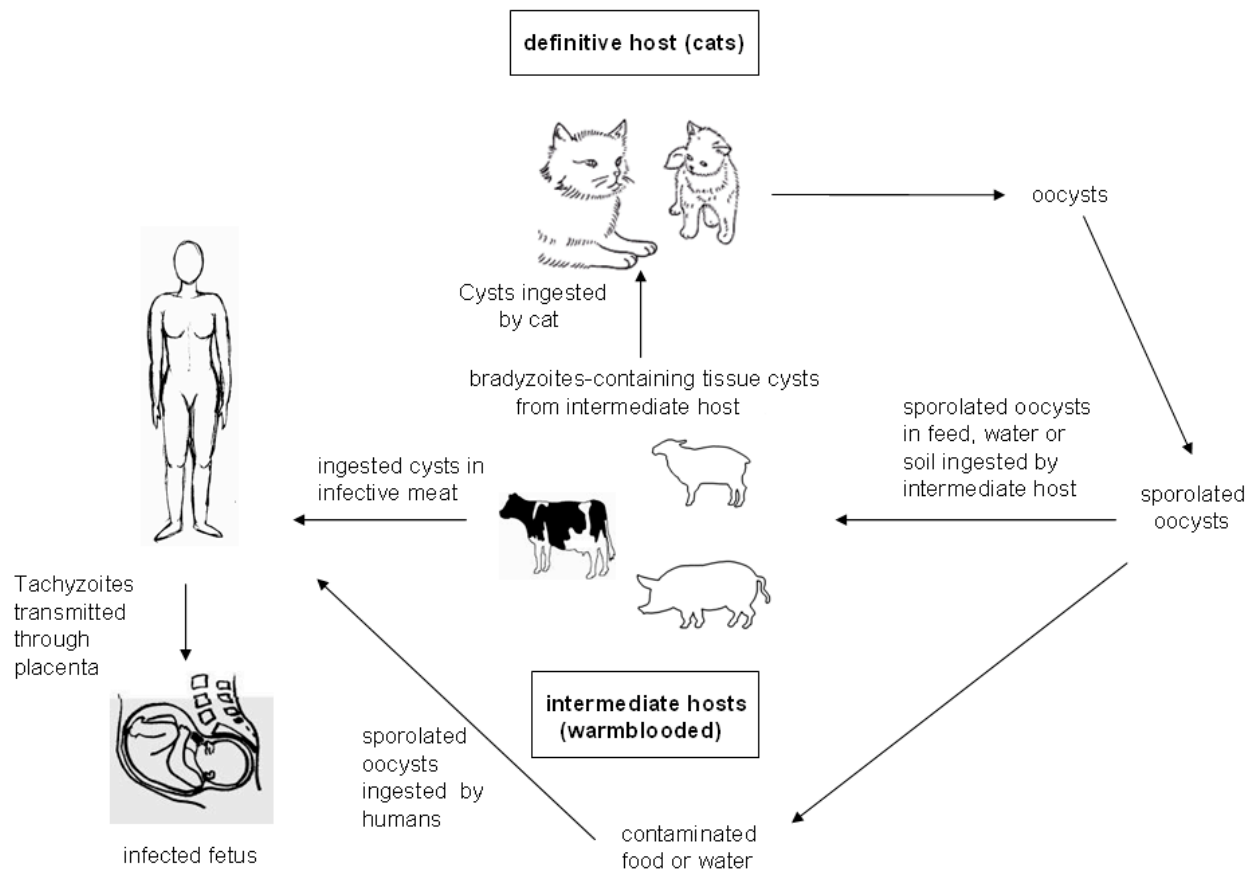

Figure 1: Life cycle of T. gondii.

Cats are the definitive hosts of $T$. gondii and can become infected by ingesting sporulated oocysts or (most often) infected animals. The oocysts are infectious to most mammals and birds. T. gondii can be transmitted to intermediate hosts through oocysts, by carnivorism, or transplacentally.

\subsection{Medical importance of Toxoplasma gondii}

T. gondii is one of the most abundant human pathogens worldwide. It is thought that about $30 \%$ of the human population are chronically infected with the parasite (McGavin 1996). In Germany the seroprevalence of $T$. gondii correlates with the age of the individuals, since about $20 \%$ of the 20 year olds, $30 \%$ of the 30 year olds and so on are infected with the parasite (Gross, 1994). In immunocompetent individuals, T. gondii most often does not 
cause any or only mild symptoms. However, reactivation of persisting bradyzoites in immunocompromised individuals, i.e. AIDS-patients or patients under immunosuppressive therapy, can lead to life-threatening toxoplasmosis with encephalitis, CNS lesions or chorioretinitis (Ambroise-Thomas et al., 1993; Ferreira et al., 2002). This indicates the medical importance of $T$. gondii as an opportunistic pathogen. T. gondii is also of major medical relevance during congenital toxoplasmosis acquired after primary maternal infection during pregnancy. This is due to the ability of $T$. gondii to transmigrate through the placenta. Fast replicating parasites can severely injure the foetus eventually leading to fatal toxoplasmosis followed by abortion (Ambroise-Thomas et al., 1993). Furthermore, development of the parasite to bradyzoites possibly results in various CNS lesions and/or chorioretinitis. Most often, however, the parasite forms tissue cysts early after transmission resulting in an asymptomatic toxoplasmosis at birth that may reactivate years later (Ambroise-Thomas et al., 1993).

\subsection{The immune response against $T$. gondii}

Infection with $T$. gondii is controlled by the humoral and the cell-mediated immunity in the immunocompetent host. The often fatal outcome of toxoplasmosis in immunocopromised patients supports the importance of the hosts immune response during $T$. gondii infection for the survival of the host. The cell-mediated immunity mainly controls the acute and chronic phase of toxoplasmosis (Denkers and Gazzinelli, 1998). Specifically, CD8-positive $\mathrm{T}$ cells play a major role as effector lymphocytes against $T$. gondii (Suzuki and Remington, 1988), whereas CD4-positive $\mathrm{T}$ cells are involved in the regulation of the immune response against T. gondii (Gazzinelli et al., 1991). During the early phase of infection, macrophages and natural killer (NK) cells are the first line of defence against $T$. gondii (Sher et al., 1993; Gazzinelli et al., 1993). Secretion of IL-12 by macrophages, neutrophils and especially by dentritic cells in response to the parasite results in differentiation and clonal expansion of Th1 T cells (Gazzinelli et al., 1994; Reis de Souza et al., 1997; Bliss et al., 1999). However, during the effector phase of the immune response, IFN- $\gamma$ is mainly involved in the control of a T. gondii infection (Suzuki et al., 1988). It induces a number of anti-parasitic effects being for example the formation of reactive oxygen and nitric oxide metabolites or the induction of tryptophan starvation (Adams et al., 1990; Murray and Cohn, 1979; Däubener et al., 1996). In addition, other proinflammatory cytokines are known to synergize with IFN- $\gamma$ in the induction of an adequate immune response against $T$. 
gondii, e.g. TNF- $\alpha$, IL-6 and IL-1 (Sibley et al., 1991; Langermany et al., 1992; Chao et al., 1994; Halonen et al., 1998).

\subsection{The intracellular life style of $T$. gondii}

The life style of intracellular pathogens protects against the hosts' humoral immune response, but this depends on a successful host cell invasion. Intracellular pathogens have evolved different strategies to enter its host cell and survive within it (Bogdan and Röllinghoff, 1999; Sibley, 2004). Trypanosoma cruzi, for example, the causing agent of chagas disease, forms a tight membranous vacuole in which the parasite resides only transiently. This formation is accomplished by the recruitment of lysosomes to the parasite attachment site, which then fuse and deliver membrane material for the vacuole. There are also reports of a lysosome-independent pathway, which involves the induced invagination of the host cell plasma membrane (Woosley et al., 2004). Once within the parasitophorous vacuole (PV), the parasite secretes a pore-forming toxin, which allows escape of $T$. cruzi into the cytosol of the host cell where the parasite grows and replicates (Bogdan and Röllinghoff, 1999). Leishmania spp. employ the host cell phagocytic pathway to enter the cell and finally end up in a phagolysosome, in which they are able to resist the acidic $\mathrm{pH}$ and the attack of lysosomal enzymes. $T$. gondii is able to actively invade its host cell, but in contrast to Plasmodium (Chitnis and Blackman, 2000), T. gondii infects a broad range of host cells. The content of three excretory/secretory organelles of the parasite, namely the micronemes, the rhoptries and the dense granules play a major role during the process of host cell invasion (Dubremetz, 1998). The content of the micronemes are thought to be important for the recognition of and the binding to the host cell (Dubremetz, 1995). Rhoptry antigens seem to be involved in the formation of the PV whereas molecules derived from the dense granules modify the PV to fit the parasites requirements and possibly to interact with the host cell (Dubremetz, 1995). The mechanism of cell entry is completely independent of the host cell cytoskeleton (Dobrowolsky and Sibley, 1996). The PV T. gondii resides in, is fusion incompetent, i.e. does not fuse with endosomes or lysosomes, thereby facilitating the parasites survival within the cell (Jones and Hirsch, 1972; Sibley et al., 1985; Joiner et al., 1990). This is accomplished by avoiding the inclusion of those host cell proteins into the membrane of the PV (PVM), which are anchored by transmembrane domains (Joiner and Dubremetz, 1993; Mordue et al., 1999). The PVM separates the parasite from the cytosol of the host cell but acts as a molecular 
sieve allowing small molecules of 1,300-1,900 Da to freely diffuse across the membrane (Schwab et al., 1994). Additionally, parasite-derived molecules are inserted into the PVM, which are thought to play a role in transport processes and may also modify the physiology of the host cell (Smith, 1995). The T. gondii-derived protein ROP 2, for example, is thought to be involved in the recruitment of mitochondria and endoplasmatic reticulum of the host cell to the PVM, possibly in order to facilitate the supply with nutritions (Sibley, 2003). T. gondii is auxotroph for purines and therefore has to acquire purines from the host cell. It is thought that a soluble NTPase derived form the dense granules may be involved in the salvage of purines by the parasite (Smith, 1995).

\subsection{Immunmodulation by intracellular pathogens}

The immune system of the host exerts multiple mechanisms to inhibit the growth of intracellular pathogens. Among others, macrophages are thought to play a critical role. Nevertheless, macrophages are important host cells for a number of protozoa (Stafford et al., 2002) and prokaryotes indicating the ability of such pathogens to successfully interfere with the afford of the immune system.

One mechanism of infected cells as well as cytotoxic immune cells is the induction of apoptosis to destroy intracellular pathogens (Williams, 1994; Liles, 1997; Everett and McFadden, 1999). However, several pathogens like L. donovani or T. gondii are able to interfere with apoptosis of their host cell to further establish the infection (Goebel et al., 2001; Heussler et al., 2001; Lüder et al., 2001). Furthermore, production of nitric oxide (NO) and reactive oxygen metabolites are key features of murine macrophages to restrict the replication of intracellular pathogens. Therefore, it is not surprising that a number of intracellular parasites interfere with such mechanisms. L. major and T. cruzi both inhibit the expression or the activity of the inducible nitric oxide synthase (iNOS) and by that successfully inhibit NO production (Bogdan and Röllinghoff, 1999). T. gondii is also able to interfere with the NO production of its host cell by inhibiting the iNOS expression in murine macrophages (Lüder et al., 2003). In addition, all three parasites are able to block the oxidative burst induced in macrophages after parasite entrance, thereby facilitating the establishment of an intracellular infection (Bogdan and Röllinghoff, 1999). Furthermore, different protozoan parasites modulate the production of cytokines by infected cells. For example, they either activate the production of anti-inflammatory cytokines like IL-10 as shown for Leishmania spp., T. cruzi and T. gondii, or they inhibit the production of pro- 
inflammatory cytokines like IL-12 in macrophages as employed by Leishmania spp. and $T$. gondii (Bogdan and Röllinghoff, 1999).

Another mechanism to avoid destruction by the immune system of the host is the interference with antigen processing and presentation by the host cell. Different intracellular pathogens including protozoan parasites, prokaryotes and viruses evolved multiple mechanisms to inhibit exposure of pathogen-derived antigens on the host cell surface. Importantly, $T$. gondii was also found to interfere with IFN- $\gamma$-induced MHC class I and class II expression on the surface of infected macrophages (Lüder et al., 1998; reviewed by Lüder and Seeber, 2001)

\subsection{The major histocompatibility complex}

The basic structure and the function of MHC class I and II have been extensively reviewed (see for example Brodsky and Guagliardi, 1991 or Jones, 1997). The major histocompatibility complex (MHC) encodes for proteins dedicated to present antigenic peptides to T cells. Such antigen presentation is accomplished by MHC class I and II proteins. Both types of molecules differ in the predominant source of the peptide they present: MHC class I molecules collect peptides that are derived from proteins synthesized in the cytosol (e.g. viral proteins), whereas MHC class II presents peptides derived from intracellular vesicles, e.g. from endocytosed proteins or from pathogens internalized by phagocytosis. In addition, the two types of MHC molecules present their antigens to different subsets of T cells: MHC class I molecules present peptides to CD8-positive T cells, whereas MHC class II molecules present peptides to CD4-positive T helper cells. The activation of certain T cell subsets is accomplished by expression of CD8 and CD4 coreceptors on the surface of the T cells that specifically bind to MHC class I and II molecules, respectively.

In most cell types, MHC class I is constitutively expressed. The molecule consists of a membrane-anchored heavy chain and a soluble, non-covalently associated $\beta_{2}$ microglobulin. The assembly of MHC class I within the endoplasmatic reticulum is facilitated by chaperones, but complete folding depends on the binding of an antigen, being a peptide of 8-10 amino acids, to the antigen binding-cleft of the molecule. The peptides are derived from cytosolic proteins, which are degraded by proteasomes. The fragments are then transported into the endoplasmatic reticulum via transporters associated with antigen processing-1/-2 (TAP1/TAP2) heterodimers, where they are eventually loaded on MHC 
class I molecules. MHC class I-peptide complexes are then transported to the cell surface. If the peptides are appropriately recognized by CD8-positive $\mathrm{T}$ cells via their $\mathrm{T}$ cell receptor, the $\mathrm{T}$ cells undergo clonal expansion and fulfill immune effector mechanisms. Since the peptides recognized by these $\mathrm{T}$ cells are mainly derived from viruses or other cytosolic pathogens, many of these organisms have evolved strategies to interfere with the MHC class I pathway (reviewed by Heemels et al., 1993).

MHC class II molecules are constitutively expressed by professional antigen-presenting cells (APC) including dendritic cells, B cells and macrophages. However, a number of different cell types can be activated by IFN- $\gamma$ to express MHC class II. MHC class II molecules consist of a heterodimer with two membrane-spanning $\alpha$ - and $\beta$-subunits. After assembly in the endoplasmatic reticulum, early peptide binding is prevented by association with the so-called invariant chain (Ii), which forms a trimer with the MHC class II molecule. The Ii also contains a signal that allows the transport of MHC class II molecules via the Golgi apparatus to lysosomal compartments of low pH. Herein, Ii is cleaved by acidic proteases leaving only a small peptide in the binding cleft, which is called class IIassociated invariant-chain peptide (CLIP). Removal of CLIP is catalyzed by non-classical MHC class II molecules H2-M in the MHC class II compartment (MIIC). H2-M also stabilizes non-peptide bound MHC class II molecules and catalyzes binding of an antigenic peptide. The binding cleft of MHC class II molecules is able to bind peptides of approximately 13-17 amino acids. Peptide-MHC class II complexes are then transported to the cell surface where they present the antigens to CD4-positive T cells. Appropriately activated CD4-positive $\mathrm{T}$ cells undergo clonal expansion or lead to the activation of other effector cells of the immune system, mainly macrophages to kill intracellular pathogens, or B cells to produce immunoglobulins. Therefore, a number of intravacuolar but also extracellular pathogens interfere with the expression of MHC class II molecules in order to interfere with activation of MHC class II-regulated immune responses.

\subsection{Regulation of MHC class II expression}

The expression of MHC class II is strictly regulated. In comparison to MHC class I molecules, which are ubiquitously expressed throughout a number of different cells, only distinct professional APCs express MHC class II constitutively. The expression of MHC class II as well as MHC class I can be induced or up-regulated by activating the cells with IFN- $\gamma$. This inducing signal is passed on via the Jak-Stat signalling pathway (Boehm et al., 
1997) (Figure 2). The IFN- $\gamma$ receptor contains two subunits: an $\alpha$-chain responsible for ligand binding and a $\beta$-chain responsible for signal transmission (reviewed by Bach et al., 1997). Each subunit is constitutively associated with janus kinases (Jaks), the $\alpha$-chain with Jak1 and the $\beta$-chain with Jak2. Upon binding of an IFN- $\gamma$ homodimer to two $\alpha$-chains of the IFN- $\gamma$ receptor, these two $\alpha$-chains dimerize and associate with two $\beta$-chains resulting in a complete ligand-receptor complex. This leads to transphosphorylation and reciprocal activation of the two Jaks. These then phosphorylate a tyrosine residue of the $\alpha$-chains of the IFN- $\gamma$ receptor, thereby creating the binding sites for $\mathrm{SH} 2$-domains of the signal transducer and activator of transcription (Stat) $1 \alpha$. Stat $1 \alpha$ is then itself phosphorylated by the Jaks at tyrosine 701 which leads to the dissociation and dimerization of Stat $1 \alpha$ molecules, forming the so called gamma-interferon activated factor (GAF) (reviewed by Bach et al., 1997). Dimerized Stat molecules translocate into the nucleus employing the Ran-GTP pathway via importin $\alpha$ and $\beta 1$ through the nuclear pore complex (NPC) (Sekimoto et al., 1997; McBride et al., 2002). The nuclear localization sequence (NLS) of activated Stat $1 \alpha$ is present in each monomer and was found to be arginine/lysine-rich (Melén et al., 2001). It is localized in close proximity to the DNA-binding domain of Stat $1 \alpha$ therefore excluding simultaneous binding of importin and DNA to Stat $1 \alpha$ (Fagerland et al., 2002). Within the nucleus, Stat1 $\alpha$ dimers are able to activate transcription by binding to their specific binding site, the palindromic consensus sequence TTCN $_{2-4}$ GAA called gamma-interferon activated site (GAS) (Decker et al., 1997). The interaction with the DNA then results in the activation of transcription. The dephosphorylation of the Stat molecules (Meyer et al., 2003) by nuclear protein tyrosine phosphatases (Haspel et al., 1999) allows the export of Stat from the nucleus employing a factor called chromosome region maintainance-1 (CRM-1) (McBride et al., 2000). Since the export signal of Stat1 $\alpha$ is localized within its DNA-binding domain, it has to be dephosphorylated before it dissociates from the DNA and is transported out of the nucleus (McBride et al., 2000).

To induce expression of MHC class II molecules by IFN- $\gamma$, dimerized Stat $1 \alpha$ has to bind to the GAS sequence in the promoter of the interferon regulated factor-1 (IRF-1), expression of which is required for transcription of the class II transactivator (CIITA) (Figure 2). CIITA has four or three distinctive pomoter regions in humans and mice, respectively (Muhlethaler-Mottet et al., 1997). The promoters I, II (only in humans) and III regulate tissue-specific constitutive transcription of CIITA leading to expression of MHC class II in distinct APCs (Muhlethaler-Mottet et al., 1997; Pai et al., 2002). The CIITA promoter IV 
regulates the inducible activation via IFN- $\gamma$ (Pai et al., 2002). It becomes activated upon binding of a Stat1 $\alpha$ dimer to the GAS sequence, of IRF-1 to its binding site, and ubiquitiously expressed upstream regulatory factor-1 (USF-1) to the E-box (MuhlethalerMottet et al., 1997). Kinetic analysis revealed, that Stat $1 \alpha$ binds to its binding site early after IFN- $\gamma$ stimulation, but CIITA transcription was found to be delayed up to two hours due to the time required for IRF-1 expression (Morris et al., 2002). CIITA is critical for transactivation of the MHC class II genes. It was found that the transcription of MHC class II genes, either FN- $\gamma$-induced or constitutive, is quantitatively dependent on the expression of CIITA (Steimle et al., 1994; Otten et al., 1998). In addition, transfection of CIITA is sufficient to induce MHC class II transcription, clearly showing that CIITA is a master regulator of MHC class II (Steimle et al., 1994).

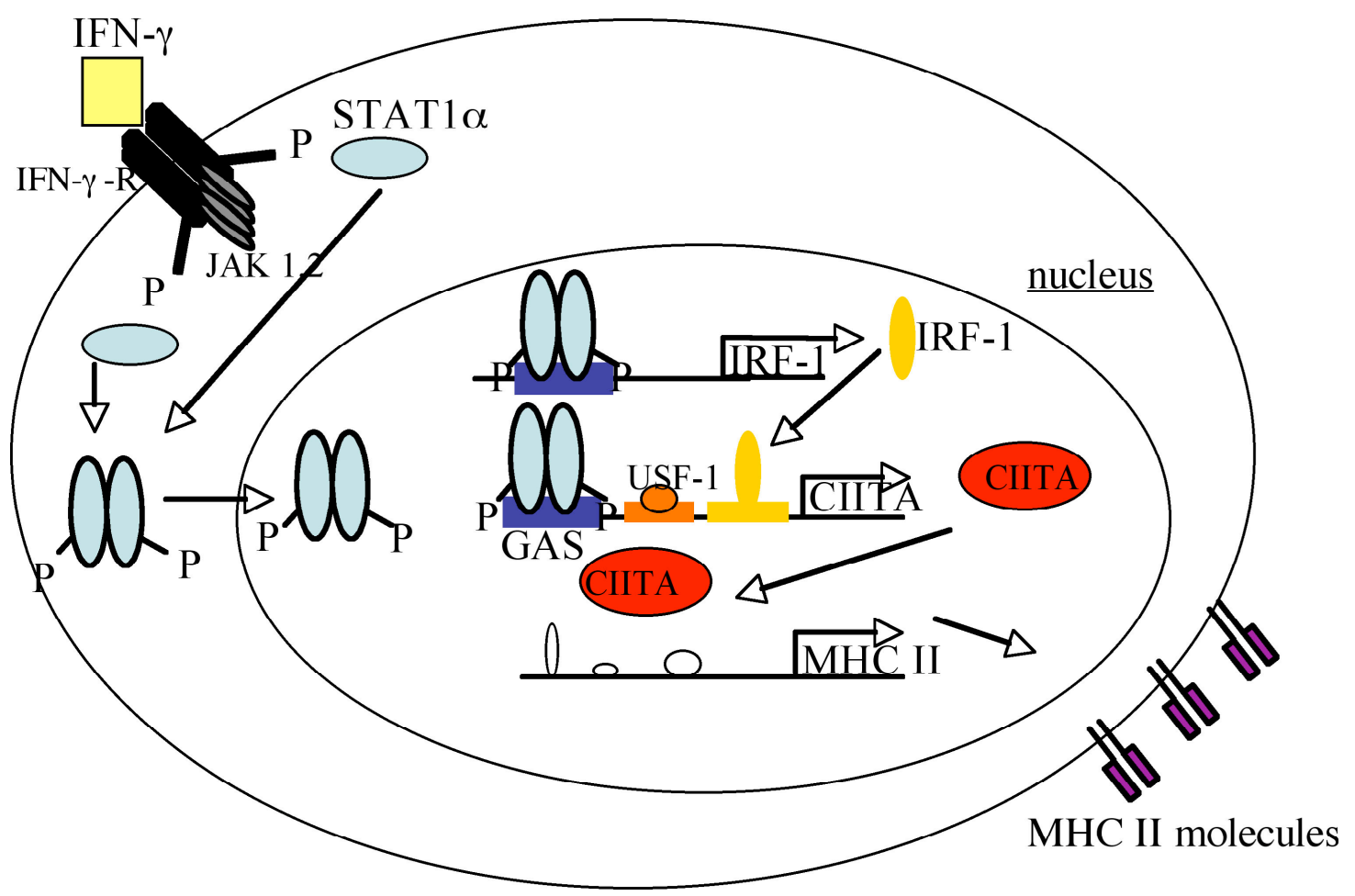

Figure 2: The Jak-Stat signalling cascade in response to IFN- $\gamma$.

Scheme of the MHC class II expression induced by IFN- $\gamma$ via the Jak-Stat signalling cascade. IFN- $\gamma-\mathrm{R}$ : IFN- $\gamma$ receptor Jak: janus kinase; Stat: signal transducer and activator of transcription; IRF-1: interferon regulatory factor 1; CIITA: class II transactivator; USF-1: upstream regulatory factor 1; GAS: gamma interferon activated site; MHC: major histocompatibility complex. 
The promoter region of MHC class II has a number of binding sites for different factors, i.e. W/S, X1, X2 and Y, ligation of which leads to the transcriptional activation of MHC class II genes. The heterotrimeric transcription factor RFX, composed of RFXB, RFX5 and RFXAP binds to X1. X2 is bound by X2BP (X2 binding protein) and $\mathrm{Y}$ is bound by the transcription factor NF-Y (Ting et al., 2002). RFX then recruits CIITA to the MHC class II promoter and is also involved in inducing the assembly of the enhanceosome (Masternak and Reith, 2002). Since all factors except for CIITA are constitutively expressed, CIITA represents the limiting factor for MHC class II expression (Boss et al., 1997).

\subsection{Alteration of MHC class II expression by pathogens}

MHC class II expression on the cell surface of infected cells and presentation of antigenic peptides to $\mathrm{T}$ cells is an important regulator of the hosts' immune defence against intracellular pathogens. Therefore, this mechanism is a target for a number of pathogens. $L$. donovani and Entamoeba histolytica, for example, interfere with MHC class II expression by inducing the autocrine secretion of prostaglandin E2 (PGE2) by the infected cell (Reiner et al., 1987; Wang and Chadee et al., 1995). L. major interferes with antigen presentation via MHC class II by inhibiting the antigen loading on the molecule (Fruth et al., 1993)), whereas L. amazonensis induces the degradation of MHC class II molecules (De Souza Leao et al., 1995).

Besides protozoan parasites, distinct viruses and bacteria are also able to interfere with antigen presentation via MHC class II. The Ebstein Barr virus (EBV) interferes with expression of MHC class II during the lytic cycle (Keating et al., 2002). The adenoviral protein E1A inhibits transcription of CIITA and MHC class II genes by inhibiting the interaction of Stat $1 \alpha$ and IRF-1 by direct binding to Stat $1 \alpha$ (Chatterjee-Kishore et al., 2000). The vaccina virus-derived phosophatase VH-1 interferes with the Jak-Stat signalling cascade by dephosphorylation of Stat1 $\alpha$ (Najarro et al., 2001). Intracellular bacteria also interfere with antigen presentation: M. tuberculosis expresses a $19 \mathrm{kDa}$ lipoprotein interfering with Jak-Stat signalling (Pai et al., 2003). Chlamydia trachomatis down-regulates MHC class II expression by inducing the degradation of USF-1 and therefore inhibiting the transcription of CIITA (Zhong et al., 1999).

T. gondii is also known to interfere with IFN- $\gamma$-induced MHC class II expression on the cell surface of infected macrophages (Lüder et al., 1998). Futhermore, the parasite is not only able to inhibit the up-regulation of MHC class II after activation with IFN- $\gamma$, but can 
also interfere with de novo synthesis of MHC class II molecules in already IFN- $\gamma$-activated macrophages. Importantly, inhibition of MHC class II expression by $T$. gondii has functional consequences since $\mathrm{T}$ cells are considerably less activated by $T$. gondii-infected macrophages treated with IFN- $\gamma$ compared to non-infected controls (Lüder et al., 2001). Additionally, the inhibition of MHC class II expression by T. gondii was found to be independent of the anti-inflammatory cytokines IL-10, TGF- $\beta$ and PGE2. Interference with MHC class II expression by the parasite is due to inhibition of transcription of MHC class II genes, which results from reduced mRNA levels of CIITA and IRF-1 (Lüder et al., 2001). However, T. gondii does neither interfere with expression of the IFN- $\gamma$ receptor nor with phosporylation of the IFN- $\gamma$ receptor or Stat $1 \alpha$ (Lüder et al., 2001). The bindingactivity of Stat1 $\alpha$ to its DNA-binding site was nevertheless diminished in parasite-infected primary bone marrow-derived macrophages (BMM). This could be due to an impaired nuclear translocation of activated Stat $1 \alpha$ in cells infected with the parasite as compared to uninfected control cells (Lüder et al., 2001).

\subsection{Specific aims}

T. gondii is able to chronically infect a wide variety of warmblooded hosts including humans. The persistence of the parasite within its host can only be achieved by a number of immune evasion strategies employed by the parasite. Interference of $T$. gondii with the MHC class II expression is one of such strategies, the underlying molecular mechanism of which is not fully understood. In the present study, the interference of $T$. gondii with IFN$\gamma$-induced Jak-Stat signalling was analysed in the monocyte/macrophage tumor cell line RAW 264.7 on the basis of the expression of MHC class II and a number of other IFN- $\gamma$ responsive genes. In order to elucidate the mechanisms of abrogation of MHC class IImediated antigen presentation after infection with $T$. gondii, the requirements of the parasite for this inhibition were analysed. Moreover, the mechanism of interference of $T$. gondii with IFN- $\gamma$-induced signalling was further examined.

Elucidation of the mechanisms of $T$. gondii to interfere with the IFN- $\gamma$-induced MHC class II expression may help to further understand the complex interaction of intracellular parasites and their host. 


\section{Material and Methods}

\subsection{Material}

Plasticware was obtained from Nunc (Roskilde, Denmark), Corning/Costar (Bodenheim), Greiner (Frickenhausen), Falcon (Becton Dickinson, Heidelberg) and Eppendorf (Hamburg).

Chemicals were purchased from Merck (Darmstadt), Roth (Karlsruhe) or Sigma (Munich), unless stated otherwise.

\subsubsection{Cell culture}

All cell culture media, reagents and additives were obtained from Biochrom (Berlin) if not indicated otherwise.

\section{RPMI 1640 (Roswell Park Memorial Institute)}

For in vitro propagation of $T$. gondii:

Instantpowder (Instamed T121-10) containing $300 \mathrm{mg} / \mathrm{l} \mathrm{L-glutamin,} \mathrm{supplemented} \mathrm{with}$ $2000 \mathrm{mg} / 1 \mathrm{NaHCO}_{3}$, adjusted to $\mathrm{pH} 7.2$, sterile filtered.

For cultivation of murine macrophages:

RPMI 1640 (FG 1215) containing 532 mg/l N-acetyl-L-alanyl-L-glutamine (stable Lglutamin) and $2000 \mathrm{mg} / \mathrm{l} \mathrm{NaHCO}_{3}$.

\section{DMEM (Dulbecco's MEM)}

Instantpowder (Instamed T 043-10) containing $4.5 \mathrm{~g} / 1$ glucose, $580 \mathrm{mg} / 1 \mathrm{~L}$-glutamin, supplemented with $3700 \mathrm{mg} / 1 \mathrm{NaHCO}_{3}$, adjusted to $\mathrm{pH}$ 7.2, sterile filtered.

$\underline{\text { Reagents and additives }}$

Penicillin-Streptomycin, $10.000 \mathrm{U} / 10.000 \mu \mathrm{g} / \mathrm{ml}$

EDTA, $1 \%$

Trypsin, $0.25 \%$

HEPES buffer, $1 \mathrm{M}$

Sodium pyruvate, $100 \mathrm{mM}$ 
Non-essential amino acids, 100x

FCS (fetal calf serum)

Dulbecco's Phosphate-buffered saline (PBS), Instamed 9.55 g/1

Trypanblue, $0.5 \%$ in PBS

Cetrimide-lysis buffer:

$1 \%$ Hexadecyltrimethylammonium bromide, $0.05 \%$ Amido black in $0.1 \mathrm{M}$ citric acid, $\mathrm{pH}$ 2.2

\section{Cytokines}

Interferon- $\gamma$, mouse (mIFN $\gamma$ ), recombinant from E.coli, $100.000 \mathrm{U} / \mathrm{ml}$ (Roche, Mannheim)

\section{Primary cells and cell lines}

Murine L929 fibroblasts

Primary murine bone marrow-derived macrophages from female BALB/c mice

Murine leukemia monocytic/macrophages, RAW 264.7 (TIB 71; ATCC, Rockville, MD)

Primary human foreskin fibroblasts (HFF)

Toxoplasma gondii NTE strain (mouse avirulent)

RAW 264.7 stably cotransfected with a construct containing -447 to +83 of CIITA promoter IV driving luciferase and pCDNA 3.1 neo (Invitrogen) (kindly provided by Dr. Ernst, New York) (Kincaid et al., 2003)

Murine NIH 3 T3 fibroblasts stably transfected with a fusion construct of Stat1 $\alpha$ conjugated with green fluorescence protein (GFP) (kindly provided by Dr. Mario Köster, Braunschweig) (Köster and Hauser, 1999)

Murine NIH 3T3 fibroblasts expressing an IRF-1/human estrogen receptor fusion protein (IRF-1/hER), which is reversibly activatable by $\beta$-estradiol (E2) (kindly provided by Dr. Andrea Kröger, Brauschweig) (Kröger et al., 2001)

\subsubsection{Enzymes}

Taq polymerase from Thermus aquaticus (Roche, Mannheim)

Fast Start Taq DNA polymerase (Roche, Mannheim)

Pronase from Streptomyces griseus (Roche, Mannheim) 


\subsubsection{Kits and reagents for nucleic acid isolation and manipulation}

RNA isolation:

GenElute Mammalian Total RNA Kit (Sigma, Munich)

Reverse transcription:

Omniscript reverse transcriptase (Qiagen, Hilden)

RNase inhibitor:

RNasin $40 \mathrm{U} / \mu 1$ (Promega, Madison, USA)

Luciferase assay:

Luciferase assay system (Promega, Madison, USA)

Oligonucleotide labeling:

Prime-It II Random Primer Labeling Kit (Stratagene, Amsterdam)

ChIP:

Chromatin Immunoprecipitation Assay Kit (Upstate cell signaling solutions, Lake Placid, USA)

IL-10 detection: Quantakine IL-10 Kit (R\&D Systems, Wiesbaden)

Light cycler PCR: LightCycler FastStart DNA Master ${ }^{\text {Plus }}$ SYBR Green I (Roche, Mannheim)

Mycoplasma detection kit: Venor GeM, Mycoplasma PCR detection kit (Minerva biolabs, Berlin)

\subsubsection{Molecular weight markers and standards}

DNA standards:

100 bp-DNA ladder: 80, 100, 200, 300, 400, 500, 600, 700, 800, 900, 1000 bp (MBI Fermentas, St. Leon-Rot)

Protein standards:

High molecular weight marker (HMW): 212, 170, 116, 76, 53 kDa (Amersham Bioscience, Freiburg)

Prestained protein marker: 175, 83, 62, 47.5, 32.5, 25, 16.5, 6.5 kDa (New England Biolabs, Frankfurt)

Protein molecular weight standards: 205, 116, 97, 80, 66, 55, 45, 30, 21, 14 and 6.5kDa (Amersham Bioscience, Freiburg)

\subsubsection{Membranes and filters}

$0.22 \mu \mathrm{m}$ Millex, syringe driven filter unit (Millipore, Bedford, USA)

$3.00 \mu \mathrm{m}$ Isopore, membrane filter (Millipore, Bedford, USA) 
$0.20 \mu \mathrm{m}$ sterile syringe filter (Corning/Costar, Bodenheim)

Centricon centrifugal filter devices, 3000 molecular weight cut off (MWCO) (Millipore, Bedford, USA)

Nitrocellulose membrane, Hybond ECL (Amersham Bioscience, Freiburg)

\subsubsection{Oligonucleotides}

The oligonucleotides were purchased from Sigma-Genosys (Darmstadt).

Oligonucleotide

$\beta$-actin forward

$\beta$-actin reverse

CIITA forward

CIITA reverse

CIITA_Promoter forward

CIITA_Promoter reverse

c-myc forward

c-myc reverse

$\mathrm{Fc} \gamma \mathrm{R} 1$ forward

$\mathrm{Fc} \gamma \mathrm{R} 1$ reverse

Fc $\gamma$ R1_Promoter forward

Fc $\gamma$ R1_Promoter reverse

Fc $\gamma$ R1-GAS-1

Fc $\gamma$ R1-GAS-2

Fc $\gamma$ R1-GAS-2A

Fc $\gamma$ R1-GAS-biot-1A

GAPDH reverse

GAPGH forward

$\mathrm{H} 2-\mathrm{Ab}$ forward

$\mathrm{H} 2-\mathrm{Ab}$ reverse

ICAM-1 forward

ICAM-1 reverse

IGTP forward

IGTP reverse

IL10_neo forward
Sequence 5'-3'

GTG GGC CGC TCT AGG CAC CAA

CTC TTT GAT GTC ACG CAC GAT TTC

CAG CCG AAC TAT AAT AAC TTG

ACT CTG TAC AGT GGT CAC TGC

GGT TGG GCT GAG ATA GAG TGA

TCT GTC TAC ACC TTC AGC TTT GG

CTC AAC GAC AGC AGC TCG CCC

GGA GAC GTG GCA CCT CTT GAG

GTC ACT TTA TGG TGT GAG GGG CCT

TGA GCA GTG GTA GAT GCC GCT G

AAG AGT GAG GTG GGA GGG ATA

AGA GGA AGG AAG TTG CCA TTT C

GTA TTT CCC AGA A

CTT TTC TGG GAA

CTT TTC TGG GAA ATA CAT C

biotin-GAT GTA TTT CCC AGA AAA G

CAC AGC CTT GGC AGC ACC AGT

TGT CAT CAA CGG GAA GCC CAT

CAG GAC AGA GGC CCT CAA CCA C

GAG GAA GAT CAC CCC AAG CAC GC

GAC CCA GCT CTC AGC AGT GCT GCT

ACA GAG TCA CTG CTG TTT GTG CTC

CAT CAG GTA CAG AGA TCC CTT AGA G

ATA CCA CCA TGA GCT TTC GAG AAG

TAG GCG AAT GTT CTT CC 


$\begin{array}{ll}\text { IL10_neo reverse } & \text { CCT GCG TGC AAT CCA TCT TG } \\ \text { INDO forward } & \text { CAG CGC CTG GCA CAC CTG GCC CTG } \\ \text { INDO reverse } & \text { CCA GAC TGG TAG CTA TGT CGT GCA } \\ \text { iNOS forward } & \text { TCT GGA GGA GCT CCT GCC TCA T } \\ \text { iNOS reverse } & \text { CAT CCC CTC TGA TGG TGC CAT C } \\ \text { IRF-1 forward } & \text { GCC CTC CTG AGT GAG TTA GGC C } \\ \text { IRF-1 reverse } & \text { CCC CTC AGG GCC AGC CCA GCG } \\ \text { Oligo dT } & \text { TTT TTT TTT TTT TTT } \\ \text { TAP 1 forward } & \text { TCT CGG GTG ACT GAG GAC ACA GCC ACC } \\ \text { TAP 1 reverse } & \text { ATT CCC GAG ACA CTC GTG GTC CAG ACT }\end{array}$

\subsubsection{Antibodies (Ab)}

Primary antibodies

rat anti-mouse H2-A/E (anti-MHC class II), IgG 2b, clone M5/114 (ATCC, Rockville, MD)

rat IgG 2b, isotype control Ab, clone R 35-38 (Pharmingen, Hamburg)

rabbit anti-Toxoplasma, serum

mouse anti-Toxoplasma, serum

mouse anti-SAG 1, clone DG 52

mouse anti-GRA 1, clone TG 17-34

biotin-conjugated anti-mouse H2-D ${ }^{\mathrm{d}}$ (anti-MHC class I), IgG 2a, clone 34-2-12

(Pharmingen, Hamburg)

biotin-conjugated mouse IgG 2a, isotype control Ab, clone G155-178 (Pharmingen, Hamburg)

rabbit anti-Stat1 $\alpha$ p91 (M-23) IgG (Santa Cruz, Santa Cruz, California, USA)

mouse anti-Stat1 C-terminus (clone 42) IgG2b (Transduction Laboratories, Lexington,KY)

rabbit anti-Stat2 (H-190) IgG (SantaCruz, Santa Cruz, California, USA)

rabbit anti-Stat3 (C-20) IgG (Santa Cruz, Santa Cruz, California, USA)

rabbit anti-Stat4 (C-29) IgG (Santa Cruz, Santa Cruz, California, USA)

rabbit anti-Stat5 (C-17) IgG (Santa Cruz, Santa Cruz, California, USA)

rabbit anti-Stat6 (M-20) IgG (Santa Cruz, Santa Cruz, California, USA)

rabbit anti-CBP (451) IgG (Santa Cruz, Santa Cruz, California, USA)

rabbit anti-p48 (C-20) IgG (Santa Cruz, Santa Cruz, California, USA)

mouse anti- $\beta$-actin (clone AC-15) IgG1 (Sigma, Munich) 
Secondary antibodies and conjugates

All secondary antibodies and conjugates were purchased from Dianova, Hamburg.

Cy 2-conjugated donkey $\mathrm{F}\left(\mathrm{ab}^{\prime}\right)_{2}$ anti-mouse IgG

Cy 2- conjugated donkey $\mathrm{F}\left(\mathrm{ab}^{\prime}\right)_{2}$ anti-rabbit $\mathrm{IgG}$

Cy 2- conjugated donkey $\mathrm{F}\left(\mathrm{ab}^{\prime}\right)_{2}$ anti-rat IgG

Cy 3- conjugated donkey $\mathrm{F}\left(\mathrm{ab}^{\prime}\right)_{2}$ anti-rabbit IgG

Cy 3- conjugated donkey $\mathrm{F}\left(\mathrm{ab}{ }^{\prime}\right)_{2}$ anti-mouse IgG

Cy 5- conjugated goat $\mathrm{F}\left(\mathrm{ab}^{\prime}\right)_{2}$ anti-mouse $\mathrm{IgG}$

Cy 5- conjugated donkey $\mathrm{F}\left(\mathrm{ab}^{\prime}\right)_{2}$ anti-rabbit IgG

R-Phycoerythrin- conjugated donkey $\mathrm{F}(\mathrm{ab})_{2}$ anti-rat IgG

R-Phycoerythrin- conjugated streptavidin

Peroxidase-conjugated donkey $\mathrm{F}\left(\mathrm{ab}{ }^{\prime}\right)_{2}$ anti-rabbit IgG

Peroxidase-conjugated goat $\mathrm{F}\left(\mathrm{ab}{ }^{\prime}\right)_{2}$ anti-mouse $\mathrm{IgG}$,

\section{2 $\underline{\text { Methods }}$}

\subsubsection{Cell culture}

Cell culturing was performed under strictly sterile conditions. In addition, cells were routinely tested and found to be negative for contamination with a variety of Mycoplasma species. Cells were maintained at $37{ }^{\circ} \mathrm{C}$ and $5 \% \mathrm{CO}_{2}$ in a humidified atmosphere.

\section{$\underline{\mathrm{L} 929}$}

L929 cells are murine fibroblasts and were used to routinely propagate $T$. gondii. The cells were cultivated in 6-well tissue culture plates in DMEM medium supplemented with 100 $\mathrm{U} / \mathrm{ml}$ penicillin, $100 \mu \mathrm{g} / \mathrm{ml}$ streptomycin, $1 \%$ heat-inactivated FCS, $1 \mathrm{mM}$ sodium pyruvate and $1 \mathrm{x}$ non-essential amino acids. They were subcultivated twice a week by scraping the confluent cells off the culture vessel with a sterile rubber policeman. Four to six drops of the homogenized cell suspension per well were recultivated in approximately $5 \mathrm{ml}$ fresh medium.

\section{RAW 264.7}

RAW 264.7, a monocyte/macrophage tumor cell line derived from a BALB/c mouse was used to determine the effect of $T$. gondii or different Toxoplasma preparations on the Jak- 
Stat signalling cascade and the expression of MHC class II molecules. The adherent cells were cultured in RPMI 1640 medium with stable L-glutamin supplemented with $10 \%$ heatinactivated FCS, $100 \mathrm{U} / \mathrm{ml}$ penicillin and $100 \mu \mathrm{g} / \mathrm{ml}$ streptomycin, $1 \mathrm{mM}$ sodium pyruvate, $10 \mathrm{mM}$ HEPES and $2.5 \mathrm{~g} / \mathrm{l}$ glucose in culture flasks. The cells were splitted twice a week and scraped off with a sterile rubber policeman. After centrifugation at $400 \mathrm{x} \mathrm{g}$ for 5 minutes, the cells were resuspended in an appropriate volume of fresh medium (splitting ratio $1: 6$ to $1: 15)$.

RAW 264.7 cells stably transfected with a construct of the luciferase gene under control of the CIITA pomoter IV were cultured as described above. Culture medium for these cells additionally contained $400 \mu \mathrm{g} / \mathrm{ml} \mathrm{G418} \mathrm{(Sigma,} \mathrm{Munich).}$

\section{$\underline{\mathrm{NIH} / 3 \mathrm{~T} 3}$}

Stable transfectants of NIH/3T3 fibroblasts were used to determine the effect of viable $T$. gondii and a $T$. gondii-lysate on the Jak-Stat signalling cascade.

Murine fibroblasts expressing the Stat $1 \alpha$-GFP fusion protein were cultured in DMEM supplemented with $10 \%$ FCS, $100 \mathrm{U} / \mathrm{ml}$ penicillin, $100 \mu \mathrm{g} / \mathrm{ml}$ streptomycin, $1 \mathrm{mM}$ sodium pyruvate and 1x non-essential amino acids. For selection of transfected cells, the culture medium was additionally supplemented with $2.5 \mu \mathrm{g} / \mathrm{ml}$ puromycin. The cells were splitted twice a week by washing with $1 \%$ EDTA and detaching $0.25 \%$ trypsin. After centrifugation for 5 minutes at $400 \mathrm{x} \mathrm{g}$, the cells were resuspended in culture medium and transferred into new flasks.

Murine fibroblasts expressing the IRF-1/hER fusion protein were cultured in DMEM supplemented with 10\% FCS (estradiol free, JRH Biosciences, Lenexa, Kansas, USA), 100 $\mathrm{U} / \mathrm{ml}$ penicillin, $100 \mu \mathrm{g} / \mathrm{ml}$ streptomycin, $1 \mathrm{mM}$ sodium pyruvate and $1 \mathrm{x}$ non-essential amino acids. Additionally, the cell culture medium was supplemented with $700 \mu \mathrm{g} / \mathrm{ml}$ G418 and $150 \mathrm{U} / \mathrm{ml}$ Hygromycin (Sigma). Cells were subcultured as described above for Stat $1 \alpha$-GFP expressing fibroblasts.

\section{$\underline{\mathrm{HFF}}$}

HFF, a primary cell line derived from human foreskin, were used for large-scale preparation of isolated $T$. gondii. The cells were cultured in DMEM medium supplemented with $10 \%$ heat-inactivated FCS, $100 \mathrm{U} / \mathrm{ml}$ penicillin, $100 \mu \mathrm{g} / \mathrm{ml}$ streptomycin, $1 \mathrm{mM}$ sodium pyruvate and 1x non-essential amino acids. For subcultivation, cells were rinsed with $1 \%$ EDTA and were detached from the culture flask by treatment with $0.25 \%$ trypsin. 
After centrifugation at $400 \mathrm{x}$ g for 5 minutes, the cells were resuspended in an appropriate volume of medium depending on the further use.

\section{T. gondii}

All experiments were conducted with the NTE strain, an european clinical isolate of $T$. gondii (Gross et al., 1991). They were cocultered with L929 as host cells in 12-well tissue culture plates in RPMI medium, supplemented with 1\% heat-inactivated FCS, $100 \mathrm{U} / \mathrm{ml}$ penicillin and $100 \mu \mathrm{g} / \mathrm{ml}$ streptomycin. T. gondii and L929 cells were mixed at different parasite to host ratios, ranging from 6 drops T. gondii suspension and 2 drops L929 suspension to 2 drops $T$. gondii suspension and 4 drops L929 suspension. Cocultures were maintained in a total volume of approximately $2 \mathrm{ml}$ per well. Depending on the parasite to host cell ratio, most L929 cells were lysed by $T$. gondii about 6 to 12 days after infection and extracellular parasites were used for infection assays or for subcultivation with uninfected L929 cells.

For infection assays, Toxoplasma was isolated from lysed L929 cells. For this, contaminating host cells were sedimented at $35 \mathrm{x} g$ for 5 minutes and the tachyzoitecontaining supernatant was centrifuged for 10 minutes at $1300 \mathrm{x} \mathrm{g}$. After washing twice in $10 \mathrm{ml}$ medium and centrifugation at $1300 \mathrm{x} \mathrm{g}$ for 10 minutes, the tachyzoites were resuspended in the appropriate host cell medium and the total number of isolated Toxoplasma cells was calculated using a Neubauer hemocytometer grid according to the following equation:

Total number of cells $=$ average number of cells in a large square $\mathrm{x}$ dilution factor $\mathrm{x}$ total resuspension volume $\times 10^{4}$.

Isolation and in vitro differentiation of primary murine bone marrow-derived macrophages To obtain primary murine bone marrow-derived macrophages (BMM), female BALB/c mice were sacrified with $\mathrm{CO}_{2}$ and the femurs were aseptically removed. Bone marrow cells were flushed out of the femurs with isolation medium RPMI 1640 supplemented with 100 $\mathrm{U} / \mathrm{ml}$ penicillin, $100 \mu \mathrm{g} / \mathrm{ml}$ streptomycin and 10\% FCS using a $26 \mathrm{G}$ needle and were collected in a Falcon tube. After sedimentation of solid material for 5 minutes, the supernatant was centrifuged at $400 \mathrm{x}$ g for 5 minutes. Cells were washed once in $10 \mathrm{ml}$ isolation medium and centrifuged again. The pellet was resuspended in an appropriate volume of differentiation medium (isolation medium additionally supplemented with 15$20 \%$ L929 supernatant as a source of GM-CSF). To determine the total number of viable 
cells, a 1:10 dilution of the cell suspension containing 0.05\% trypanblue in PBS was counted using a Neubauer hemocytometer grid and calculated as described above. Contaminating erythrocytes or erythrocyte precursers were not counted. After adjusting the suspension to an appropriate cell concentration using differentiation medium, cells were seeded in tissue culture plates and kept at $37^{\circ} \mathrm{C}$ for 3 days. On the third day $50 \%$ of the medium was exchanged using freshly prepared differentiation medium. After additional 3 days, the medium was completely removed and BMM were cultured for 16-20 hours in isolation medium, and then infected with $T$. gondii or left uninfected.

\subsubsection{Preparation of UV-irradiated and heat-inactivated $T$. gondii}

In order to determine the requirement of host cell invasion or intracellular replication for the modulation of MHC class II expression by murine macrophages, parasites were heatinactivated or UV-irradiated, respectively. For this, tachyzoites were isolated from $T$. gondii/L929 cocultures as described above. After counting the tachyzoites using a Neubauer hemocytometer grid, the number of cells was adjusted to 1 x $10^{7}$ per $\mathrm{ml}$ in culture medium of those host cells, which are used during the infection assay.

For UV-irradiation, the cell suspension was distributed in a tissue culture plate and the parasites were irradiated with UV light of $254 \mathrm{~nm}$ for 1 minute with a distance of the UVlight source of $20 \mathrm{~cm}$. The tachyzoites were then used for infection assays. The inability of UV-irradiated parasites to replicate intracellularly was confirmed by immunofluorescence microscopy two days after addition of inactivated parasites to RAW 264.7 cells.

For heat-inactivation, $1 \times 10^{7}$ parasites per $\mathrm{ml}$ were incubated in a thermomixer at $60^{\circ} \mathrm{C}$ for 30 minutes. After cooling to room temperature, the inactivated T. gondii were used for infection assays. The inability to invade host cells was confirmed by immunofluorescence microscopy two days after addition of the inactivated parasites to RAW 264.7 cells.

\subsubsection{Preparation of $T$. gondii-lysate}

T. gondii were isolated from L929 cocultures as described above. About $3 \times 10^{7}$ T. gondii were then used for infection of confluent HFF cells raised in $80 \mathrm{~cm}^{2}$ cell culture flasks. After lysis of the majority of host cells, contaminating HFF were removed by passing the tachyzoites through a filter with $3 \mu \mathrm{m}$ pore size. The $T$. gondii containing filtrate was centrifuged for 10 minutes at 1,300 x g. The pellet was washed twice in PBS and was then 
resuspended in $1 \mathrm{ml} \mathrm{PBS}, \mathrm{pH}$ 7.4. The cell number was determined using a Neubauer hemocytometer grid. The cells were then centrifuged again and the pellet was stored at $-80^{\circ} \mathrm{C}$.

The pellets of several preparations (about $5 \times 10^{9}$ ) were resuspended and pooled in $1.5 \mathrm{ml}$ PBS. After 3 cycles of freezing in liquid nitrogen and thawing at $37^{\circ} \mathrm{C}$, the cells were sonicated with a Branson Sonifier 250 for 10 minutes on ice with a duty cycle of $30 \%$ and an output level of 3 to homogenize the parasites. After 20 minutes on ice, the sample was sonicated again as described above. The lysate was centrifuged for 20 minutes at $20,800 \mathrm{x}$ $\mathrm{g}$ at $4^{\circ} \mathrm{C}$. The protein concentration of the supernatant was determined using the BCAassay according to the protocol of the manufacturer (Pierce, Rockford, IL) with BSA as protein standard. The $T$. gondii-lysate was stored at $-80^{\circ} \mathrm{C}$ until further use.

\subsubsection{Preparation of excreted/secreted antigens (ESA's) of $T$.gondii}

HFF in cell culture flasks were infected with T. gondii from L929 cocultures as described above. Three to four days later, when most of the HFF cells were lysed and the parasites still appeared healthy, the content of the culture flasks was thoroughly resuspended and filtered through a $3 \mu \mathrm{m}$ pore size filter to separate parasites from reminant host cells. The filtrate was collected in Falcon tubes and the parasites were centrifuged at 1,300 $\mathrm{xg}$ for 10 minutes. The cell pellets were pooled and resuspended in a total volume of $3 \mathrm{ml}$ RPMI 1640 medium. The total parasite number was determined as described above by counting an aliquot of a 1:1000 dilution using a Neubauer hemocytometer grid. The cell suspension was adjusted to $1 \times 10^{8}$ cells $/ \mathrm{ml}$, and was equally distributed in three wells of a six-well tissue culture plate. Since the protein content of ESA preparations differ depending on the secretion medium and the additives (Rabenau et al., 2001; Prigione et al., 2000; Carruthers et al., 1999), three different secretion conditions were employed: (1) 3\% FCS and 1\% ethanol (final concentrations) were added and parasites were incubated for 30 minutes at $37^{\circ} \mathrm{C}$, (2) $1 \%$ ethanol (final concentration) were added and parasites were also incubated for 30 minutes at $37^{\circ} \mathrm{C}$ and (3) $10 \%$ FCS were added and parasites were incubated for 3 hours at $37^{\circ} \mathrm{C}$. After incubation, the cell suspensions were centrifuged for 10 minutes at $1,300 \mathrm{x}$ g. The ESA-containing supernatants were sterilefiltered $(0,2 \mu \mathrm{m})$ and the ESA's were stored at $-80^{\circ} \mathrm{C}$ until further use. 


\subsubsection{Transwell experiments}

To determine whether T.gondii secretes/excretes molecules into the medium that interfere with MHC class II expression in murine macrphages, parasites were separated from the host cells by cultivating them in transwells with a pore size of $0.4 \mu \mathrm{m}$ allowing free diffusion of soluable material. For this RAW 264.7 cells were seeded in 24 well plates on glass cover slips at $1 \times 10^{5}$ per well. After 24 hours, T. gondii was isolated as described above and was added in different doses to transwells placed in 24 well tissue culture plates $(6.5 \mathrm{~mm})$ in which host cells have been seeded. Two to three hours after infection, cells

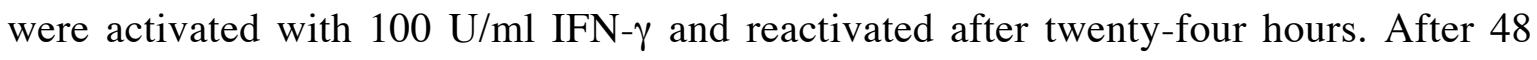
hours, cells were anlaysed by double immunofluorescence analysis.

\subsubsection{Isolation of RNA}

RNA was isolated using the GenElute Mammalian Total RNA Kit according to the manufacturers instructions (Sigma). The Spin Protocol for isolating total RNA from animal cells is based on the selective binding of nucleic acids to a silica-gel-based membrane under high-salt conditions, whereas contaminations are washed away. Bound RNA is then eluted under low-salt conditions.

For RNA experiments, $0.5 \times 10^{6}$ RAW 264.7 or $1 \times 10^{6}$ BMM or $1 \times 10^{5}$ NIH/3T3 IRF1/hER per well were seeded in 6 well plates. After complete differentiation of BMM as described above or 24 hours after seeding of RAW 264.7, NIH/3T3 IRF-1/hER, cells were infected with viable $T$. gondii or were treated with different $T$. gondii preparations as indicated and were activated with $100 \mathrm{U} / \mathrm{ml} \mathrm{IFN-} \gamma$ two to three hours later. Twenty-four hours post infection or treatment, cells were washed once with PBS and were then lysed directly in the tissue culture plate with $350 \mu \mathrm{l} /$ well of guanidine thiocyanate-containing buffer (lysis buffer supplemented with $\beta$-mercaptoethanol). The samples were homogenized by using the GenElute filtration columns included in the kit. This procedure shears the genomic DNA and reduces the viscosity of the lysate. To adjust the binding conditions, an equal volume of $70 \%$ ethanol (containing DEPC-treated water) was added and the samples were loaded onto the GenElute binding columns and were centrifuged at $8.000 \mathrm{x} \mathrm{g}$ for 15 seconds. Contaminations were removed by washing once with washing buffer 1 and twice with washing buffer 2 (both included in the kit). Finally, the RNA was eluted in $100 \mu \mathrm{l}$ RNase-free water and stored at $-80^{\circ} \mathrm{C}$. 
To determine the RNA concentration in different samples, RNA was diluted 1:10 in DEPC-treated water. The concentration was determined using an Ultraspec 1000 photometer (Pharmacia Biotech, Freiburg) at a wavelength of $260 \mathrm{~nm}$ and calculated according to the following equations:

Concentration of RNA sample $=40 \times$ A260 $x$ dilution factor

Total RNA yield $=$ concentration $\mathrm{x}$ volume of sample in milliliters .

\subsubsection{Reverse transcription}

RNA was reverse transcribed using the Omniscript reverse transcriptase (Quiagen). Reaction mixtures containing $2 \mu \mathrm{g}$ of RNA were combined with 1x RT buffer, $0.5 \mathrm{mM}$ each dNTP, $1 \mu \mathrm{M}$ oligo-dT primer, $10 \mathrm{U}$ RNase inhibitor, $4 \mathrm{U}$ Omniscript reverse transcriptase (final concentrations) and RNase-free water in a total volume of $20 \mu 1$ per sample. RNA was reverse transcribed at $37^{\circ} \mathrm{C}$ for $60-90$ minutes. The resulting cDNA was diluted 1:20 in water and stored at $-20^{\circ} \mathrm{C}$.

\subsubsection{Polymerase chain reaction (PCR)}

PCR was used to amplify distinct cDNA sequences using gene specific primer pairs. Amplification with $\beta$-actin-specific primers was employed to standardise the cDNA concentration in the different probes. IRF-1, CIITA and H2-Ab (MHC class II) cDNA's were amplified to compare the amount of these cDNAs in the different samples.

For each PCR a negative control was run in parallel containing distilled water instead of cDNA. Reaction mixtures were set up in a total volume of $50 \mu \mathrm{l}$ per sample containing:

$5 \mu 1 \quad 10 \times$ PCR-buffer

$1 \mu \mathrm{l} \quad \mathrm{dNTP}($ each $10 \mu \mathrm{M})$

$0.5 \mu \mathrm{l}$ forward-Primer $(50 \mu \mathrm{M})$

$0.5 \mu \mathrm{l}$ reverse Primer $(50 \mu \mathrm{M})$

$0.3 \mu \mathrm{l}$ Taq Polymerase $(5 \mathrm{U} / \mu \mathrm{l})$

$2 \mu \mathrm{l}$ cDNA template

dd $\mathrm{H}_{2} \mathrm{O}$ ad $50 \mu \mathrm{l}$.

PCR was performed in a T3 Thermocycler (Biometra, Göttingen ). For amplification of $\beta$ actin cDNA, samples were incubated for 3 minutes at $94^{\circ} \mathrm{C}$ followed by 26 cycles of denaturation for 1 minute at $94^{\circ} \mathrm{C}$, annealing for 1 minute at $60^{\circ} \mathrm{C}$ and extension for 1 
minute at $72^{\circ} \mathrm{C}$. Thereafter, polymerase reactions were completed for 10 minutes at $72^{\circ} \mathrm{C}$, before the samples were cooled to $4^{\circ} \mathrm{C}$. For all other genes examined, optimal amplification conditions were established and employed.

\subsubsection{Agarose gelelectrophoresis}

PCR products were seperated by agarose gelelectrophoresis. For this, $10 \mu 1$ of each sample were mixed with 10x loading dye (see below) and were separated on a $1 \%$ agarose gel in TAE (see below) supplemented with $1 \mu \mathrm{g} / \mathrm{ml}$ ethidiumbromide. To determine the size of the PCR products, a 100 base pair DNA ladder was separated in parallel. The bands were visualized by UV-light and the band intensities were quantitated using a BioDoc II digital imaging system (Biometra, Göttingen).

$\begin{array}{lll}\text { TAE buffer } & \underline{10 x \text { loading dye }} & \underline{\text { TES }} \\ 40 \mathrm{mM} \text { Tris } & 0.07 \% \text { bromphenolblue } & 0.05 \mathrm{M} \text { Tris } \\ 1 \% \text { acetic acid } & 33 \% \text { glycerin } & 0.005 \mathrm{M} \mathrm{EDTA} \\ 1 \mathrm{mM} \text { EDTA, pH } 8.0 & 7 \% \text { SDS } & 0.05 \mathrm{M} \mathrm{NaCl} \\ & \text { in TES } & \mathrm{pH} 8.0\end{array}$

\subsubsection{Analysis of murine macrophages by fluorescence activated cell sorting (FACS)}

FACS analysis was used to determine the expression of MHC class II proteins on the cell surface of Toxoplasma-infected, T. gondii-lysate-treated and uninfected BMM or RAW 264.7 quantitatively. For this, $0.8 \times 10^{7}$ RAW 264.7 cells or $1 \times 10^{7} \mathrm{BMM}$ were seeded in $92 \mathrm{~mm}$ cell culture dishes. After 24 hours or after complete differentiation of the BMM, cells were infected with viable $T$. gondii or were incubated with $T$. gondii-lysate. Cells were activated with $100 \mathrm{U} / \mathrm{ml} \mathrm{IFN}-\gamma$ two to three hours post infection and were reactivated with additional $100 \mathrm{U} / \mathrm{ml} \mathrm{IFN- \gamma} 24$ hours after infection. Forty to forty-five hours post infection, bone marrow-derived macrophages were rinsed with $1 \%$ EDTA, detached by incubation for 2-4 minutes with $0.25 \%$ trypsin and then resuspended in RPMI 1640 supplemented with $10 \%$ FCS, $100 \mathrm{U} / \mathrm{ml}$ penicillin and $100 \mu \mathrm{g} / \mathrm{ml}$ streptomycin. Thereafter, the remaining adherent cells were dislodged using a sterile rubber policeman and combined with the other cells of the same sample. RAW 264.7 cells were scraped off the dishes by 
using sterile rubber policemen and collected in $50 \mathrm{ml}$ tubes. After centrifugation of BMM or RAW 264.7 for 5 minutes at $400 \mathrm{x} \mathrm{g}$ and $4^{\circ} \mathrm{C}$, they were washed in the appropriate culture medium and centrifuged again. Pellets were resuspended in $1 \mathrm{ml}$ medium and the number of viable cells was determined by trypaneblue exclusion using a Neubauer hemocytometer grid. For each FACS staining, 500,000 cells per well were transferred in a 96 well V-bottom microtitre plate. After centrifuging the plate for 5 minutes at $400 \mathrm{x} \mathrm{g}$ and $4^{\circ} \mathrm{C}$, cells were incubated for 30 minutes on ice in $1 \%$ bovine serum albumin (BSA), 1 $\mathrm{mg} / \mathrm{ml}$ normal mouse gamma globulin and $0.1 \% \mathrm{NaN}_{3}$ in PBS. After centrifugation, cells were incubated for 30 minutes on ice with primary antibodies (see table 1) diluted in 1\% BSA and $0.1 \% \mathrm{NaN}_{3}$ in PBS (BSA/ $\left.\mathrm{NaN}_{3} / \mathrm{PBS}\right)$. Thereafter, cells were washed three times with $\mathrm{BSA} / \mathrm{NaN}_{3} / \mathrm{PBS}$, and were then incubated for 30 minutes on ice with secondary antibodies (see table 1) diluted in $\mathrm{BSA} / \mathrm{NaN}_{3} / \mathrm{PBS}$. Cells were washed again three times in $\mathrm{BSA} / \mathrm{NaN}_{3} / \mathrm{PBS}$ and were finally fixed in $300 \mu 11 \%$ paraformaldehyde in PBS. Samples were stored at $4^{\circ} \mathrm{C}$ until analysis using a Becton Dickinson FACScan.

Table 1: Primary and secondary antibodies used for FACS analysis

\begin{tabular}{|l|l|l|l|l|}
\hline & Primary antibody & Concentr. & Secondary antibody & dilution \\
\hline $\begin{array}{l}\text { negative } \\
\text { control }\end{array}$ & PBS/BSA & PBS/BSA & \\
\hline anti-MHC II & $\begin{array}{l}\text { anti-mouse H2-A/E } \\
(\mathrm{M} 5 / 114, \text { rat IgG2b }\end{array}$ & $2 \mu \mathrm{g} / \mathrm{ml}$ & $\begin{array}{l}\text { R-Phycoerythrin donkey } \\
\mathrm{F}\left(\mathrm{ab}^{\prime}\right)_{2} \text { anti-rat IgG }\end{array}$ & $1: 50$ \\
\hline $\begin{array}{l}\text { isotype } \\
\text { control }\end{array}$ & rat IgG2b (R35-38) & $2 \mu \mathrm{g} / \mathrm{ml}$ & $\begin{array}{l}\text { R-Phycoerythrin donkey } \\
\mathrm{F}(\text { ab' })_{2} \text { anti-rat IgG }\end{array}$ & $1: 50$ \\
\hline anti-MHC I & $\begin{array}{l}\text { biot. anti-mouse } \mathrm{H} 2-\mathrm{D} \\
(34-2-12, \text { mouse IgG2a) }\end{array}$ & $2 \mu \mathrm{g} / \mathrm{ml}$ & $\begin{array}{l}\text { R-Phycoerythrin- } \\
\text { Strepavidin }\end{array}$ & $1: 50$ \\
\hline $\begin{array}{l}\text { isotype } \\
\text { control }\end{array}$ & $\begin{array}{l}\text { biot. mouse IgG2a } \\
(\mathrm{G} 115-178)\end{array}$ & $2 \mu \mathrm{g} / \mathrm{ml}$ & $\begin{array}{l}\text { R-Phycoerythrin- } \\
\text { Strepavidin }\end{array}$ & $1: 50$ \\
\hline
\end{tabular}

\subsubsection{Double immunofluorescence staining and microscopy}

To determine the effect of T.gondii and different T.gondii preparations on the expression of MHC class II antigens or on subcellular localization of activated Stat $1 \alpha$ or $\beta$-actin on the single cell level, cells were immunostained and analysed microscopically. 
For immunofluorescence staining, $0.5 \times 10^{5}$ RAW 264.7 cells, $1 \times 10^{5}$ BMM or $0.3 \times 10^{5}$ Stat-GFP-transfected NIH/3T3 cells were seeded in 24 well plates containing glass cover slips. The following day or after complete differentiation of BMM as described (2.2.1), cells were infected with viable $T$. gondii, incubated with $T$. gondii-lysate or were left uninfected. In order to analyse the MHC class II expression, cells were activated with 100 $\mathrm{U} / \mathrm{ml} \mathrm{IFN}-\gamma$ two to three hours post infection and were reactivated 24 hours later. Forty to forty-five hours post infection cells were then washed twice with PBS and fixed with 4\% paraformaldehyde in $0.1 \mathrm{M}$ sodium cacodylat $/ \mathrm{HCl}, \mathrm{pH} 7.4$ at room temperature. For analysis of the nuclear translocation of Stat $1 \alpha$ or the subcellular localization of $\beta$-actin, cells were activated 24 hours post infection with $300 \mathrm{U} / \mathrm{ml}$ IFN $\gamma$ (Stat-GFP cells and the RAW 264.7) or $500 \mathrm{U} / \mathrm{ml}$ IFN- $\gamma$ (BMM) for 30, 60 or 90 minutes. Thereafter, cells were washed twice with PBS and fixed as described above. After washing twice for 5 minutes with PBS, cells were quenched for 10 minutes with $50 \mathrm{mM} \mathrm{NH}_{4} \mathrm{Cl}$ in PBS and washed again once in PBS. Cells were then permeabilized with $0.1 \mathrm{mg} / \mathrm{ml}$ saponin in PBS containing $1 \%$ BSA to block unspecific binding sites (saponin/BSA/PBS) for one hour at room temperature. Thereafter, cells were incubated for 1 hour at room temperature with one or an appropriate mixture of primary antibodies (see table 2) diluted in saponin/BSA/PBS. For this, the coverslips were incubated upsidedown in $30 \mu 1$ of antibody solution on Parafilm. After washing three times for 10 minutes with $0.1 \mathrm{mg} / \mathrm{ml}$ saponin in PBS (saponin/PBS), cells were incubated for one hour at room temperature as described above with the appropriate mixture of secondary antibodies (see table 2) diluted in saponin/BSA/PBS. Unbound antibodies were then removed by washing the cells three times for 10 minutes in saponin/PBS and once for 5 minutes in PBS. To visualize the total cell population, cover slips were incubated with $5 \mu \mathrm{g} / \mathrm{ml}$ propidiumiodide in PBS for 3 minutes, thereby staining nucleic acids unspecifically. After washing twice for 5 minutes with PBS, coverslips were rinsed in demineralized water and mounted on slides with $10 \mu \mathrm{l}$ Mowiol (Calbiochem, Bad Soden/Ts) per cover slip and dried over night at room temperature. The samples were stored at $4^{\circ} \mathrm{C}$ until examination using a Leica TCS SP2 confocal microscope.

Table 2: Primary and secondary antibodies used for immunofluorescence staining

\begin{tabular}{|l|l|l|l|}
\hline Primary antibody & concentration & Secondary antibody & concentration \\
\hline rat anti-mouse $\mathrm{H} 2-\mathrm{A} / \mathrm{E}$ & $5 \mu \mathrm{g} / \mathrm{ml}$ & $\mathrm{Cy} 2$-donkey $\mathrm{F}\left(\mathrm{ab}^{\prime}\right)_{2}$ anti-rat & $14 \mu \mathrm{g} / \mathrm{ml}$ \\
\hline
\end{tabular}




\begin{tabular}{|c|c|c|c|}
\hline $\begin{array}{l}\text { (clone M5/114) } \\
+ \text { rabbit anti-Toxoplasma } \\
\quad \text { (serum) }\end{array}$ & $1: 200$ & $\begin{array}{l}\operatorname{IgG} \\
+\mathrm{Cy} 5 \text { donkey anti-rabbit } \\
\text { IgG }\end{array}$ & 1:800 \\
\hline $\begin{array}{l}\text { rabbit anti-STAT } 1 \alpha \text { p91 } \\
(\mathrm{M}-23) 200 \mu \mathrm{g} / 0.1 \mathrm{ml} \\
+ \text { mouse anti-Toxoplasma } \\
\text { (serum) }\end{array}$ & $\begin{array}{l}2 \mu \mathrm{g} / \mathrm{ml} \\
1: 200\end{array}$ & $\begin{array}{l}\text { Cy2-donkey anti-rabbit } \\
\text { IgG } \\
+ \text { Cy5 goat anti-mouse } \\
\text { IgG }\end{array}$ & $\begin{array}{l}1: 50 \\
1: 50\end{array}$ \\
\hline $\begin{array}{l}\text { mouse anti- } \beta \text {-actin } \\
+ \text { rabbit anti-Toxoplasma } \\
\quad \text { (serum) }\end{array}$ & $\begin{array}{l}1: 62,5 \\
1: 200\end{array}$ & $\begin{array}{l}\text { Cy2-donkey anti-mouse } \\
\text { IgG } \\
+ \text { Cy5 donkey anti-rabbit } \\
\text { IgG }\end{array}$ & $\begin{array}{l}1: 50 \\
1: 50\end{array}$ \\
\hline
\end{tabular}

\subsubsection{Preparation of nuclear and cytosolic cell fractions}

To analyse the effect of $T$. gondii on nuclear translocation and DNA-binding activity of Stat $1 \alpha$ after activation with IFN- $\gamma$, cells were lysed in two steps to isolate cytosolic and nuclear fractions. For this, RAW 264.7 cells $\left(0.5 \times 10^{7} /\right.$ dish $)$ or BMM $\left(1 \times 10^{7} /\right.$ dish $)$ were seeded in $92 \mathrm{~mm}$ cell culture dishes. After complete differentiation of BMM or 24 hours after seeding RAW 264.7, cells were infected with viable $T$. gondii, incubated with parasite-lysate or left uninfected. Twenty-four hours post infection cells were scraped off and centrifuged at $400 \mathrm{x}$ g for 5 minutes. Thereafter, the cells were washed once in fresh medium and the pellet was resuspended in $10 \mathrm{ml}$ medium. A 1:2 dilution with trypanblue was counted in a Neubauer hemocytometer grid and equal cell numbers were seeded again and activated with $300 \mathrm{U} / \mathrm{ml} \mathrm{IFN}-\gamma$ for 30 minutes at $37^{\circ} \mathrm{C}$ or left non-activated. Thereafter, the cells were scraped off and transferred into $50 \mathrm{ml}$ tubes. After centrifugation at $400 \mathrm{x}$ g for 5 minutes, the pellet was washed in $1.5 \mathrm{ml}$ PBS containing $12.5 \mathrm{mM} \mathrm{NaF}, 1$ $\mathrm{mM} \mathrm{Na} \mathrm{VO}_{4}$ and centrifuged for 1 minute at $10,000 \mathrm{x} \mathrm{g}$ and $4{ }^{\circ} \mathrm{C}$. The pellet was then resuspended in $1.5 \mathrm{ml}$ hypotonic lysis buffer and incubated on ice for cell swelling. After 15 minutes, $81.2 \mu 1$ 10\% Nonidet P40 was added and each sample was vigorously mixed for 15 seconds. To further disrupt host cell membranes, the samples were passed five times through a $26 \mathrm{G}$ needle. Nearly complete cell lysis was confirmed by staining an aliquot of the samples with trypanblue. After centrifugation for 1 minute at $10,000 \mathrm{x} \mathrm{g}$ and $4^{\circ} \mathrm{C}$, the supernatants containing the cytosolic fraction were stored at $-80^{\circ} \mathrm{C}$. The pellet containing 
the host cell nuclei was washed once in $500 \mu \mathrm{l}$ of the hypotonic lysis buffer, was then resuspended in $100 \mu \mathrm{l}$ buffer $\mathrm{C}$ and incubated for 20 minutes at $4^{\circ} \mathrm{C}$ on a rotating platform. After centrifugation for 5 minutes at $15,000 \mathrm{x}$ g and $4^{\circ} \mathrm{C}$, the supernatant was stored at $80^{\circ} \mathrm{C}$ until further use.

Hypotonic lysis buffer:

$50 \mathrm{mM}$

HEPES

$50 \mathrm{mM}$

$\mathrm{KCl}$

$0.39 \mathrm{M}$

$\mathrm{NaCl}$

$1 \mathrm{mM}$

DTT

$0.1 \mathrm{mM}$

EDTA

$17.6 \mu \mathrm{g} / \mathrm{ml}$

PMSF

$0.04 \mathrm{mM}$

$\mathrm{Na}_{3} \mathrm{VO}_{4}$

in double distilled water

\section{Buffer C:}

$10 \mathrm{mM}$ HEPES

$10 \mathrm{mM} \quad \mathrm{KCl}$

$2 \mathrm{mM} \quad \mathrm{MgCl}_{2}$

$1 \mathrm{mM} \quad$ DTT

$0.1 \mathrm{mM} \quad$ EDTA

$17.6 \mu \mathrm{g} / \mathrm{ml} \quad$ PMSF

$0.1 \mathrm{mM} \quad \mathrm{Na}_{3} \mathrm{VO}_{4}$

10\% Glycerin

in double distilled water

\subsubsection{Preparation of complete host cell extracts}

To compare the total amount of activated Stat $1 \alpha$ and to precipitate Stat $1 \alpha$ and other oligonucleotide-bound proteins by pull-down assays in non-infected and $T$. gondii-infected cells, a complete cell extracts was prepared. For this, RAW 264.7 cells $\left(0.5 \times 10^{7} / \mathrm{dish}\right)$ or BMM (1 x 10 $10^{7} /$ dish) were seeded in $92 \mathrm{~mm}$ cell culture dishes. After complete differentiation of BMM or 24 hours after seeding RAW 264.7, cells were infected with viable $T$. gondii or were left uninfected. Twenty-four hours post infection cells were scraped off and a 1:2 dilution of an aliquot in trypanblue was counted using a Neubauer hemocytometer grid. Equal amounts of cells were activated with $300 \mathrm{U} / \mathrm{ml}$ IFN- $\gamma$ for 30 minutes at $37^{\circ} \mathrm{C}$ or were left unstimulated. Afterwards, cells were scraped off and centrifuged for 5 minutes at $400 \mathrm{x} \mathrm{g}$ and $4^{\circ} \mathrm{C}$. The pellets were resuspended in complete cell lysis buffer and incubated for one hour on ice. Thereafter, the probes were centrifuged for 15 minutes at $15,000 \mathrm{x} g$ and $4^{\circ} \mathrm{C}$ and the supernatants were stored at $-80^{\circ} \mathrm{C}$.

Complete cell lysis buffer:

$1 \% \quad$ Triton $\mathrm{X}-100$

$150 \mathrm{mM} \quad \mathrm{NaCl}$ 


$\begin{array}{ll}50 \mathrm{mM} & \text { Tris, pH } 8.0 \\ 50 \mathrm{mM} & \mathrm{NaF} \\ 5 \mathrm{mM} & \text { Sodium pyrophosphate } \\ 1 \mathrm{mM} & \text { PMSF } \\ 10 \mu \mathrm{M} & \text { Leupeptin } \\ 5 \mu \mathrm{g} / \mathrm{ml} & \text { Aprotinin } \\ 1 \mathrm{mM} & \mathrm{Na}_{3} \mathrm{VO}_{4} \\ 1 \mathrm{mM} & \text { EDTA pH } 8.0 \\ \text { in double distilled water }\end{array}$

\subsubsection{Precipitation of oligonucleotide-bound proteins}

To analyse the binding of Stat $1 \alpha$ and associated proteins to the GAS-sequence in T. gondii infected and uninfected cells, a pull-down assay using biotin-conjugated oligonucleotides was performed. For this, RAW 264.7 cells were seeded in $92 \mathrm{~mm}$ cell culture dishes at 0.5 x $10^{7}$ cells per dish. After 24 hours, cells were infected with viable $T$. gondii or were left uninfected. Twenty-four hours post infection cells were scraped off and a 1:2 dilution of an aliquot in trypanblue was counted using a Neubauer hemocytometer grid. Equal amounts of cells were then activated with $300 \mathrm{U} / \mathrm{ml} \mathrm{IFN-} \gamma$ for 30 minutes at $37^{\circ} \mathrm{C}$. Afterwards, a complete cell lysate was prepared as described above. The protein lysates were then incubated for 2 hours at $4{ }^{\circ} \mathrm{C}$ under constant mixing with $1 \mu \mathrm{M}$ dimerized biotin-conjugated oligonucleotides containing the GAS-sequence ( $\mathrm{Fc} \gamma \mathrm{R}$ 1-GAS-biot-1A: biotin-GAT GTA TTT CCC AGA AAA G and Fc $\gamma$ R1-GAS-2A: CTT TTC TGG GAA ATA CAT C). Dimerization was achieved as described in 2.2.16. In order to pull down oligonucleotide bound proteins, the samples were then incubated for one hour with UltraLink Immobilized Streptavidin Gel (Pierce, Rockford, IL). Thereafter, unspecifically bound proteins were removed by three consecutive washing steps in lysis buffer containing $100 \mathrm{mM} \mathrm{KCl}$ and one final washing step in lysis buffer.

During washing, samples were centrifuged at 2,500 $\mathrm{xg}$ and $4^{\circ} \mathrm{C}$ for 2 minutes. Finally, the pellet was resuspended in equal amounts of lysis buffer and 2x SDS sample buffer (125 $\mathrm{mM}$ Tris-HCl, $\mathrm{pH}$ 6.8, 20\% glycerol, 4\% SDS, $65 \mathrm{mM}$ DTT and 0.02\% bromphenol blue) and incubated for 5 minutes at $99^{\circ} \mathrm{C}$ under constant shaking. After centrifugation for 5 minutes at $4^{\circ} \mathrm{C}$ and $4,000 \mathrm{x}$ g, the supernatant was stored at $-80^{\circ} \mathrm{C}$ for further analysis. 


\subsubsection{SDS-polyacrylamid gelelectrophoresis (PAGE)}

In order to compare the protein content of samples or the proteins pulled-down by oligoprecipitation, complete or fractionated cell lysates of $T$. gondii-infected and uninfected cells as well as the oligoprecipitates were seperated by SDS-PAGE and analysed by immunoblotting.

For this, a $10 \%$ polyacrylamide separating gel or a 5\%-17\% gradient polyacrylamide gel using the gradient former model 385 (Biorad, Munich) was poured into a vertical gel cassette with spacers of $0.75 \mathrm{~mm}$ (Mini Protean 3, Biorad, Munich). To allow complete polymerization, the seperating gel was overlaid with isopropanol. Thereafter, isopropanol was removed by washing with destilled $\mathrm{H}_{2} \mathrm{O}$ and a $4.4 \%$ polyacrylamide stacking gel was poured onto the seperating gel and the comb was inserted.

The samples were diluted with SDS sample buffer to final concentrations as indicated below and heated for 5 minutes at $99^{\circ} \mathrm{C}$. The samples were then separated by SDS-PAGE in a discontinuous electrophoresis buffer (see below) at $25 \mathrm{~mA}$ per gel for about 60 minutes until the bromphenol blue tracking dye reached the bottom of the gel. High molecular weight protein marker as well as a prestained protein marker were separated in parallel.

$10 \%$ Separating gel:

$944 \mu 1$

$2 \mathrm{M}$ Tris- $\mathrm{HCl}, \mathrm{pH} 8.8$

$100 \mu 1$

$10 \%$ SDS

$1,670 \mu 1$

acrylamid/bisacrylamid $30 \%$

$2,265 \mu 1$

$20 \mu 1$

$10 \mu 1$ water (bidest.)

APS $10 \%$

TEMED

$0.04 \%$

$0.2 \%$

$5 \%$ and $17 \%$ separating gels were prepared as indicated for the $10 \%$ separating gel, except that $835 \mu \mathrm{l}$ or $2,837 \mu \mathrm{l}$ of $30 \%$ acrylamide/bisacrylamide were used respectively.

\section{4\% Stacking gel:}

$\begin{array}{ll}625 \mu \mathrm{l} & 0.5 \mathrm{M} \text { Tris-HCl, } \mathrm{pH} 6.8 \\ 50 \mu \mathrm{l} & 10 \% \mathrm{SDS} \\ 360 \mu \mathrm{l} & \text { acrylamid/bisacrylamid } 30 \% \\ 1,450 \mu \mathrm{l} & \text { water (bidest.) }\end{array}$

final concentrations:

$0.125 \mathrm{M}$

$0.2 \%$

$4.4 \%$ 
$5 \mu \mathrm{l} \quad$ bromphenol blue

$\begin{array}{lll}10 \mu \mathrm{l} & \text { APS } 10 \% & 0.04 \% \\ 10 \mu \mathrm{l} & \text { TEMED } & 0.4 \%\end{array}$

electrophoresis buffer:

SDS sample buffer:

$\begin{array}{llll}25 \mathrm{mM} & \text { Tris, } \mathrm{pH} 8.3 & 62.5 \mathrm{mM} & \text { Tris-HCl, pH } 6.8 \\ 192 \mathrm{mM} & \text { glycin } & 10 \% & \text { glycerin } \\ 0.1 \% & \text { SDS } & 32.5 \mathrm{mM} & \text { DTT } \\ & & 2 \% & \text { SDS } \\ & & 0,01 \% & \text { bromphenol blue }\end{array}$

\subsubsection{Western blotting and immunostaining}

Proteins separated by SDS-PAGE were transferred on nitrocellulose membranes (Hybond ECL) using a semidry blot system. For this, a blot sandwich was built up in the following order:

anode

6 Whatman filter papers soaked in $0.3 \mathrm{M}$ Tris- $\mathrm{HCl}, \mathrm{pH} 10.4$ and $20 \%$ methanol

3 Whatman filter papers soaked in $25 \mathrm{mM}$ Tris- $\mathrm{HCl}, \mathrm{pH} 10.4$ and $20 \%$ methanol nitrocellulose membrane

SDS-PAGE gel

9 Whatman filter papers soaked in $40 \mathrm{mM}$ 6-aminocapronic acid, $\mathrm{pH} 7.6$ and $20 \%$

methanol

kathode

The proteins were transferred at $0.8 \mathrm{~mA}$ per $\mathrm{cm}^{2}$ gel size for 90 minutes. To control the efficency of the protein transfer and to visualize marker proteins, membranes were stained with Ponceau S solution (Sigma) for 2 minutes and rinsed with distilled water.

To detect specific proteins, the membrane was immunostained using ECL reagents (enhanced chemiluminescence, Amersham Biosciences, Freiburg). The detection is based on the oxidation of luminol by horseradish peroxidase (HRP) conjugated to the secondary antibody. Oxidation of luminol leads to the formation of excitated luminal, which then converts back by emitting light. This process is enhanced through the presence of chemical enhancers, i.e. phenol. The membrane was blocked over night at $4{ }^{\circ} \mathrm{C}$ in blocking solution 
(see below). After washing 5 minutes in washing solution, the membrane was incubated with primary antibodies (Table 3) diluted in incubation solution (see below) for 120 minutes at room temperature or over night at $4^{\circ} \mathrm{C}$. After washing three times 5 minutes each, the membrane was incubated for 90 minutes at room temperature with the appropraite HRP-conjugated secondary antibody (see table 3) diluted in incubation solution. The membrane was then washed once for 15 minutes and five times 5 minutes each in washing solution. Afterwards, the ECL-reagents were mixed 1:2 and the membrane was incubated for 1 minute. Superfluous solution was removed and the membrane was covered with plastic foil. Immunolabeling was then visualized by exposing Hyperfilm ECL to the membrane (Amersham Biosciences, Freiburg).

Table 3: Primary and secondary antibodies used for immunolabeling of Western blots

\begin{tabular}{|c|c|c|c|}
\hline Primary antibody & dilution & Secondary antibody & dilution \\
\hline $\begin{array}{l}\text { rabbit } \\
\text { anti-Toxoplasma } \\
\text { serum }\end{array}$ & $1: 2000$ & $\begin{array}{l}\text { Peroxidase- } \\
\text { conjugated donkey } \\
\text { anti-rabbit IgG }\end{array}$ & $1: 10,000$ \\
\hline $\begin{array}{l}\text { mouse anti-SAG1 } \\
\text { (clone DG 52) }\end{array}$ & $1: 1000$ & $\begin{array}{l}\text { peroxidase- } \\
\text { conjugated } \mathrm{F}\left(\mathrm{ab}^{\prime}\right)_{2} \\
\text { goat anti-mouse IgG }\end{array}$ & $1: 10,000$ \\
\hline $\begin{array}{l}\text { mouse anti-GRA1 } \\
\text { (clone TG 17-34) }\end{array}$ & $1: 20,000$ & $\begin{array}{l}\text { peroxidase- } \\
\text { conjugated } \mathrm{F}\left(\mathrm{ab}^{\prime}\right)_{2} \\
\text { goat anti-mouse IgG }\end{array}$ & $1: 10,000$ \\
\hline $\begin{array}{l}\text { mouse anti-STAT } 1 \alpha \\
\text { C-terminus (clone } \\
42)\end{array}$ & $1: 2500$ & $\begin{array}{l}\text { peroxidase- } \\
\text { conjugated } \mathrm{F}\left(\mathrm{ab}{ }^{\prime}\right)_{2} \\
\text { goat anti-mouse } \mathrm{IgG}\end{array}$ & 1: 10,000 \\
\hline $\begin{array}{l}\text { mouse anti- } \beta \text { actin } \\
\text { (clone AC-15) }\end{array}$ & $1: 1250$ & $\begin{array}{l}\text { peroxidase- } \\
\text { conjugated } \mathrm{F}\left(\mathrm{ab}{ }^{\prime}\right)_{2} \\
\text { goat anti-mouse } \mathrm{IgG}\end{array}$ & $1: 10,000$ \\
\hline $\begin{array}{l}\text { rabbit anti-CBP/P300 } \\
(451)\end{array}$ & $1: 250$ & $\begin{array}{l}\text { Peroxidase- } \\
\text { conjugated donkey } \\
\text { anti-rabbit IgG }\end{array}$ & 1: 10,000 \\
\hline
\end{tabular}




\begin{tabular}{|c|c|c|}
\hline Blocking solution: & Washing solution: & Incubation solution: \\
\hline dry skimmed milk & $0.05 \%$ Tween-20 & $5 \%$ dry skimmed milk \\
\hline $0.2 \% \quad$ Tween-20 & in $\mathrm{PBS}, \mathrm{pH} 7.4$ & $0.05 \%$ Tween-20 \\
\hline $0.02 \% \mathrm{NaN}_{3}$ & & in PBS, $\mathrm{pH} 7.4$ \\
\hline
\end{tabular}
in PBS, pH 7.4

\subsubsection{Two-dimensional gelelectrophoresis}

To analyse the proteins bound to GAS-containing oligonucleotides isolated by pull down assay (2.2.14) of T. gondii infected and non-infected RAW 264.7 cell lysates, twodimensional gelelectrophoresis was performed. Proteins are separated in the first dimension according to their isoelectric point and in the second dimension according to their molecular weight. For this, complete cell lysates of parasite-infected and non-infected RAW 264.7 cells were prepared and the oligoprecipitation was performed as described. To concentrate the proteins and to remove salts, protein samples were washes twice in $2 \mathrm{ml}$ of double distilled water using centricon centrifugal filter devices with a 3,000 MWCO. The devices were centrifuged at $2,500 \mathrm{xg}$ and $4^{\circ} \mathrm{C}$ until the volume was reduced to about 200 $\mu 1$. Afterwards the probes were lyophilized and separated in the first dimension according to their isoelectric point employing an isoelectric focusing device (Amersham Bioscience, Freiburg). For this probes were redissolved in $350 \mu 1$ of rehydration solution supplemented with $2.8 \mathrm{mg} / \mathrm{ml}$ DTT and incubated for two hours at room temperature under constant mixing. The IPGphor strip holders were washed with detergent (IPG strip holder cleaning solution, Amersham Bioscience) prior use and coated with Repel-Silane ES (Amersham Bioscience) for one hour followed by extensive cleaning. Thereafter, probes were loaded on Immobiline DryStrips pH 3-10 (18 cm) in the IPGphor strip holders and covered with IPG cover fluid (Amersham Bioscience). Isoelectric focusing was then carried out in the IPGphor system (Amersham Bioscience) as follows: $50 \mu \mathrm{A}$ per strip at $20^{\circ} \mathrm{C}$ for 12 hours for rehydration, 0-500 V increasing gradient for 2 hours, 500-1,000 V increasing gradient for 1 hour and 20 minutes, 1,000-800 V decreasing gradient for 7 hours. In total, 33,500 Vhrs were applied. After isoelectric focusing, the strips were incubated for 15 minutes in the equilibrium buffer supplemented with $10 \mathrm{mg} / \mathrm{ml}$ DTT and were then loaded on a $10 \%$ SDS polyacrylamide gel $(16 \times 20 \mathrm{~cm})$ and covered with agarose $(0.5 \%$ agarose in SDS running buffer). A broad range molecular weight marker (6.5-205 kDa, Amersham 
Bioscience) was separated in parallel. The gel was run in the Protean II xi system (Biorad, Munich) in 1x SDS running buffer at $10 \mathrm{~mA}$ per gel for 15 minutes and then at $20 \mathrm{~mA}$ per gel until the bromphenolblue front reached the end of the gel. Separated proteins were then visualized by silverstaining or colloidal coomassie staining.

Rehydration solution:

$\begin{array}{ll}8 \mathrm{M} & \text { Urea } \\ 2 \% & \text { CHAPS } \\ 0.5 \% & \text { IPG Buffer } \\ & \text { (Amersham Bioscience) } \\ \text { trace } & \text { bromophenol blue } \\ \text { in double distilled water }\end{array}$

$\underline{\text { SDS running buffer: }}$

$\begin{array}{ll}25 \mathrm{mM} & \text { Tris } \\ 192 \mathrm{mM} & \text { glycine } \\ 0.1 \% & \text { SDS }\end{array}$

10\% Separating gel:

$\begin{array}{lll}7,500 \mu \mathrm{l} & \text { Tris-HCl, pH 8.8 } & 0.375 \mathrm{M} \\ 300 \mu \mathrm{l} & \text { SDS 10\% } & 0.1 \% \\ 10,000 \mu \mathrm{l} & \text { acrylamide/bisacrylamide 30\% } & 10 \% \\ 24,120 \mu \mathrm{l} & \text { double distilled water } & \\ 150 \mu \mathrm{l} & \text { APS 10\% } & 0.05 \% \\ 10 \mu \mathrm{l} & \text { TEMED } & 0.03 \%\end{array}$

SDS equilibration buffer:

$\begin{array}{ll}50 \mathrm{mM} & 1.5 \mathrm{M} \text { Tris- } \mathrm{HCl}, \mathrm{pH} 8.8 \\ 6 \mathrm{M} & \text { Urea } \\ 30 \% & \text { glycerin } \\ 2 \% & \text { SDS } \\ \text { trace } & \text { bromophenol blue } \\ \text { in double distilled water }\end{array}$

final concentration:

$0.375 \mathrm{M}$

$0.1 \%$

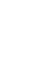


visualized in $2.5 \%$ sodiumcarbonate $/ 0.01 \%$ formaldehyde until protein spots and marker proteins were clearly visible (less than 20 minutes). The developing reaction was terminated by adding $0.05 \mathrm{M}$ EDTA.

\section{Colloidal Coomassie staining}

To visualize proteins separated by two-dimensional gelelectrophoresis for further analysis by Matrix Assisted Laser Desorbtion Ionization-Time of flight (MALDI-Tof), a colloidal coomassie staining was employed.

For this, the gel was fixed in $8.5 \%$ o-phosphoric acid and $20 \%$ methanol for one hour at room temperature. The proteins were then stained for 15 hours in Roti-Blue staining solution (Roth) supplemented with 20\% methanol. Afterwards the gel was washed in $25 \%$ methanol. The gel was then stored in water until further analysis.

\subsubsection{MALDI-Tof}

In order to identify proteins separated by two-dimensional gelelectrophoresis, proteins were visualized with colloidal commassie staining and distinctive spots were cut out of the gel and analyzed by MALDI-Tof (in collaboration with Dr. Hassan Dihazi, Department of Nephrology, University Göttingen).

\subsubsection{Electrophoretic mobility shift assay (EMSA)}

To analyse the influence of $T$. gondii and Toxoplasma lysate on the DNA binding activity of Stat $1 \alpha$, EMSA's were performed. For this, the GAS-sequence from the promotor region of the IFN- $\gamma$-dependent Fc-gamma receptor 1 was used as Stat $1 \alpha$ DNA-binding site.

Primary bone marrow macrophages were seeded on $92 \mathrm{~mm}$ cell culture dishes, using $1 \mathrm{x}$ $10^{7}$ cells per dish. After complete differentiation of BMM as described in 2.2.1, they were infected with viable $T$. gondii, incubated with parasite lysate or were left uninfected. Twenty-four hours post infection, cells were activated with $500 \mathrm{U} / \mathrm{ml} \mathrm{IFN-} \gamma$ for 30 minutes followed by the preparation of cytosolic and nuclear fractions as described above. Double stranded synthetic oligonucleotides containing the gamma interferon activated site (GAS) of the promotor region of the Fcgamma receptor $1(\mathrm{Fc} \gamma \mathrm{R} 1)$ was prepared by denaturating of $1 \mu \mathrm{M}$ Fc $\gamma \mathrm{R} 1-\mathrm{GAS} 1$ (GTA TTT CCC AGA A) and $1 \mu \mathrm{M}$ Fc $\gamma$ R1-GAS2 (CTT TTC TGG GAA) for 5 minutes at $80^{\circ} \mathrm{C}$ and by cooling down to room temperature to allow 
dimerization. The oligonucleotides were end-labelled with $\gamma-{ }^{32} \mathrm{P}$-ATP (Amersham Bioscience, Freiburg) using the Prime-It II random primer labeling kit (Stratagene). For this, 14 pmol of dimerized oligonucleotides were incubated for 30 minutes at $37^{\circ} \mathrm{C}$ with $\gamma$ ${ }^{32} \mathrm{P}-\mathrm{ATP}$ and $10 \mathrm{U}$ of Exo(-) Klenow enzyme in 1x Klenow dATP buffer containing all dNTPs except dATP. Afterwards, the reaction was stopped by using the stop mix included in the kit and DNA was precipitated over night at $-20^{\circ} \mathrm{C}$ in ethanol containing $13 \mu \mathrm{g} / \mathrm{ml}$ poly(I)poly(C) and $0.4 \mathrm{M}$ ammoniumacetat. The oligonucleotides were then centrifuged at $20,000 \times \mathrm{g}$ and $4^{\circ} \mathrm{C}$ for 30 minutes and the pellet was washed once in $80 \%$ ethanol. After drying the pellet, it was resuspended in $35 \mu \mathrm{T}$ TE buffer (see below).

The electrophoretic mobility shift assay was performed using $7.5 \mu 1$ nuclear or cytosolic cell fractions diluted in binding buffer (1 mM DTT, 1 mM EDTA, $20 \mathrm{mM}$ HEPES, $50 \mathrm{mM}$ $\mathrm{KCl}$ and $4 \%$ Ficoll) supplemented with $1 \mu \mathrm{g}$ poly(I)poly(C) and, if indicated, with specific antibodies (Table 4) for supershift analysis. The probes were incubated for 45 minutes at room temperature with $2 \mu \mathrm{l}$ of the dimerized and radioactively labelled oligonucleotides. Separation was performed in a $4 \%$ acrylamide/bisacrylamide gel $(16 \times 20 \mathrm{~cm})$ under native conditions, containing 0.25x TBE, 2.7\% glycerol, 0.04\% APS and 0.1\% TEMED. Prior loading of the samples, the gel was prerun for 1 hour at $200 \mathrm{~V}$ in $0.25 \mathrm{x}$ TBE using a vertical electrophoretic system (Gibco/Invitrogen, Karlsruhe, model V15-17). The samples were then separated at $150 \mathrm{~V}$ for about three hours. Thereafter, radioactively labelled bands were visualized using Hyperfilm MP (Amersham Bioscience).

Table 4: Antibodies for supershift analysis in EMSA

\begin{tabular}{|l|l|}
\hline antibody & concentration \\
\hline rabbit anti-Stat1 $\alpha \mathrm{p} 91(\mathrm{M}-23)$ & $10 \mu \mathrm{g} / 0.1 \mathrm{ml}$ \\
\hline rabbit anti-Stat2 (L-20) & $10 \mu \mathrm{g} / 0.1 \mathrm{ml}$ \\
\hline rabbit anti-Stat3 (C-20) & $10 \mu \mathrm{g} / 0.1 \mathrm{ml}$ \\
\hline rabbit anti-Stat4 (C-29) & $10 \mu \mathrm{g} / 0.1 \mathrm{ml}$ \\
\hline rabbit anti-Stat5 (C-17) & $10 \mu \mathrm{g} / 0.1 \mathrm{ml}$ \\
\hline rabbit anti-Stat6 (M-20) & $10 \mu \mathrm{g} / 0.1 \mathrm{ml}$ \\
\hline rabbit anti-p48 (C-20) & $10 \mu \mathrm{g} / 0.1 \mathrm{ml}$ \\
\hline
\end{tabular}


TE buffer:

TBE buffer:

$\begin{array}{llll}10 \mathrm{mM} & \text { Tris- } \mathrm{HCl}, \mathrm{pH} 7.5 & 89 \mathrm{mM} & \text { Tris- } \mathrm{HCl}, \mathrm{pH} 8.0 \\ 1 \mathrm{mM} & \text { EDTA } & 89 \mathrm{mM} & \text { boric acid } \\ & & 10 \mathrm{mM} & \text { EDTA }\end{array}$

\subsubsection{Transient transfection}

To analyse the effect of viable $T$. gondii or parasite lysate on a minimal GAS-containing promoter, RAW 264.7 cells were transiently transfected using the PathDetect GAS cisReporting System (Stratagene).

For this, RAW 264.7 were seeded at $2 \times 10^{6}$ cells per $92 \mathrm{~mm}$ cell culture dish. Twenty-four hours later, cells were transiently transfected with $5 \mu \mathrm{g}$ pGAS-luciferase reporter plasmid using the TransIT-LT transfection reagent (mirus, distributed by MoBiTec, Göttingen). For this, $15 \mu \mathrm{l}$ of TransIT transfection reagent were added to $100 \mu$ l of FCS-free RAW 264.7 culture medium, mixed thoroughly and incubated for 20 minutes at room temperature. Thereafter, $5 \mu \mathrm{g}$ of PathDetect GAS cis-Reporter plasmid (Stratagene) were carefully added to the diluted TransIT reagent, gently mixed and incubated for additional 20 minutes at room temperature. Prior dropwise addition of the transfection complex to the cells, the medium of RAW 264.7 was replaced by fresh medium. For transfection, the cells were incubated for 8 hours at $37^{\circ} \mathrm{C}$. Afterwards, the cells were scraped off the dishes and washed once with fresh RAW 264.7 medium followed by plating the transfected cells into 6 well plates. The cell population of one $92 \mathrm{~mm}$ dish was evenly distributed into three 35 $\mathrm{mm}$ wells. Thereafter, the cells were allowed to recover for additional 12 hours at $37^{\circ} \mathrm{C}$. Transiently transfected RAW 264.7 cells were then infected with viable $T$. gondii, incubated with parasite lysate or were left uninfected. Three hours after infection, cells were activated with $100 \mathrm{U} / \mathrm{ml} \mathrm{IFN}-\gamma$. Twenty-four hours post infection the cells were isolated, lysed and further analysed for luciferase activity.

\subsubsection{Luciferase assay}

To analyse the luciferase activity in cells transiently or stably transfected with luciferaseencoding reporter gene constructs under different infection conditions, the luciferase assay 
system (Promega) was employed. Cells were seeded in 6 well plates at $1 \times 10^{6}$ cells per well. After 24 hours, cells were infected with $T$. gondii, incubated with $T$. gondii-lysate of left uninfected and were activated with $100 \mathrm{U} / \mathrm{ml} \mathrm{IFN- \gamma}$ as indicated. Twenty-four hours after infection, cells were scraped off and centrifuged for 5 minutes at $1,700 \mathrm{x} \mathrm{g}$ and $4{ }^{\circ} \mathrm{C}$. The pellet was resuspended in 500 $\mu \mathrm{l}$ PBS and a 1:2 dilution of an aliquot with trypanblue was counted using a Neubauer hemocytometer grid. Equal amounts of cells were then used for the luciferase assay. After the cells were centrifuged for 5 minutes at 1,700 x g and $4^{\circ} \mathrm{C}$, the pellet was resuspended in $1 \mathrm{x}$ lysis buffer $\left(400 \mu \mathrm{l} / 3 \times 10^{7}\right.$ cells) included in the kit, vigorously mixed for 15 seconds and centrifuged for 2 minutes at $15,000 \mathrm{x} \mathrm{g}$ and $4^{\circ} \mathrm{C}$. The supernatant was stored at $-80^{\circ} \mathrm{C}$ or directly used for the luciferase assay. For this the cell lysates were diluted 1:4 in 1x lysis buffer in 96 well Nunc Immuno ${ }^{\circledR}$ plates and $100 \mu 1$ of luciferase substrate, were added just prior measurement. Measurements were performed using Trilux 1450 Microbeta (Wallac, Turku).

\subsubsection{IL-10 ELISA}

To determine whether $T$. gondii or parasite-lysate induce the secretion of IL-10 in primary murine bone marrow macrophages, the Quantikine mouse IL-10 immunoassay (R\&D system) was employed. The assay is based on a sandwich immunoassay technique using microtiter plates pre-coated with anti-IL-10 antibodies. Primary BMM were prepared as described above and $1 \times 10^{5}$ cells were seeded per well in 24 well plates. After complete differentiation, the BMM were infected with viable $T$. gondii, were incubated with $T$. gondii lysate or were left uninfected. Three hours post infection the cells were activated with $100 \mathrm{U} / \mathrm{ml}$ IFN- $\gamma$ and reactivated after 24 hours when cultured for additional 24 hours. After 24 or 48 hours, supernatants of the cells were isolated and sterile filtered to exclude contaminations with $T$. gondii and stored at $-80^{\circ} \mathrm{C}$. The IL-10 ELISA was performed according to the manufacturer instructions using the standards and controls included in the kit. Samples were diluted 2-fold in Calibrator Diluent RD5T. After adding $50 \mu 1$ of Assay Diluent RD1-14 to each well, $50 \mu 1$ of standards, controls or samples were added and incubated for 2 hours at room temperature. After five washing steps with $100 \mu l$ Wash buffer, $100 \mu \mathrm{l}$ of mouse IL-10 conjugate (IL-10 antibody conjugated to horseradish peroxidase) were added and incubated for 2 hours at room temperature. After repeating the washing steps as described above, $100 \mu$ of Substrate Solution were added and incubated for 30 minutes at room temperature avoiding exposure to light. The enzyme reaction was 
terminated using $100 \mu \mathrm{l}$ of the stop solution per well and the optical density was measured in a microplate reader at $450 \mathrm{~nm}$ and a reference wavelength of $540 \mathrm{~nm}$.

\subsubsection{Chromatin immunoprecipitaion (ChIP)}

To analyse whether $T$. gondii interferes with chromatin modification as an important prerequisite for transcriptional initiation of the CIITA pomoter after activation with IFN- $\gamma$, the acetylation of the histone $\mathrm{H} 4$ was determined employing the chromatin immunoprecipitation (ChIP) kit (Upstate cell signaling solutions). For this, RAW 264.7 were seeded in $92 \mathrm{~mm}$ cell culture dishes using $0.5 \times 10^{7}$ cells per dish. After 24 hours, the cells were infected with viable $T$. gondii or were left uninfected. Twenty-four hours post infection, RAW 264.7 cells were activated with $300 \mathrm{U} / \mathrm{ml} \mathrm{IFN}-\gamma$ and incubated for two hours at $37^{\circ} \mathrm{C}$. To cross-link histones and DNA, cells were then incubated for 10 minutes at $37^{\circ} \mathrm{C}$ with $1 \%$ formaldehyde. Thereafter, cells were rinsed twice with ice cold PBS supplemented with $1 \mathrm{mM}$ PMSF, $1 \mu \mathrm{g} / \mathrm{ml}$ aprotinin and $1 \mu \mathrm{g} / \mathrm{ml}$ pepstatin and scraped off. After counting the cells, $5 \times 10^{6}$ cells per sample were resuspended in $1 \mathrm{ml}$ of SDS-lysis buffer (included in the kit) supplemented with $1 \mathrm{mM} \mathrm{PMSF}, 1 \mu \mathrm{g} / \mathrm{ml}$ aprotinin and $1 \mu \mathrm{g} / \mathrm{ml}$ pepstatin, and incubated for 10 minutes on ice. To shear chromosomal DNA to fragments of 200-1,000 base pairs, the cell lysates were sonicated on salted ice water using a Branson Sonifier 250. Twenty cycles of 10 seconds sonification at an output level of $15 \%$ followed by an interval of 50 seconds were employed for DNA shearing. Samples were then centrifuged for 10 minutes at $18,000 \mathrm{x} \mathrm{g}$ and $4{ }^{\circ} \mathrm{C}$ and the supernatants were stored at $-20^{\circ} \mathrm{C}$ until further use.

For the ChIP assay, a $200 \mu \mathrm{l}$ aliquot (equals to $1 \times 10^{6}$ RAW 264.7 cells) of the sonicated DNA was ten-fold diluted in ChIP dilution buffer included in the kit and supplemented with $1 \mathrm{mM}$ PMSF, $1 \mu \mathrm{g} / \mathrm{ml}$ aprotinin and $1 \mu \mathrm{g} / \mathrm{ml}$ pepstatin. To quantitate the amount of DNA present in the different samples, $20 \mu \mathrm{l}$ of diluted sonicated DNA was removed and DNA reverse cross-linked and recovered using the PCR purification kit (Qiagen). As a negative control, one sample was processed in parallel without addition of antibody. To reduce non-specific background, samples were incubated with $75 \mu \mathrm{l}$ of salmon sperm DNA/protein A agarose-50\% slurry for 30 minutes at $4{ }^{\circ} \mathrm{C}$ on a rotating platform. After brief centrifugation, the supernatant was transferred into a new tube and $5 \mu$ l of a polyclonal mouse anti-actylated histone $\mathrm{H} 4$ antibody (Upstate cell signaling solutions) were added and incubated over night at $4^{\circ} \mathrm{C}$ with rotation. Thereafter, $60 \mu 1$ of the salmon 
sperm DNA/protein A agarose-50\% slurry was added and incubated for one hour at $4^{\circ} \mathrm{C}$ on a rotating platform. The samples were then centrifuged for one minute at $1,000 \mathrm{xg}$ and $4^{\circ} \mathrm{C}$ and washed once in $1 \mathrm{ml}$ of low salt immune complex wash buffer, once in high salt immune complex wash buffer, once in $\mathrm{LiCl}$ immune complex wash buffer and twice in TE buffer, all provided by the manufacturer. Each washing was done for 3 minutes at $4^{\circ} \mathrm{C}$ on a rotating platform followed by centrifugation for one minute at $1000 \mathrm{x} \mathrm{g}$ and $4{ }^{\circ} \mathrm{C}$. The DNA-histone complex was then eluted from the antibody by incubating the pellet twice in $250 \mu \mathrm{l}$ of freshly prepared elution buffer containing $1 \%$ SDS and $0.1 \mathrm{M} \mathrm{NaHCO}_{3}$ for 15 minutes each at room temperature on a rotating platform. To reverse the histone-DNA crosslink, $200 \mathrm{mM} \mathrm{NaCl}$ was added to the samples and incubated for 4 hours at $65^{\circ} \mathrm{C}$. The DNA was then recovered using the PCR Purification Kit (Qiagen). For this, $2.5 \mathrm{ml}$ of buffer PB were added to the $500 \mu \mathrm{l}$ samples and loaded on QIAquick spin columns for DNA binding followed by centrifugation at $18,000 \mathrm{x} g$ for 1 minute. The columns were washed once with $700 \mu \mathrm{l}$ of PE buffer. Finally, the DNA was eluted by adding $50 \mu 1$ of water. To determine the amount of promoter-specific DNA precipitated with the ChIP assay, PCR was perfomed using primer pairs specific for the CIITA promoter IV. The PCR reaction mix was set up as described in 2.2.8, except, that $5 \mu 1$ of the precipitated DNA was used as template. For amplification of CIITA-Promoter DNA, samples were incubated for 3 minutes at $94^{\circ} \mathrm{C}$ followed by 35 cycles of denaturation for 1 minute at $94^{\circ} \mathrm{C}$, annealing for 1 minute at $60^{\circ} \mathrm{C}$ and extension for 1 minute at $72^{\circ} \mathrm{C}$. Thereafter, polymerization was completed by incubation for 10 minutes at $72^{\circ} \mathrm{C}$. PCR products were then separated by agarose gelelectrophoresis as described in 2.2.15 and the amount of amplified DNA was semiquantitatively analysed and normalized against the negative control and the amount of DNA present in each sample before the ChIP. 


\section{$\underline{\text { 3. Results }}$}

\subsection{Interference of $T$. gondii with IFN- $\gamma$-regulated gene expression}

\subsubsection{T. gondii interferes with the expression of MHC class II in RAW 264.7 cells}

It was shown before, that viable $T$. gondii interfere with the MHC class II expression in primary murine bone marrow-derived macrophages (BMM) (Lüder et al., 1998). In order to determine whether $T$. gondii tachyzoites are also able to inhibit the expression of MHC class II in the monocyte/macrophage cell line RAW 264.7, such cells were infected with viable T. gondii at parasite to host cell ratios of $4: 1$ and $8: 1$ and analysed by flow cytometry. RAW 264.7 cells did not express the MHC class II molecules I-A/I-E constitutively (Figure 3A), however, the expression was strongly induced after activation

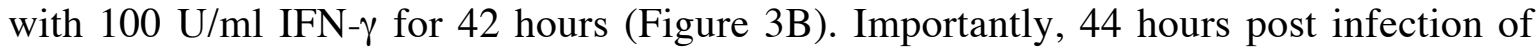
RAW 264.7 cells with increasing numbers of $T$. gondii, IFN- $\gamma$-induced up-regulation of I$\mathrm{A} / \mathrm{I}-\mathrm{E}$ molecules on the cell surface was dose-dependently diminished as compared to uninfected control cells.

Therefore, viable $T$. gondii tachyzoites also interfere with the IFN- $\gamma$-induced up-regulation of MHC class II molecules on the surface of the monocyte/macrophage cell line RAW 264.7.

\subsubsection{T. gondii tachyzoites differentially interfere with IFN- $\gamma$-responsive genes}

In order to determine whether $T$. gondii tachyzoites only interfere with the expression of MHC class II in RAW 264.7 cells, or if other IFN- $\gamma$-responsive genes are also influenced by the parasite, RT-PCR analyses were performed. Equal amounts of cDNA in the different samples were ensured by using $\beta$-actin and glyceraldehyde-3-phosphate dehydrogenase (GAPDH) as internal standards. H2-Ab (MHC class II), intracellular adhesion molecule-1 (ICAM-1), inducible nitric oxide synthase (iNOS) and interferoninducible GTP-binding protein (IGTP) mRNA's were not detectable in unstimulated cells and this was not changed after concomitant infection with viable $T$. gondii for 24 hours

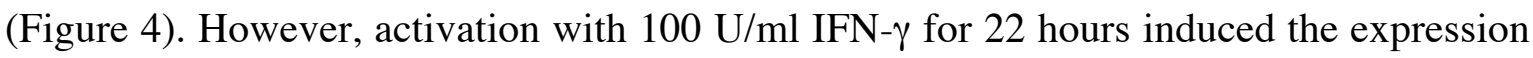
of these genes considerably (Figure 4). Importantly, this cytokine-induced up-regulation of $\mathrm{H} 2-\mathrm{Ab}$, ICAM-1, iNOS and IGTP transcripts was inhibited in cells concomitantly infected with $T$. gondii tachyzoites (Figure 4). The $\operatorname{IgG~Fc}$ receptor type 1 (Fc $\gamma \mathrm{R} 1)$ and the 
indolamine 2,3-dioxygenase (INDO) were constitutively expressed in RAW 264.7 cells and this was not changed after infection with T. gondii for 24 hours. Stimulation with 100 $\mathrm{U} / \mathrm{ml}$ IFN- $\gamma$ for 22 hours, however, considerably induced the mRNA levels of these genes (Figure 4).

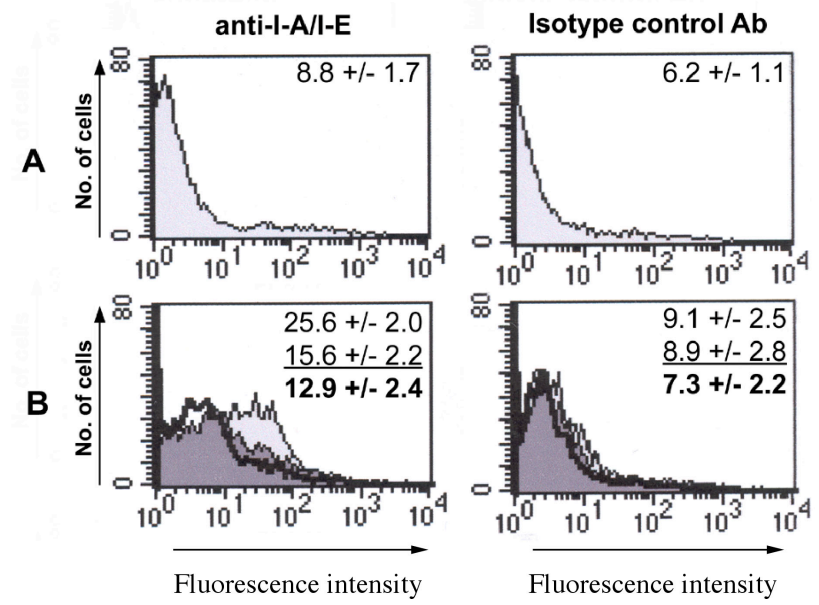

Figure 3: T. gondii tachyzoites interfere with the expression of MHC class II molecules in the monocyte/macrophage cell line RAW 264.7

RAW 264.7 cells were infected with viable $T$. gondii at parasite to host cell ratios of 4:1 (dark grey area), 8:1 (thick lines) or were left uninfected (pale grey area). They were stimulated with $100 \mathrm{U} / \mathrm{ml}$ IFN- $\gamma$ 2-3 hours post infection (B) or were left unstimulated (A). At 44 hours post infection, surface expression of I-A/I-E (MHC class II) molecules was quantified by flow cytometry, staining with an isotype control antibody was performed in parallel. Data represent mean +/- S.E.M. $(n=3)$ of the mean fluorescence intensities of noninfected control cultures (light numbers) and $T$. gondii-infected cell cultures with parasite to host cell ratios of 4:1 (light numbers underlined) and 8:1 (bold numbers).

Concomitant infection with viable $T$. gondii diminished up-regulation of Fc $\gamma \mathrm{R} 1$ and INDO in response to IFN- $\gamma$. In contrast, $T$. gondii did not interfere with the cytokine-induced expression of the transporters associated with antigen processing-1 (TAP1). TAP1 was constitutively expressed, however, stimulation with IFN- $\gamma$ resulted in a considerable increase of TAP1 mRNA levels. This IFN- $\gamma$-induced up-regulation was not changed after concomitant infection with $T$. gondii for 24 hours. Furthermore, mRNA levels of the protooncogene c-myc were not detectable in unstimulated cells, however, infection with $T$. 
gondii resulted in an increase of c-myc transcripts. Additionally, activation of RAW 264.7 with $100 \mathrm{U} / \mathrm{ml} \mathrm{IFN- \gamma}$ led to an up-regulation of c-myc expression, the mRNA levels of which were even further increased in cells concomitantly infected with $T$. gondii tachyzoites.

Taken together, these results reveal, that $T$. gondii tachyzoites interfere with the expression of the majority but not all IFN- $\gamma$-responsive genes in murine macrophages.
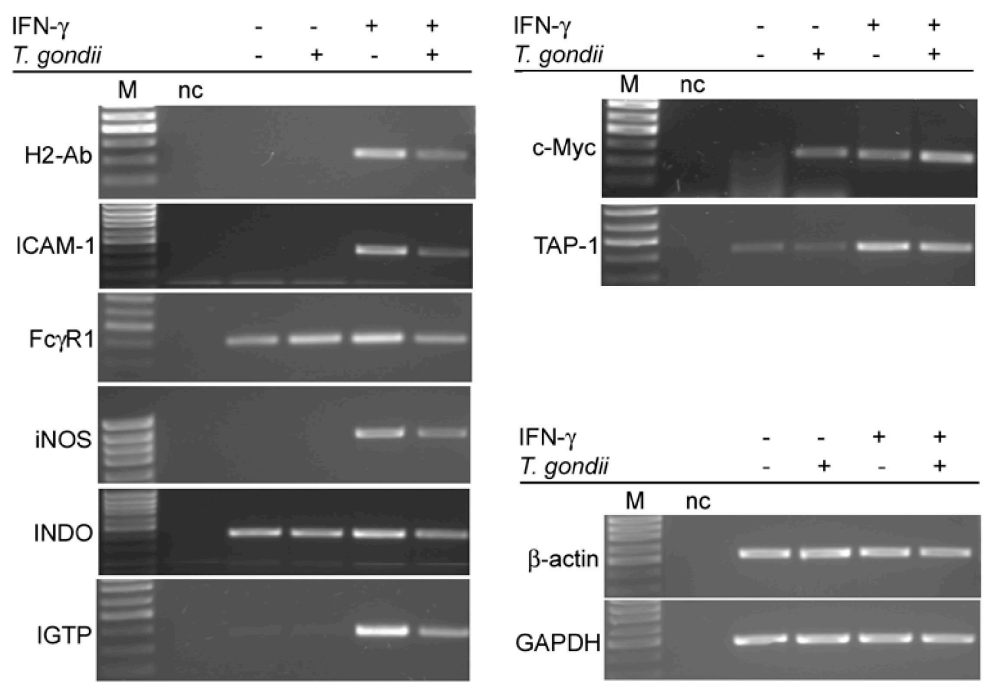

Figure 4: $T$. gondii differentially interfere with IFN- $\gamma$-responsive genes

RAW 264.7 cells were infected with $T$. gondii tachyzoites at a parasite to host cell ratio of 8:1 or were left uninfected. Two to three hours post infection, cells were activated with $100 \mathrm{U} / \mathrm{ml}$ IFN- $\gamma$ or left unstimulated. Total RNA was isolated 24 hours after infection, reverse transcribed and cDNA's were then amplified by PCR using specific primer pairs for the indicated genes. PCR products were separated by agarose gelelectrophoresis and visualized by ethidium bromide staining. ICAM-1: intracellular adhesion molecule 1, Fc $\gamma R$ 1: IgG Fc receptor type 1, iNOS: inducible nitric oxide synthase, INDO: indolamine 2,3-dioxygenase, IGTP: interferon-inducible GTP-binding protein, TAP1: transporters associated with antigen processing-1, GAPDH: glyceraldehyde-3-phosphate dehydrogenase. The results shown are representative for two independent experiments.

\subsection{Parasite factors regulating IFN- $\gamma$-mediated MHC class II expression}

The following experiments were conducted in order to determine the parasite requirements to interfere with the IFN- $\gamma$-regulated gene expression of its host cell. As a model, this was 
investigated by elucidating the effect of $T$. gondii on the expression of MHC class II molecules.

\subsubsection{Host cell invasion is required for $T$. gondii-mediated inhibition of MHC class II expression}

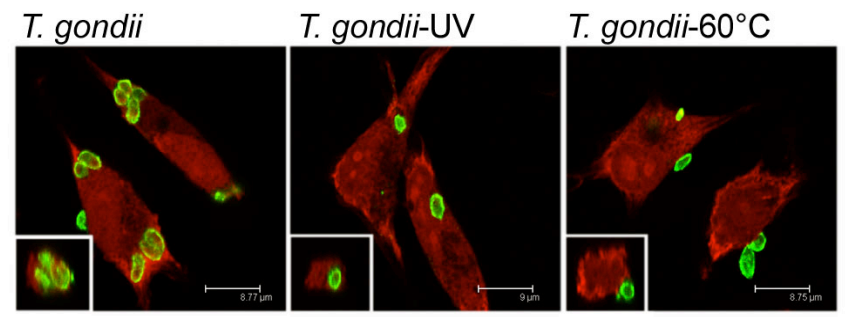

Figure 5: Ability of UV-irradiated and heat-inactivated $T$. gondii for host cell invasion and intracellular replication

L929 cells were infected or incubated with viable, UV-irradiated or heat-inactivated T. gondii at a parasite to host cell ratio of 4:1. Twenty-four hours post infection, cells were fixed and analysed by immunofluorescence staining. Cells were incubated with anti-Toxoplasma serum (green) and propidiumiodide (red) to unspecifically visualize nucleic acids. Images of each fluorescence were simultaneously obtained by confocal laser scanning microscopy and were superimposed. The inserts represent overlays of XZ-sections in order to emphasize the replication and the localization of the differentially treated $T$. gondii.

It was shown before, that viable $T$. gondii tachyzoites interfere with the IFN- $\gamma$-induced MHC class II expression in murine macrophages (Lüder et al., 1998, see 3.1.1). In order to determine the parasites' prerequisites for this parasite-host interaction, $T$. gondii were UVirradiated or heat-inactivated prior addition to host cells. The mRNA levels of $\mathrm{H} 2-\mathrm{Ab}$ were determined semiquantitatively by RT-PCR in RAW 264.7 cells infected or incubated with the different $T$. gondii-preparations or left uninfected as control. As an internal standard, the amounts of cDNA in the different samples were compared by amplification of $\beta$-actin specific cDNA and the band intensities were used for normalization. The capability of UVirradiated and heat-inactivated T. gondii to enter the host cell and to replicate within the host cell was compared to untreated $T$. gondii by double immunofluorescence staining (Figure 5). 

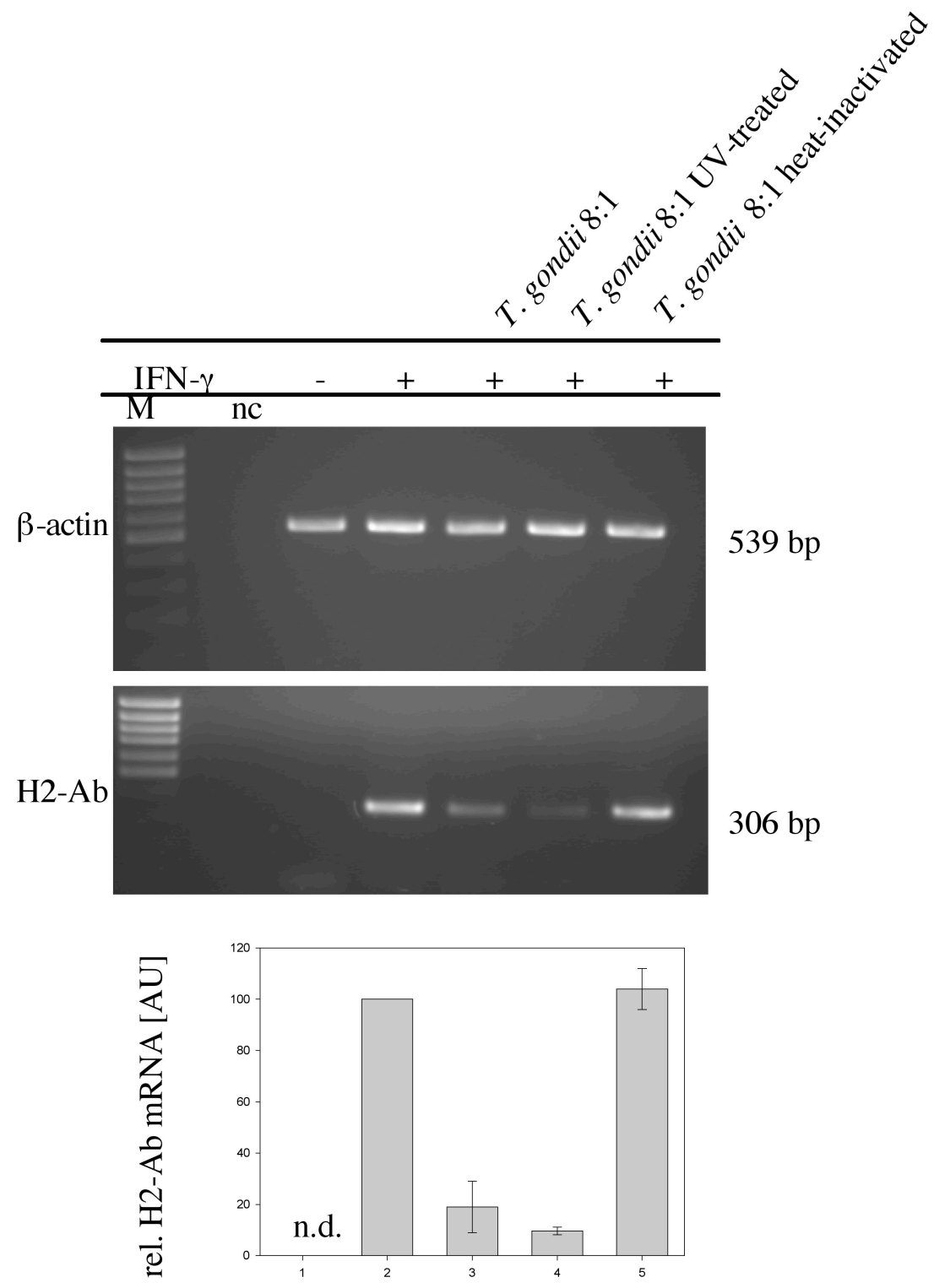

Figure 6: Interference of $T$. gondii with IFN- $\gamma$-induced up-regulation of MHC class II expression requires host cell invasion but not intracellular replication of the parasite

RAW 264.7 macrophages were infected or incubated with untreated $T$. gondii, with UV-irradiated parasites or with heat-inactivated $T$. gondii at a parasite to host cell ratio of 8:1 and were stimulated with $100 \mathrm{U} / \mathrm{ml}$ IFN- $\gamma$ two to three hours post infection as indicated. Total RNA was isolated 24 hours after infection and reverse transcribed. The cDNA's were then amplified by PCR using specific primer pairs for H2-Ab and for $\beta$-actin. PCR products were separated by agarose gelelectrophoresis and visualized by ethidium bromide staining. The intensities of $\mathrm{H} 2-\mathrm{Ab}$-specific amplicons were analysed semiquantitatively using a digital imaging system. The relative amounts of $\mathrm{H} 2-\mathrm{Ab}$ transcripts compared to $\beta$-actin transcripts of the same sample were calculated $(\mathrm{H} 2-\mathrm{Ab} / \beta$-actin x 100). The relative intensity for the non-infected, IFN- $\gamma$ activated sample was defined as $100 \%$ and the other values were calculated relative to the intensity of this sample. Bars represent mean $+/$ - standard deviation $(n=3)$. n.d.: not detectable 
It revealed, that UV-irradiated parasites entered the host cell to a similar extent as untreated parasites, but did not replicate intracellularly. In contrast, heat-inactivated parasites were not able to enter host cells any more (Figure 5).

$\mathrm{H} 2-\mathrm{Ab}$ mRNA was not detectable in RAW 264.7 cells that were unstimulated. However, transcript levels of H2-Ab were strongly induced after activation with IFN- $\gamma$ (Figure 6). As expected, this cytokine-dependent up-regulation of $\mathrm{H} 2-\mathrm{Ab}$ mRNA levels was considerably inhibited in cells that were infected with untreated $T$. gondii. Similar results were obtained with RAW 264.7 cells infected with UV-irradiated parasites. In these cells, IFN- $\gamma$ also failed to induce the transcription of $\mathrm{H} 2-\mathrm{Ab}$ significantly. However, RAW 264.7 macrophages that were incubated with heat-inactivated parasites up-regulated the mRNA levels of $\mathrm{H} 2-\mathrm{Ab}$ in response to IFN- $\gamma$ to a similar extent as those cultured in the absence of T. gondii (Figure 6). In accordance with these results, flow cytometry and immunofluorescence analyses revealed, that only untreated or UV-irradiated $T$. gondii that were able to enter the host cell interfered with IFN- $\gamma$-induced MHC class II expression (data not shown). Heat-inactivated parasites, by contrast, did not inhibit the expression of MHC class II in response to the cytokine.

These results clearly indicate, that host cell invasion by $T$. gondii is required for the inhibition of MHC class II expression in response to IFN- $\gamma$, whereas the ability for intracellular replication of $T$. gondii is dispensable.

\subsubsection{A parasite lysate mimics the interference of viable $T$. gondii with IFN- $\gamma$-induced MHC class II expression}

To further characterize the T. gondii-mediated inhibition of IFN- $\gamma$-induced MHC class II expression in murine macrophages, the effect of a crude parasite extract on mRNA levels of H2-Ab was determined by semiquantitative RT-PCR. For this, RAW 264.7 cells were incubated with different concentrations of $T$. gondii lysate or were infected with viable parasites at a parasite to host cell ratio of 8:1 as positive control or were left uninfected as a negative control. After 24 hours, total RNA was isolated, reverse transcribed and analysed for $\mathrm{H} 2-\mathrm{Ab}$ or $\beta$-actin mRNA's. $\mathrm{H} 2-\mathrm{Ab}$ transcripts were undetectable in cells that were not stimulated with IFN- $\gamma$ but were considerably increased in cells that were activated with 100 $\mathrm{U} / \mathrm{ml} \mathrm{IFN- \gamma}$ (Figure 7). As expected, this up-regulation was inhibited in cells that were infected with viable $T$. gondii. Likewise, RAW 264.7 cells that were incubated with 
increasing amounts of $T$. gondii lysate for 24 hours were also defective in up-regulating $\mathrm{H} 2-\mathrm{Ab}$ transcripts in response to IFN- $\gamma$ stimulation.
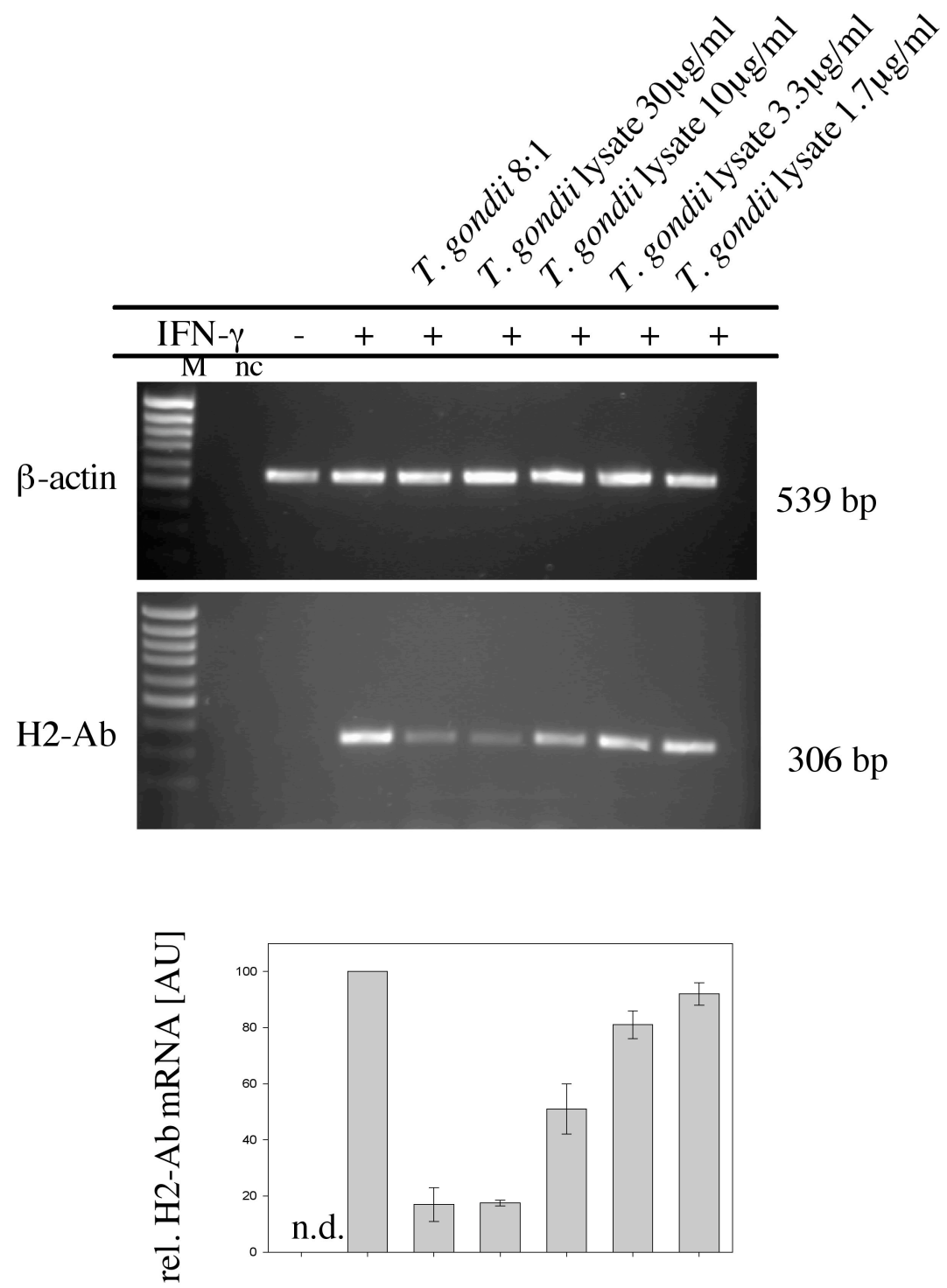

Figure 7: $T$. gondii lysate mimics the inhibition of IFN- $\gamma$-induced MHC class II expression mediated by viable parasites

RAW 264.7 cells were infected with viable $T$. gondii or were incubated with different concentrations of $T$. gondii lysate as indicated. Cells were activated with $100 \mathrm{U} / \mathrm{ml} \mathrm{IFN- \gamma}$ two to three hours later or left unstimulated and after 24 hours, total RNA was isolated and reverse transcribed. The cDNA's were then amplified by PCR with $\mathrm{H} 2$-Ab-specific and $\beta$-actin-specific primer pairs. The PCR products were separated by agarose gelelectrophoresis, visualized by ethidium bromide staining and intensities of $\beta$-actin and $\mathrm{H} 2-\mathrm{Ab}$ specific amplicons were analysed semiquantitatively using a digital imaging system. The relative amounts of $\mathrm{H} 2-\mathrm{Ab}$ transcripts compared to $\beta$-actin transcripts in the same sample were calculated ( $\mathrm{H} 2-\mathrm{Ab} / \beta$-actin $\times 100)$. The intensity of the non-infected, IFN- $\gamma$ activated sample was defined as $100 \%$ and the other intensities were calculated relative to this sample. Bars represent mean + -- standard deviation $(n=2)$. n.d.: not detectable 
Additionally, the interference of parasite lysate with the IFN- $\gamma$-induced $\mathrm{H} 2-\mathrm{Ab}$ transcription was found to be concentration dependent, since higher concentrations of lysate resulted in a stronger interference with IFN- $\gamma$-induced up-regulation of $\mathrm{H} 2-\mathrm{Ab}$ mRNA levels (Figure 7).
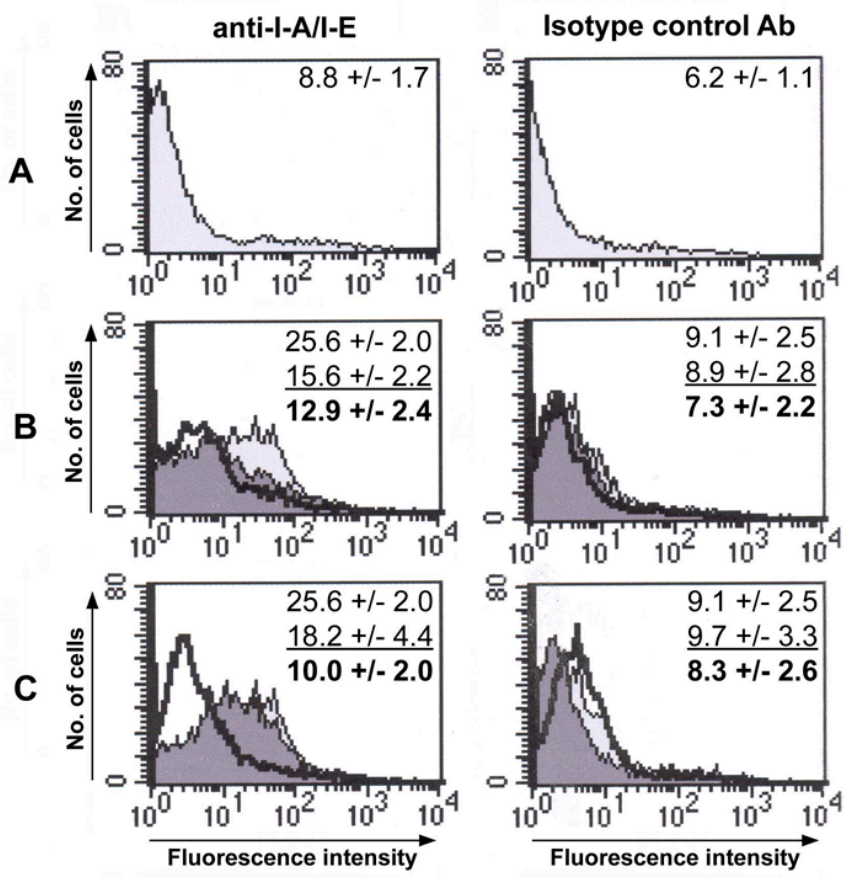

Figure 8: $T$. gondii lysate interfere with the expression of MHC class II molecules on the cell surface of murine macrophages

RAW 264.7 cells were infected with viable $T$. gondii at parasite to host cell ratios of 4:1 (dark grey area), 8:1 (thick lines) or were left uninfected (pale grey area) and were stimulated with $100 \mathrm{U} / \mathrm{ml}$ IFN- $\gamma$ 2-3 hours post infection (B). In parallel, RAW 264.7 cells were incubated with $5 \mu \mathrm{g} / \mathrm{ml} T$. gondii lysate (dark grey area), 50 $\mu \mathrm{g} / \mathrm{ml}$ T. gondii lysate or were left untreated (pale grey area) and were activated with $100 \mathrm{U} / \mathrm{ml}$ IFN- $\gamma$ 2-3 hours post incubation (C). The amount of MHC class II-positive cells in unstimulated and non-infected RAW 264.7 control cells is shown in A. Data represent mean +/- S.E.M. $(n=3)$ of the mean fluorescence intensities of non-infected control cultures (A-C, light numbers), cell cultures infected with $T$. gondii at a parasite to host cell ratios of 4:1 (B, light numbers underlined) and 8:1 (B, bold numbers) and cell cultures incubated with $5 \mu \mathrm{g} / \mathrm{ml}$ (C, light numbers underlined) and $50 \mu \mathrm{g} / \mathrm{ml}$ (C, bold numbers) T. gondii lysate. Cells were analysed by flow cytometry after staining with antibodies specific for MHC class II molecules I-A/I-E or after control staining with isotype-matched antibodies.

The inhibition of MHC class II expression by $T$. gondii lysate was confirmed by analysing the effect of $T$. gondii lysate on the appearence of MHC class II molecules on the host cell 
surface. For this, flow cytometry analyses were performed with RAW 264.7 cells incubated with $T$. gondii lysate, infected with viable $T$. gondii or left uninfected. The results show, that the amount of MHC class II-positive cells was low in cell populations cultured in the absence of IFN- $\gamma$ (Figure 8A) and this did not change in the presence of viable parasites or parasite lysate (data not shown).

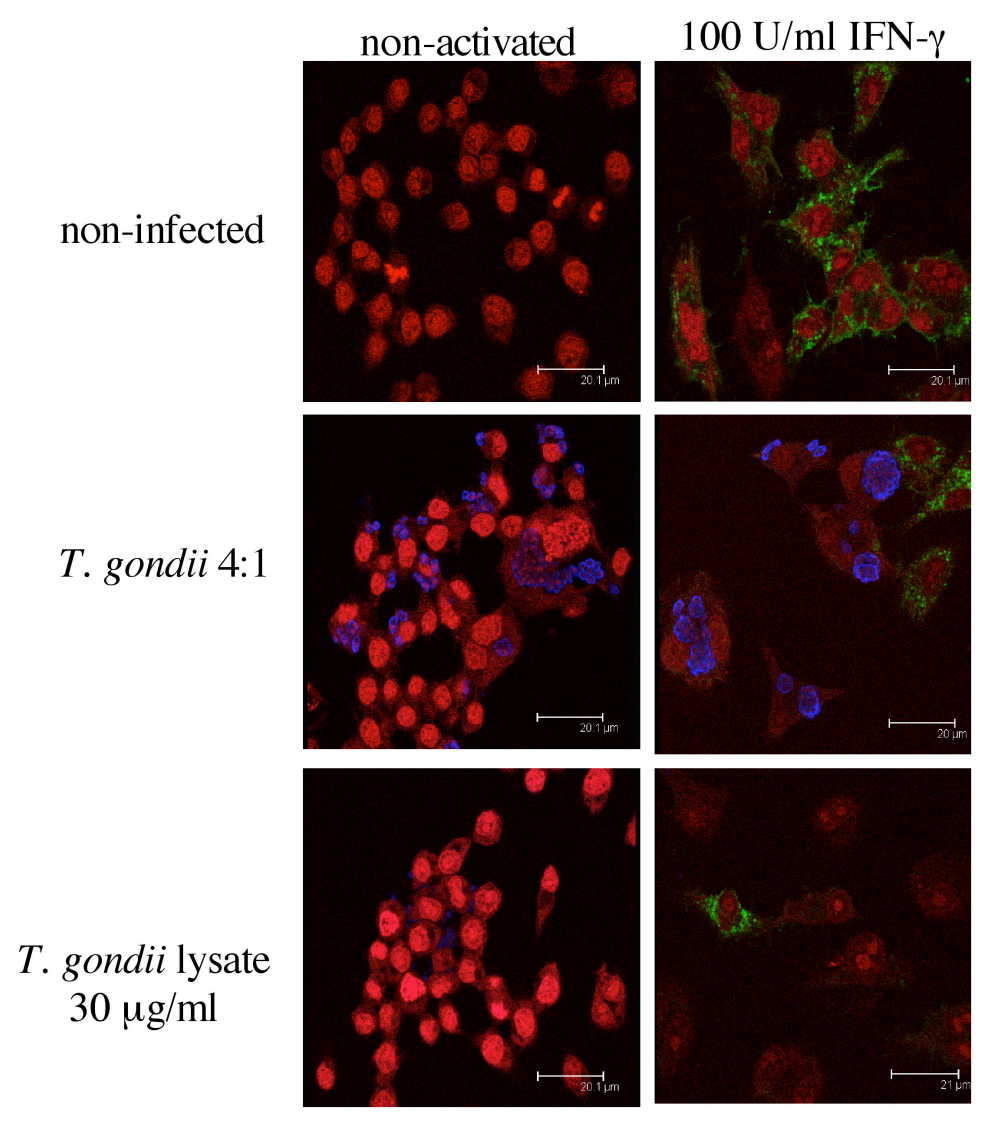

Figure 9: T. gondii lysate interfere with the MHC class II expression in RAW 264.7 cells

RAW 264.7 cells were infected with viable parasites, were incubated with $T$. gondii lysate or were left uninfected. Two to three hours post infection, cells were activated with $100 \mathrm{U} / \mathrm{ml} \mathrm{IFN-} \gamma$ and reactivated after additional 24 hours. Forty-four hours after infection, cells were fixed and analysed by double immunofluorescence staining. RAW 264.7 cells were incubated with anti-MHC class II antibodies (green), anti-Toxoplasma-serum (blue) and propidiumiodide (red) to unspecifically visualize nucleic acids. Images of each fluorescence were simultaneously obtained by confocal laser scanning microscopy and were superimposed. The results shown are representative for three independent experiments.

After activation with $100 \mathrm{U} / \mathrm{ml} \mathrm{IFN}-\gamma$ for 42 hours, however, the expression of the MHC class II molecules I-A/I-E on the surface of non-infected RAW 264.7 cells considerably 
increased (Figure 8B). In cells that were concomitantly infected with viable $T$. gondii in parasite to host cell ratios of $4: 1$ and $8: 1$, the IFN- $\gamma$-induced up-regulation of I-A/I-E was abrogated by $40 \%$ or $50 \%$, respectively (Figure 8B). Likewise, incubation of RAW 264.7 cells with 5 or $50 \mu \mathrm{g} / \mathrm{ml} \mathrm{T}$. gondii lysate also interfered with IFN- $\gamma$-stimulated upregulation of I-A/I-E on the host cell surface by $30 \%$ or $60 \%$, respectively (Figure $8 \mathrm{C}$ ). Such differences were not observed after staining the RAW 264.7 cells with isotype control antibodies confirming the specificity of the results. These data were further supported on the single cell level by double immunofluorescence staining. No expression of MHC class II molecules was detectable in unstimulated RAW 264.7 cells (Figure 9). Furthermore, this did not change after infection with viable $T$. gondii or treatment with $T$. gondii lysate. However, after stimulation of the cells with $100 \mathrm{U} / \mathrm{ml}$ IFN- $\gamma$ for 42 hours, the amount of MHC class II-positive RAW 264.7 cells was clearly increased in the absence of T. gondii. After concomitant infection with viable parasites, T. gondii-positive host cells failed to up-regulate cytokine-stimulated MHC class II expression (Figure 9). In contrast, most parasite-negative host cells of the IFN- $\gamma$-activated and T. gondii-infected RAW 264.7 cell population successfully up-regulated MHC class II molecules (Figure 9). Furthermore, RAW 264.7 cells incubated with parasite lysate also failed to up-regulate MHC class II molecules in response to IFN- $\gamma$ (Figure 9).

Taken together, these results clearly show, that a crude $T$. gondii lysate is able to mimic the inhibitory effect of viable $T$. gondii on IFN- $\gamma$-induced MHC class II expression in murine macrophages.

\subsubsection{The molecule within the $T$. gondii lysate mediating the interference with IFN- $\gamma$ - induced MHC class II expression is pronase sensitive}

As shown above, $T$. gondii lysate is able to mimic the interference of viable parasites with IFN- $\gamma$-induced MHC class II expression in murine macrophages. To further characterize the molecules' identity mediating the inhibition of $T$. gondii lysate with $\mathrm{H} 2-\mathrm{Ab}$ transcript levels, $T$. gondii extracts were incubated with the protease pronase. The effect of pronasedigested $T$. gondii lysate on IFN- $\gamma$-induced mRNA levels of $\mathrm{H} 2-\mathrm{Ab}$ was then compared to the effect of native lysate by semiquantitative RT-PCR. In unstimulated RAW 264.7 cells, $\mathrm{H} 2-\mathrm{Ab}$ transcripts were not detectable (Figure 10). 


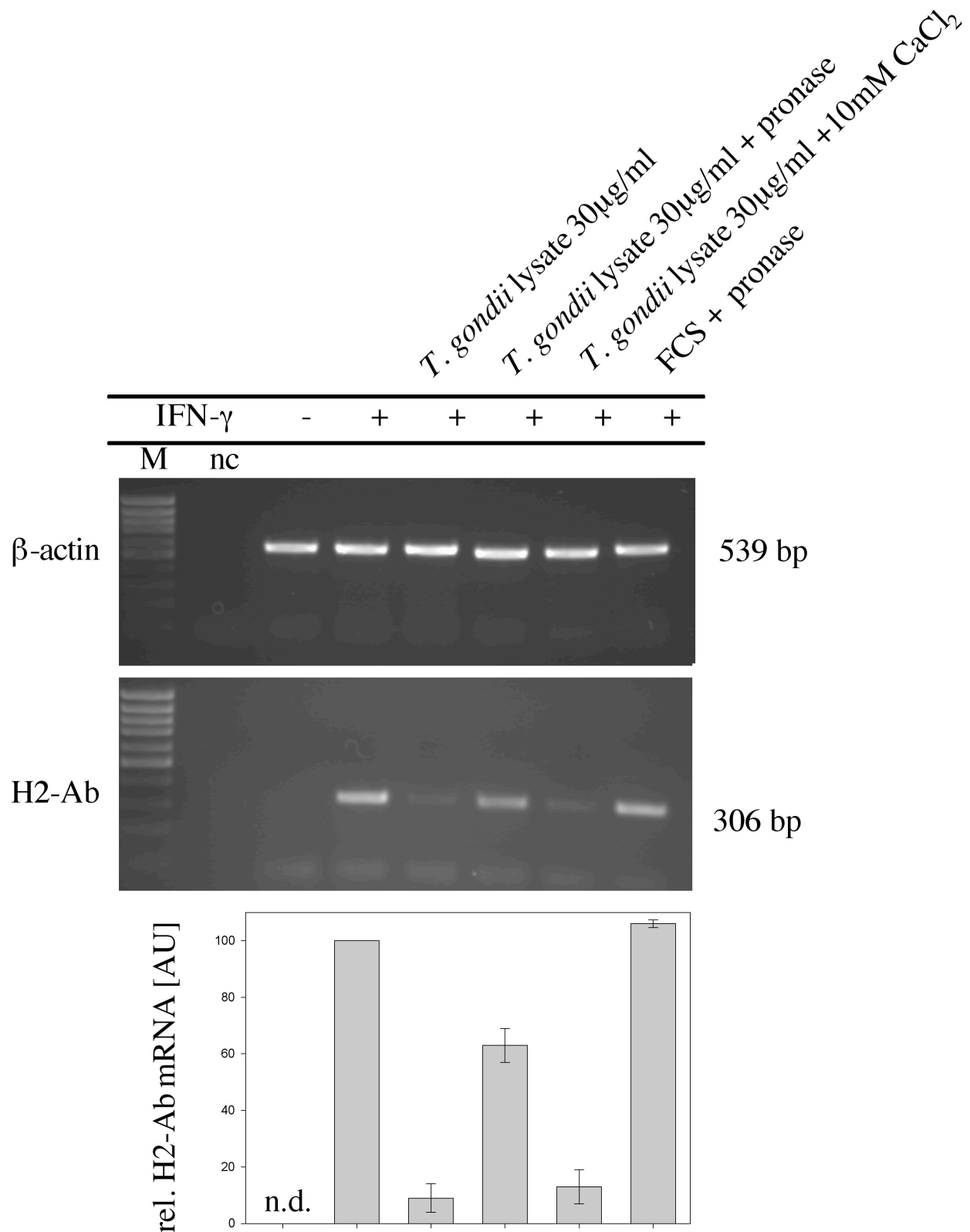

Figure 10: The molecule within the T. gondii lysate inhibiting up-regulation of MHC class II transcripts in response to IFN- $\gamma$ is pronase sensitive

RAW 264.7 cells were incubated with untreated $T$. gondii lysate or with parasite lysate digested with 10 $\mathrm{mg} / \mathrm{ml}$ pronase. As a control, RAW 264.7 cells were also incubated with $T$. gondii lysate diluted in digestion buffer of the pronase $\left(10 \mathrm{mM} \mathrm{CaCl}_{2}\right)$ or with pronase-digested FCS in parallel. Cells were activated with 100 $\mathrm{U} / \mathrm{ml} \mathrm{IFN- \gamma}$ two to three hours post treatment and total RNA was isolated after 24 hours. The mRNA was reverse transcribed and cDNA was amplified by PCR using $\mathrm{H} 2$-Ab-and $\beta$-actin-specific primer pairs. PCR products were separated by gelelectrophoresis and the amplicon intensities were analysed semiquantitatively using a digital imaging system. The relative amounts of $\mathrm{H} 2-\mathrm{Ab}$ transcripts in the different samples were calculated (H2-Ab/ $\beta$-actin x 100). The non-infected, IFN- $\gamma$ activated sample was defined as $100 \%$ and the other values were calculated relative to this sample. Bars represent means $+/$ - standard deviation $(n=2)$. n.d.: not detectable 
Activation with IFN- $\gamma$ resulted in an increase of $\mathrm{H} 2-\mathrm{Ab}$ mRNA levels. The cytokineinduced up-regulation of $\mathrm{H} 2-\mathrm{Ab}$ transcripts was almost completely abrogated in cells that were concomitantly incubated with native $T$. gondii lysate. In contrast, pronase-digestion clearly reduced the inhibitory effect of the $T$. gondii lysate on the induction of $\mathrm{H} 2-\mathrm{Ab}$ transcription in response to IFN- $\gamma$. Control samples showed that this was indeed due to the treatment of the lysate with pronase but not mediated by the digestion buffer or by an unspecific effect of the protease (Figure 10). Therefore, interference of $T$. gondii lysate with IFN- $\gamma$-induced MHC class II expression is at least partially mediated by a pronase sensitive protein.

\subsubsection{Interference of $T$. gondii with IFN- $\gamma$-induced MHC class II expression appears to} be mediated by excreted/secreted antigens

In order to determine the possible involvement of parasite derived excreted/secreted antigens (ESA's) in the interference of $T$. gondii with MHC class II expression, primary murine bone marrow-derived macrophages (BMM) from BALB/c mice were incubated with viable $T$. gondii, which were separated from the macorphages by a semipermeable membrane. For this, the percentage of MHC class II-positive cells was determined after double immunofluorescence staining by counting the number of MHC class II-positive BMM within a total population of at least 500 cells (Figure 11). The constitutive expression of MHC class II by BMM is very low in the absence of IFN- $\gamma$. After activation with $100 \mathrm{U} / \mathrm{ml}$ IFN- $\gamma$, appropriatly $55 \%$ of the whole cell population expressed detectable amounts of MHC class II molecules. This value was then defined as $100 \%$ to enable comparison of results between different experiments (Figure 11). In macrophages that were directly infected with viable $T$. gondii at parasite to host cell ratios of $1.5: 1$ or $3: 1$, the percentage of cells expressing MHC class II molecules declined to 56\% and 38\%, respectively. Furthermore, in BMM cultures that were incubated with viable $T$. gondii, which were separated by a semipermeable membrane in parasite to host cell ratios of 10:1, 20:1 and 50:1, the percentage of MHC class II-positive cells was reduced to $80 \%, 62 \%$ and $57 \%$, respectively as compared to non-infected cells (Figure 11). Similar results were obtained in a single control experiment with RAW 264.7 cells (data not shown).

These results suggest that viable $T$. gondii are able to secrete molecule(s) in the presence of host cells, which interfere with IFN- $\gamma$-induced MHC class II expression in murine macrophages. 


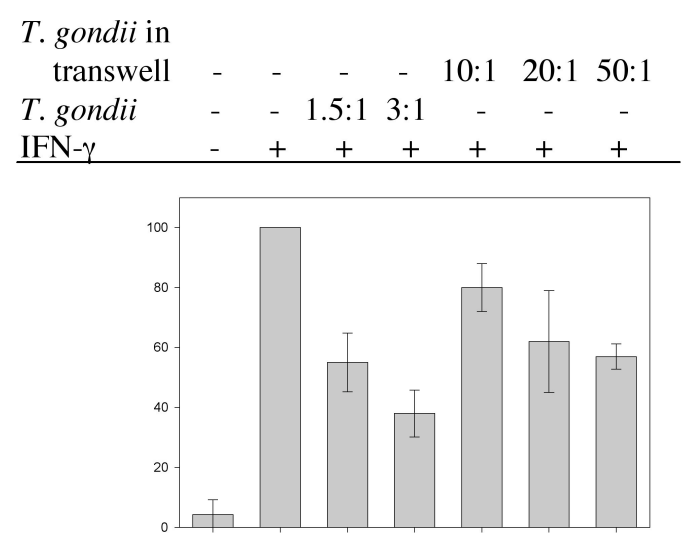

Figure 11: Excretory/secretory antigens of $T$. gondii appear to be involved in the interference with IFN- $\gamma$-induced MHC class II expression in murine macrophages

Primary bone marrow-derived macrophages (BMM) were directly infected with viable $T$. gondii at parasite to host cell ratios of $1.5: 1$ and $3: 1$, were incubated with viable parasites separated by a semipermeable membrane (transwell) at parasite to host cell ratios of 10:1, 20:1 and 50:1, or were left uninfected. Two to three hours post infection, cells were stimulated with $100 \mathrm{U} / \mathrm{ml}$ IFN- $\gamma$ and reactivated after 24 hours. Fortyfour hours after infection, cells were fixed and analysed by double immunofluorescence staining. The number of MHC class II-positive cells was determined within a total of at least 500 cells per sample. Percentages were calculated (number of MHC class II-positive cells / total number of cells x 100) and the value in the non-infected, IFN- $\gamma$ stimulated sample was defined as $100 \%$. All other values were calculated relative to this sample. Bars represent means $+/$ - standard deviation $(n=3)$.

\subsubsection{Different preparations of excreted/secreted antigens derived from $T$. gondii did not interfere with IFN- $\gamma$-induced MHC class II expression}

T. gondii possess three excretory/secretory organelles, namely the micronemes, the rhoptries and the dense granules, the content of which play a major role during the process of host cell invasion and are important for the successful establishment of an intracellular infection. Previous experiments suggested the involvement of ESA's in the interference of T. gondii with MHC class II expression. In order to further elucidate whether ESA's derived from $T$. gondii are involved, $T$. gondii ESA's were prepared according to different protocols (Cesbron-Delauw, 1994; Carruthers et al., 1999) and were then incubated with RAW 264.7 cells. After 24 hours, the amount of H2-Ab transcripts was determined by semiquantitative RT-PCR. In unstimulated cells, H2-Ab transcripts were not detectable. After activation with IFN- $\gamma$, the transcription of $\mathrm{H} 2-\mathrm{Ab}$ was clearly increased (Figure 12). This IFN- $\gamma$-induced up-regulation was abrogated in cells concomitantly infection with 
viable T. gondii (Figure 12). However, none of three different ESA preparations interfered with IFN- $\gamma$-induced up-regulation of $\mathrm{H} 2-\mathrm{Ab}$ transcripts (Figure 12).

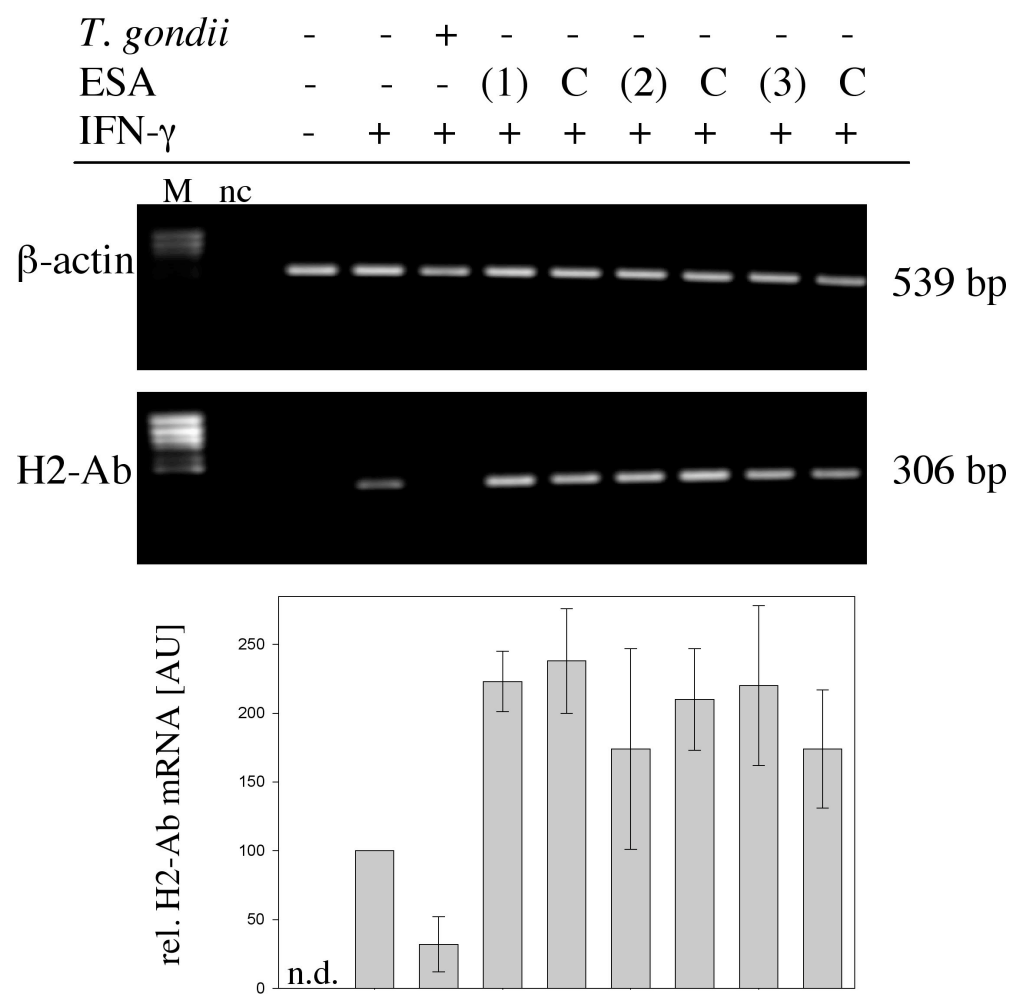

Figure 12: Different preparations of $T$. gondii excretory/secretory antigens do not interfere with IFN- $\gamma$ induced MHC class II expression in murine macrophages

RAW 264.7 cells were infected with viable parasites, were left uninfected or were incubated with different ESA preparations: (1) T. gondii incubated for 30 minutes at $37^{\circ} \mathrm{C}$ in RPMI $1640+3 \% \mathrm{FCS}+1 \%$ ethanol; (2) T. gondii incubated for 30 minutes at $37^{\circ} \mathrm{C}$ in RPMI $1640+1 \%$ ethanol and (3) T. gondii incubated for 3 hours at $37^{\circ} \mathrm{C}$ in RPMI $1640+10 \%$ FCS. Incubation with the respective secretion media used for the different ESA preparations were performed in parallel (C). Two to three hours after infection or treatment, cells were activated with $100 \mathrm{U} / \mathrm{ml}$ IFN- $\gamma$ as indicated. Total RNA was isolated 24 hours post infection/treatment and was reverse transcribed. The cDNA's were then amplified by PCR using primer pairs for $\mathrm{H} 2-\mathrm{Ab}$ and $\beta$-actin. PCR products were separated by agarose gelelectrophoresis, visualized by ethidiumbromide staining and analysed semiquantitatively using a digital imaging system. Relative intensities of $\mathrm{H} 2-\mathrm{Ab}$ amplicons were calculated $(\mathrm{H} 2-\mathrm{Ab} / \beta$-actin x 100$)$ and the intensity of the non-infected, IFN- $\gamma$ activated sample was defined as $100 \%$. All other values were calculated relative to this sample. Bars represent means + - standard deviation $(n=3)$. n.d.: not detectable 
Furthermore, incubation of RAW 264.7 cells with highly concentrated ESA's kindly provided by V. Carruthers (Baltimore, USA) also did not abrogate up-regulation of $\mathrm{H} 2-\mathrm{Ab}$ transcripts in response to IFN- $\gamma$ stimulation (data not shown).

These results indicate that the effector molecule that mediates the inhibition of MHC class II up-regulation and that is obviously secreted by viable $T$. gondii in the presence of host cells is not present in the different $T$. gondii-derived ESA preparations at a sufficient concentration in order to mediate the interference with MHC class II expression.

\subsection{Mechanisms of $T$. gondii interfering with IFN- $\gamma$-regulated MHC class II expression}

\subsubsection{Viable parasites and $T$. gondii lysate do not inhibit nuclear translocation of activated Stat1 $\alpha$ in response to IFN- $\gamma$}

The results described so far characterised parasite requirements for inhibition of $T$. gondii with IFN- $\gamma$-induced gene expression. In order to get further insights into this parasite-host interaction experiments were performed to elucidate the mechanism of interference of $T$. gondii with the IFN- $\gamma$-stimulated Jak-Stat signalling cascade.

The IFN- $\gamma$-induced translocation of the signal transducer and activator of transcription (Stat) $1 \alpha$ into the nucleus is essential for transcriptional activation of the majority of IFN$\gamma$-responsive genes. In order to determine whether $T$. gondii interferes with the Jak-Stat signalling cascade by inhibiting the transport of activated Stat $1 \alpha$ dimers into the nucleus, Western blot analyses as a biochemical approach as well as double immunofluorescence staining as an analysis on the single cell level were applied. For the immunoblot analyses, RAW 264.7 cells were infected with viable $T$. gondii, or were incubated with $T$. gondii lysate, or were left uninfected as a control. The results show that cytosolic extracts from RAW 264.7 cells activated with IFN- $\gamma$ contained less Stat $1 \alpha$ as compared to unstimulated control cells, whereas the amount of Stat $1 \alpha$ in the nuclear extracts increased dramatically after cytokine stimulation (Figure 13). Importantly, this subcellular distribution of Stat1 $\alpha$ was not altered in IFN- $\gamma$-stimulated cells concomitantly infected with viable $T$. gondii or incubated with parasite lysate (Figure 13). In addition, the total amount of Stat $1 \alpha$ in complete RAW 264.7 cell extracts was not altered by viable $T$. gondii or by parasite lysate (Figure 13). Double immunofluorescence staining of RAW 264.7 cells either infected with viable parasites, or incubated with $T$. gondii lysate, or left uninfected as a control further 
supported the results described above. In unstimulated cells, i.e. those culture in the absence of exogenous IFN- $\gamma$, most Stat $1 \alpha$ was accumulated in the cytosol of the cells while only small amounts could be detected in the nucleus (Figure 14).

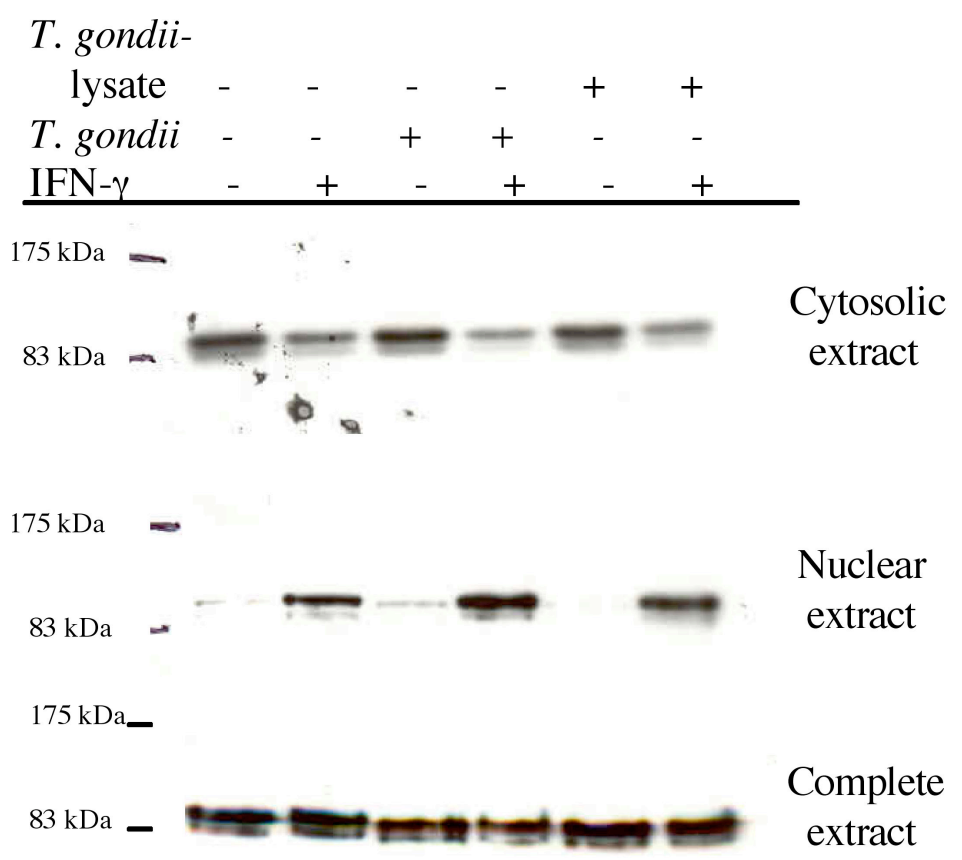

Figure 13: The IFN- $\gamma$-induced nuclear translocation of Stat1 $\alpha$ is not abrogated by T. gondii and parasite lysate as determined by subcellular fractionation of RAW 264.7 cells and Western blot analysis

RAW 264.7 cells were infected with viable $T$. gondii at a parasite to host cell ratio of 8:1, incubated with 30 $\mu \mathrm{g} / \mathrm{ml}$ parasite lysate, or were left uninfected. After 24 hours, cells were activated for 30 minutes with 300 $\mathrm{U} / \mathrm{ml}$ IFN $-\gamma$ as indicated. Thereafter, cytosolic and nuclear extracts or complete cell lysates were prepared, separated by SDS-PAGE and analysed by immunoblot using anti-Stat $1 \alpha$ antibodies. The results shown are representative for three independent experiments.

This distribution of Stat $1 \alpha$ did not change after infection with viable parasites or incubation with parasite-lysate. After activation of non-infected or those cultured in the absence of lysate with $300 \mathrm{U} / \mathrm{ml}$ IFN- $\gamma$ for 30 minutes, Stat $1 \alpha$ was clearly accumulated in the nuclei compared to unstimulated cells. Importantly, this IFN- $\gamma$-induced nuclear translocation of Stat $1 \alpha$ was similarly observed in cells concomitantly infected with viable 
parasites or cells incubated with $T$. gondii lysate (Figure 14). To further support these results, stable transfectants of the mutant mouse fibroblast cell line NIH/3T3 expressing a Stat-GFP fusion protein were infected with $T$. gondii or were incubated with parasite lysate, or were left uninfected and analysed by immunofluorescence microscopy.

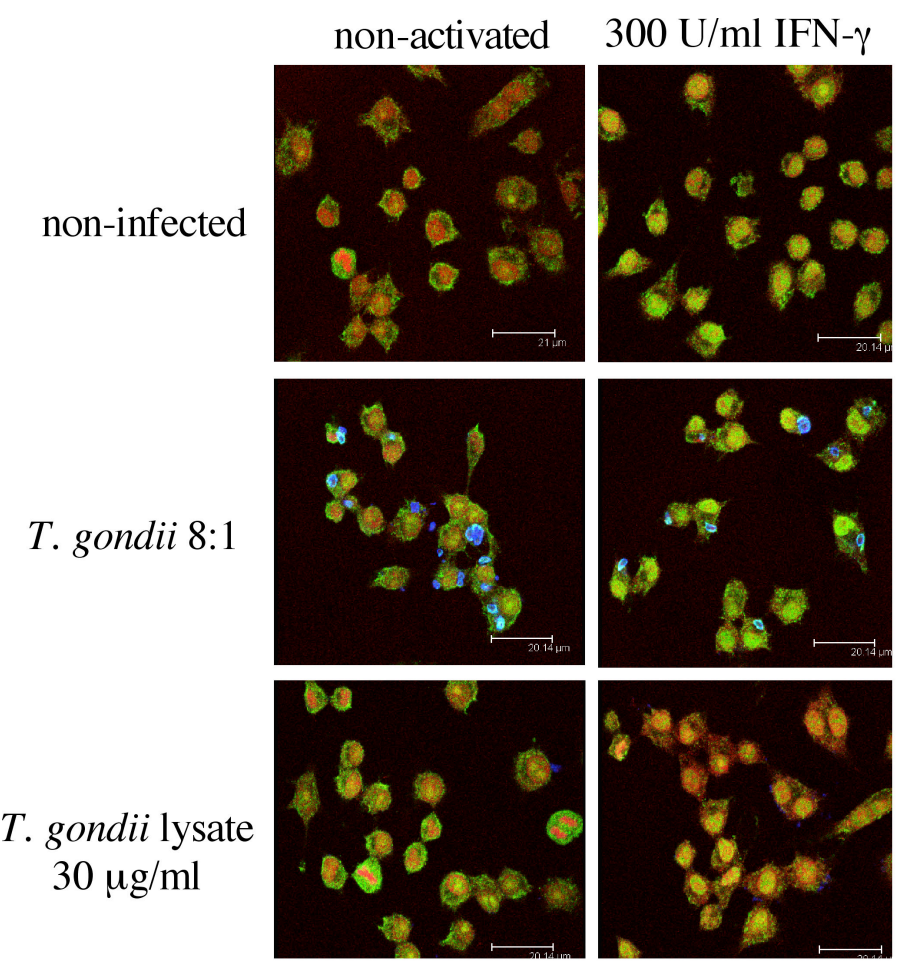

Figure 14: $T$. gondii and parasite lysate do not abrogate the nuclear translocation of Stat1 $\alpha$ in response to IFN- $\gamma$

RAW 264.7 cells were infected with viable parasites at a parasite to host cell ratio of 8:1, incubated with 30 $\mu \mathrm{g} / \mathrm{ml}$ T. gondii lysate or were left non-infected. Twenty-four hours later, cells were activated with $300 \mathrm{U} / \mathrm{ml}$ IFN- $\gamma$ for 30 minutes or were left unstimulated as indicated. Cells were fixed and the subcellular distribution of Stat $1 \alpha$ in response to IFN- $\gamma$ was analysed by double immunofluorescence staining. Stat $1 \alpha$ was visualized with anti-Stat $1 \alpha$ antibodies (green) and T. gondii were stained with an anti-Toxoplasma serum (blue). Nuclei were visualized by staining of nucleic acids with propidiumiodide. Images of each fluorescence were obtained in parallel by confocal laser scanning microscopy and were superimposed. The results shown are representative for three independent experiments.

In unstimulated cells, Stat-GFP was predominantly localized in the cytosol and this was not altered after infection with viable parasites or incubation with $T$. gondii lysate (Figure

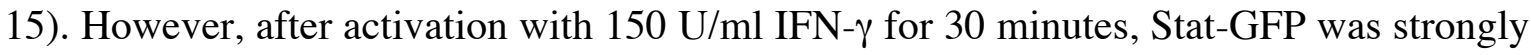


translocated into the nucleus. In accordance with the experiments described above, the nuclear translocation of Stat-GFP in response to IFN- $\gamma$ was not reduced in cells infected with viable parasites or incubated with different concentrations of $T$. gondii lysate.

Taken together, these results show, that neither viable $T$. gondii nor parasite lysate interfere with the IFN- $\gamma$-induced Jak-Stat signalling by inhibiting nuclear translocation of activated Stat $1 \alpha$ dimers.
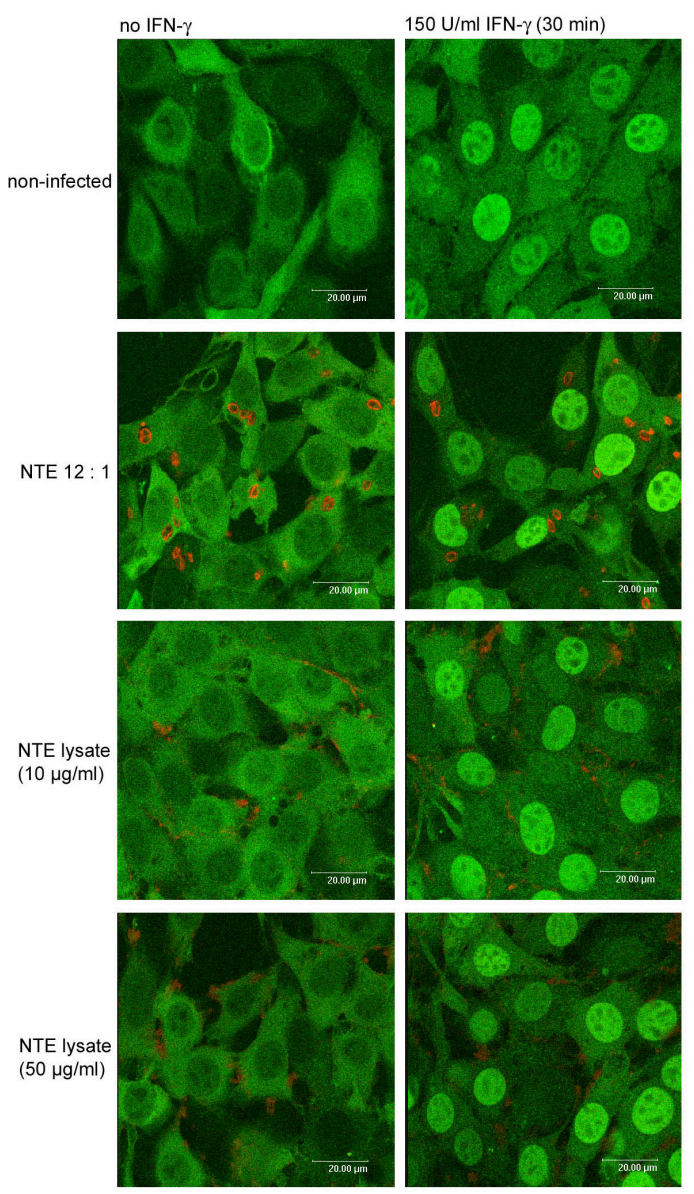

Figure 15: The nuclear translocation of Stat-GFP fusion proteins in response to IFN- $\gamma$ is not inhibited by viable $T$. gondii or $T$. gondii lysate

NIH/3T3 cells stably transfected with a Stat-GFP fusion protein construct were infected with viable T. gondii at a parasite to host cell ratio of $12: 1$, incubated with 10 and $50 \mu \mathrm{g} / \mathrm{ml}$ parasite lysate or were left non-

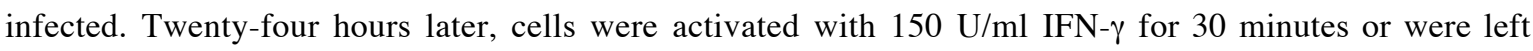
unstimulated as indicated. Cells were then fixed and analysed by immunofluorescence staining. Stat-GFP emits green light and $T$. gondii was visualized by anti-Toxoplasma serum (red). Images of each fluorescence were obtained simultaneously by confocal laser scanning microscopy and were superimposed. The results shown are representative for three independent experiments. 


\subsubsection{T. gondii interfere with MHC class II expression in cells expressing an IRF-}

\section{1/hER fusion protein after stimulation with estradiol}

The transcription of MHC class II genes in NIH/3T3 cells expressing a fusion protein of the transcription factor interferon regulatory factor-1 (IRF-1) and the human estradiol recepter (hER) can not only be induced by IFN- $\gamma$ via the classical Jak-Stat signalling cascade but also by stimulation with estradiol leading to nuclear translocation of the IRF1/hER fusion protein and up-regulation of MHC class II transcripts.
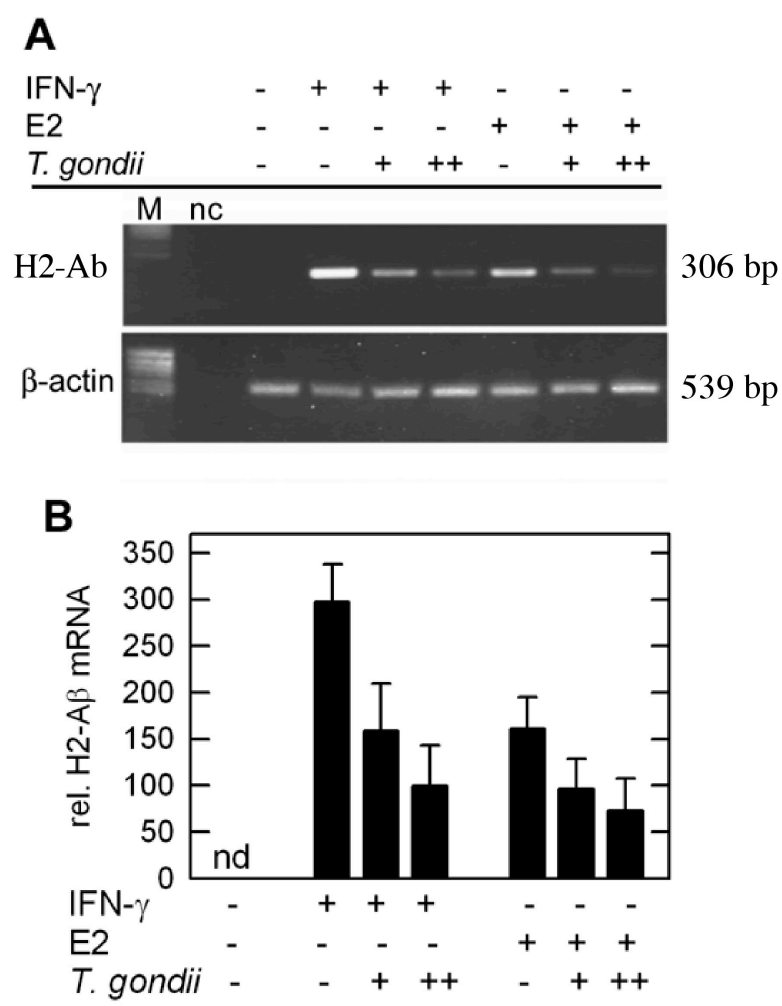

Figure 16: T. gondii interferes with expression of MHC clas S II in estradiol-activated NIH/3T3 expressing an IRF-1/hER fusion protein

NIH/3T3 cells stably transfected with a construct encoding IRF-1 fused to the human estrogen receptor (IRF1/hER) were incubated with viable $T$. gondii or were left uninfected as indicated. Two to three hours post infection, cells were activated with $100 \mathrm{U} / \mathrm{ml} \mathrm{IFN}-\gamma$, with $100 \mathrm{nM}$ estradiol, or were left unstimulated. Twenty-four hours post infection, total RNA was isolated, reverse transcribed and cDNA was amplified by PCR with specific primer pairs for $\beta$-actin or H2-Ab. The PCR products were separated by agarose gelelectrophoresis and analysed semiquantitatively using a digital imaging system. The intensities of $\mathrm{H} 2-\mathrm{Ab}$ amplicons in comparison to the $\beta$-actin amplicons in the same sample were calculated (H2-Ab/ $\beta$-actin x 100). Bars represent means +/- S.E.M (n=4). n.d.: not detectable 
In order to determine whether viable $T$. gondii are also able to interfere with $\mathrm{H} 2-\mathrm{Ab}$ expression in mutant $\mathrm{NIH} / 3 \mathrm{~T} 3$ cells activated with estradiol via such an alternative signalling pathway, cells were infected with viable parasites or were left uninfected and were activated with $100 \mathrm{U} / \mathrm{ml}$ IFN- $\gamma$ or $100 \mathrm{nM}$ estradiol. The mRNA levels of $\mathrm{H} 2-\mathrm{Ab}$ were then determined by semiquantitative RT-PCR. No transcripts of H2-Ab were detectable in unstimulated cells (Figure 16). After activation with both IFN- $\gamma$, or estradiol, the amount of $\mathrm{H} 2-\mathrm{Ab}$ transcripts was considerably increased. However, activation with IFN- $\gamma$ resulted in a stronger induction of $\mathrm{H} 2-\mathrm{Ab}$ transcripts as compared to the activation with estradiol. Importantly, this up-regulation was abrogated in cells concomitantly infected with increasing numbers of $T$. gondii. Herein, the parasite not only dosedependently inhibited up-regulation of $\mathrm{H} 2-\mathrm{Ab}$ transcripts in response to IFN- $\gamma$, but also after stimulation of cells with estradiol.

These results further suggest that viable $T$. gondii interfere with activation-induced expression of MHC class II molecules downstream of nuclear translocation of Stat $1 \alpha$.

\subsubsection{T. gondii and $T$. gondii lysate differentially interfere with IFN- $\gamma$-mediated signalling}

According to results presented above, T. gondii and parasite lysate interfere with IFN- $\gamma$ induced transcript levels of MHC class II (see Figure 7). The transcription of MHC class II genes in response to IFN- $\gamma$ is directly dependent on expression of the class II transactivation (CIITA). Therefore, mRNA levels of CIITA in RAW 264.7 cells infected with viable parasites or incubated with $T$. gondii lysate were compared to non-infected control cells by semiquantitative RT-PCR. CIITA transcripts were not detectable in unstimulated cells and this did not change after infection with viable parasites or after incubation with T. gondii lysate (Figure 17). Activation with IFN- $\gamma$ strongly induced mRNA levels of CIITA in non-infected cells. This cytokine-dependent up-regulation of CIITA transcripts was, however, clearly decreased in cells that were concomitantly infected with increasing amounts of viable parasites in a dose-dependent manner. Furthermore, CIITA mRNA levels were also considerably diminished in cells that were incubated with $T$. gondii lysate (Figure 17). Transcriptional activation of CIITA depends on nuclear translocation and DNA-binding of activated Stat $1 \alpha$, but also requires expression and binding of the transcription factor IRF-1. Therefore, the mRNA levels of 
IRF-1 in response to IFN- $\gamma$ stimulation in cells infected with viable parasites or incubated with $T$. gondii lysate were semiquantitatively determined by RT-PCR.

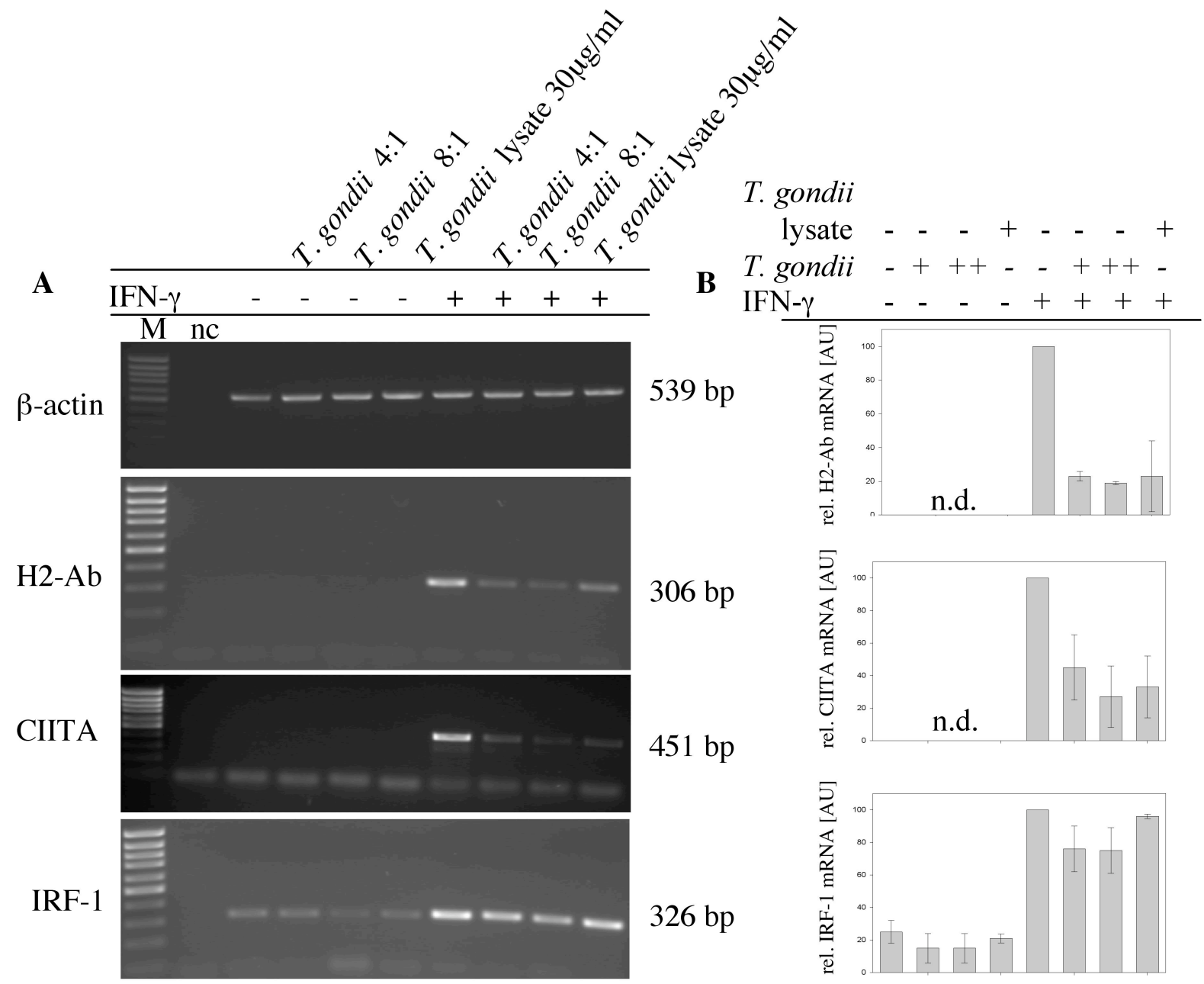

Figure 17: Viable T. gondii and parasite lysate differentially interfere with IFN- $\gamma$-induced gene expression

RAW 264.7 cells were infected with viable $T$. gondii at parasite to host cell ratios of 4:1 and 8:1, or were incubated with $30 \mu \mathrm{g} / \mathrm{ml} \mathrm{T}$. gondii lysate, or were left non-infected. Two to three hours post infection, cells were activated with $100 \mathrm{U} / \mathrm{ml} \mathrm{IFN- \gamma}$ as indicated. After 24 hours, total RNA was isolated and reverse transcribed. The cDNA was amplified by PCR using specific primer pairs for $\beta$-actin, H2-Ab, CIITA and IRF-1. Amplicons were separated by agarose gelelectrophosesis (A) and were semiquantitatively analysed employing a digital imaging system. Relative intensities were calculated $(\mathrm{H} 2-\mathrm{Ab} / \beta$-actin x $100 ; \mathrm{CIITA} / \beta$ actin $x 100$; IRF-1/ $\beta$-actin $\times 100$ ) and the intensity for the non-infected, IFN- $\gamma$-activated sample was defined as $100 \%$, the other values were calculated relative to the intensity of this sample (B). Bars represent mean $+/-$ standard deviation $(\mathrm{n}=2)$. n.d.: not detectable 
In unstimulated cells, IRF-1 was constitutively expressed at low levels, and this did not considerably change in cells infected with viable parasites or incubated with $T$. gondii lysate (Figure 17). After activation with IFN- $\gamma$, the transcript levels of IRF-1 considerably increased in non-infected cells. This up-regulation was partially inhibited in cells concomitantly infected with viable $T$. gondii. In contrast, $T$. gondii lysate did not interfere with cytokine-induced mRNA levels of IRF-1 (Figure 17).

These results indicate, that viable parasites and $T$. gondii lysate employ different mechanisms to interfere with IFN- $\gamma$-induced signalling. Nevertheless, both strategies result in inhibition of MHC class II expression in murine macrophages.

\subsubsection{T. gondii and parasite lysate interfere with transcriptional activation of the} CIITA promoter IV

Viable parasites and $T$. gondii lysate are able to interfere with the up-regulation of CIITA transcripts in response to IFN- $\gamma$ stimulation as shown in 3.3.3. In order to determine the influence of viable $T$. gondii and parasite lysate on transcriptional activity of IFN- $\gamma$ responsive promoters, reporter assays were performed. For this, RAW 264.7 cells stably transfected with a construct encoding luciferase under the control of the CIITA promoter IV kindly provided by J. Ernst, New York (Kincaid and Ernst, 2003; Figure 18A) were infected with viable $T$. gondii, or were incubated with $T$. gondii lysate, or were left uninfected as a control. Unstimulated cells, i.e. those cultured in the absence of exogenous IFN- $\gamma$, showed a basal luciferase activity, which was not changed in cells infected with viable parasites or incubated with $T$. gondii lysate (Figure 18B). Activation with IFN- $\gamma$ led to a two-fold increase of luciferase activity in uninfected cell populations. Such upregulation of luciferase expression in response to cytokine stimulation was completely abrogated in cells concomitantly infected with viable $T$. gondii as well as in those incubated with $T$. gondii lysate (Figure 18B).

Thus, viable $T$. gondii and $T$. gondii lysate interfere with transcriptional activation of the CIITA promoter IV in response to IFN- $\gamma$. 


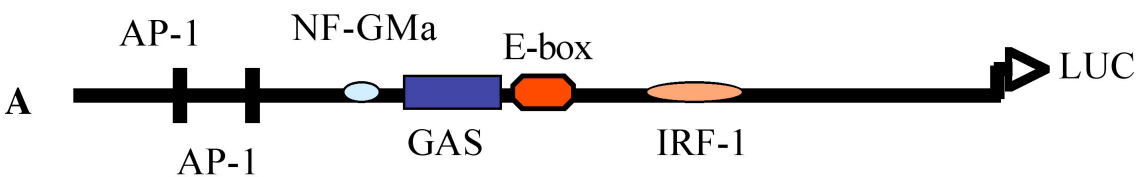

B

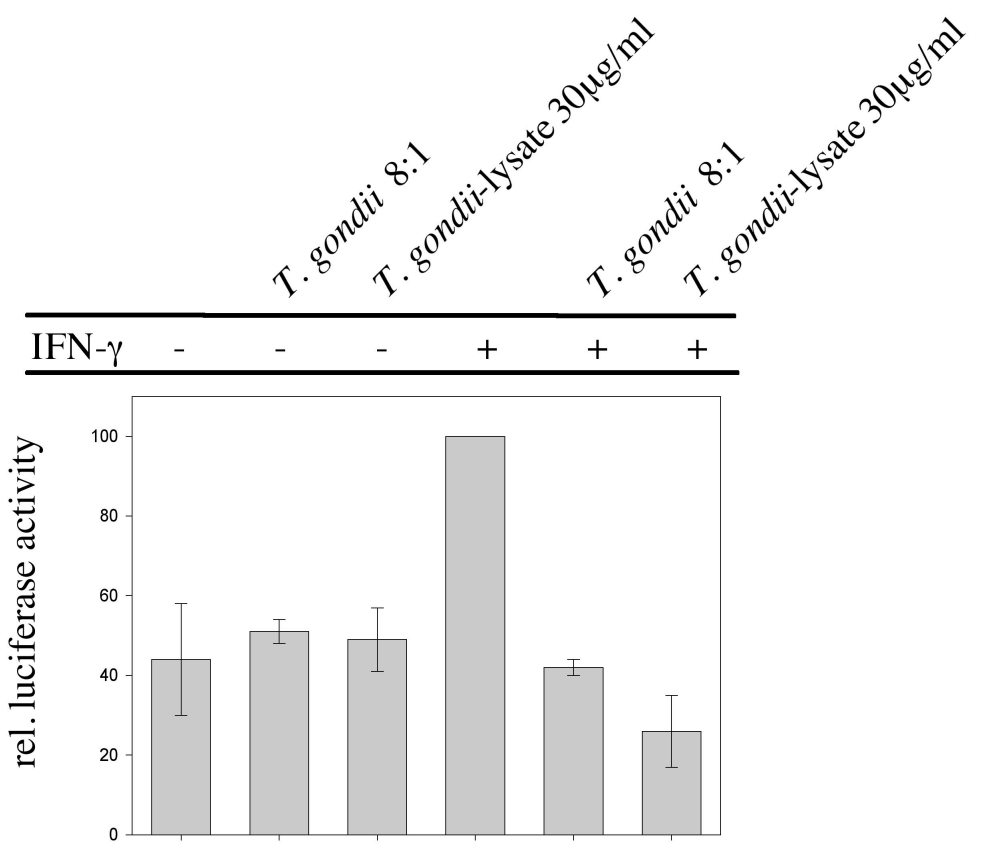

Figure 18: Viable parasites and $T$. gondii lysate interfere with CIITA-promoter IV-driven luciferase activity

(A) Schematic representation of the CIITA promoter IV construct driving luciferase. AP-1: activator protein 1; NF-GMa: nuclear transcription factor GMa; GAS: gamma interferon activated site; IRF-1: interferon regulatory factor-1; LUC: luciferase. (B) RAW 264.7 stably transfected with a construct of the CIITA promoter IV driving luciferase were infected with viable $T$. gondii at a parasite to host cell ratio of 8:1, incubated with $30 \mu \mathrm{g} / \mathrm{ml} \mathrm{T}$. gondii lysate, or were left uninfected. Two to three hours post infection, cells were activated with $100 \mathrm{U} / \mathrm{ml} \mathrm{IFN- \gamma}$ as indicated and after 24 hours equal amounts of cells for each sample were lysed and luciferase activity was measured. The luciferase activity of non-infected, IFN- $\gamma$-activated cells were defined as $100 \%$, the other values were calculated relative to the activity of this sample. Bars represent means $+/$ - standard deviation $(n=3)$.

\subsubsection{Only viable $T$. gondii are able to interfere with a minimal GAS-containing promoter}

The transcriptional activation of the CIITA promoter IV depends on binding of activated Stat1 $\alpha$, IRF-1 and USF-1 to their respective DNA-binding sites. In order to determine which region of the promoter is crucial for interference of viable parasites and parasite 
lysate with transcriptional activation of the CIITA promoter IV in response to IFN- $\gamma$, RAW 264.7 cells were transiently transfected with a luciferase reporter construct under the control of a minimal promoter with four GAS elements as enhancers (Figure 19A). Unstimulated cells showed no detectable luciferase activity, and this did not change in cells infected with viable $T$. gondii or incubated with $T$. gondii lysate (Figure 19B).

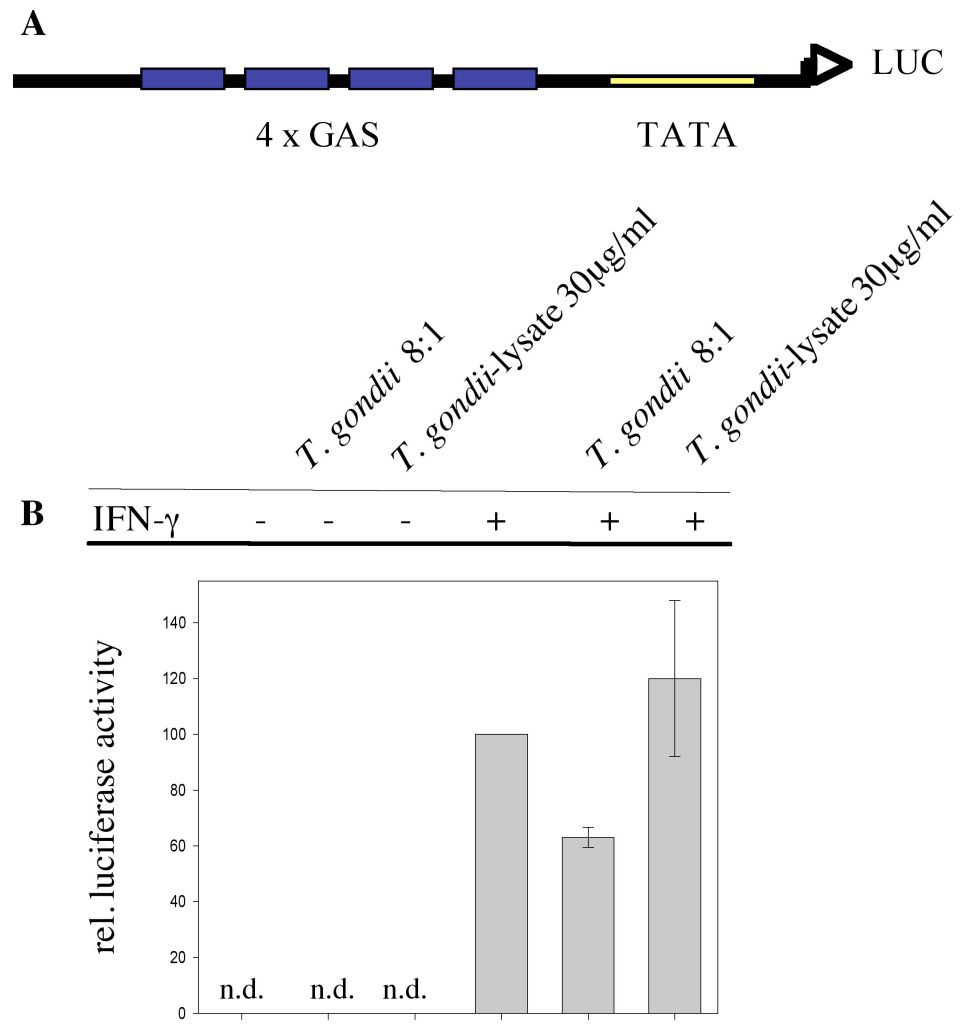

Figure 19: Viable $T$. gondii but not parasite lysate interfere with transcriptional activity of a minimal GAS-containing promoter

(A) Schematic representation of the minimal GAS-containing promoter driving luciferase. GAS: gamma interferon activated site; TATA: TATA box; LUC: luciferase. (B) RAW 264.7 cells were transiently transfected with a construct of a minimal GAS-containing promoter driving luciferase and were infected with viable $T$. gondii at a parasite to host cell ratio of 8:1, incubated with $30 \mu \mathrm{g} / \mathrm{ml} T$. gondii lysate, or were left uninfected. Two to three hours post infection, cells were activated with $100 \mathrm{U} / \mathrm{ml} \mathrm{IFN-} \gamma$ or left unstimulated. After 24 hours, equal amounts of cells for each sample were lysed and analysed employing a luciferase assay system. The luciferase activity of the non-infected, IFN- $\gamma$ activated sample was defined as $100 \%$, the other values were calculated relative to the activity of this sample. Bars represent means +/- standard deviation $(n=3)$. n.d.: not detectable 
The luciferase activity clearly increased in response to stimulation with $100 \mathrm{U} / \mathrm{ml}$ IFN- $\gamma$ for 24 hours and this up-regulation was diminished in activated cells concomitantly infected with viable T. gondii (Figure 19B). In contrast, T. gondii lysate did not inhibit upregulation of luciferase expression in response to IFN- $\gamma$ (Figure 19B).

These results indicate, that viable $T$. gondii abrogate transcriptional activation of the CIITA promoter IV at least partially by interfering with the GAS-containing sequence. In contrast, parasite lysate do not inhibit transcriptional activity via interference with GAS-binding elements.

\subsubsection{T. gondii lysate stimulate the secretion of IL-10 by bone marrow-derived macrophages}

IL-10 is a cytokine, which is known to interfere with expression of MHC class II (O'Keefe et al., 1994) via a mechanism that is not yet fully understood. In addition, it has been described previously, that the secretion of IL-10 in mice treated with T. gondii lysate is increased compared to non-treated control animals (Gazzinelli et al., 1996). Therefore, the influence of viable $T$. gondii and parasite lysate on the IL-10 secretion by BMM was determined by ELISA, and compared to uninfected control cells. Low levels of IL-10 were secreted by unstimulated cells and this did not change in cells infected with viable $T$. gondii at 24 and 48 hours (Figure 20). In contrast, incubation with T. gondii lysate strongly induced the secretion of IL-10 by BMM at 24 and 48 hours post incubation (Figure 20). After stimulation of BMM with IFN- $\gamma$, uninfected cells or those infected with viable $T$. gondii again did not produce considerable amounts of IL-10 at 22 or 46 hours post stimulation. However, cells that were activated with IFN- $\gamma$ and concomitantly incubated with parasite lysate secreted high levels of IL-10 at 24 hours and this further increased after 48 hours (Figure 20). These results opened the possibility, that down-regulation of MHC class II molecules by parasite lysate is mediated by an increased secretion of IL-10 by murine macrophages. In order to determine the functional role of IL-10 in the downregulation of MHC class II expression by $T$. gondii lysate, BMM from IL-10 knock-out (KO) mice (Kühn et al., 1993; kindly provided by U. Steinhoff, MPI for Infectious Biology, Berlin) or C57/B16 control mice were infected with viable parasites, were incubated with $T$. gondii lysate or were left uninfected as a control. The effect of parasite lysate and viable $T$. gondii on the appearance of MHC class II molecules on the cell surface of wild type and IL-10 KO cells was then analysed by flow cytometry. The results 
show, that the expression of MHC class II molecules was low in unstimulated cell populations, e.g. those cells incubated in the absence of exogenous IFN- $\gamma$ (Figure 21A).

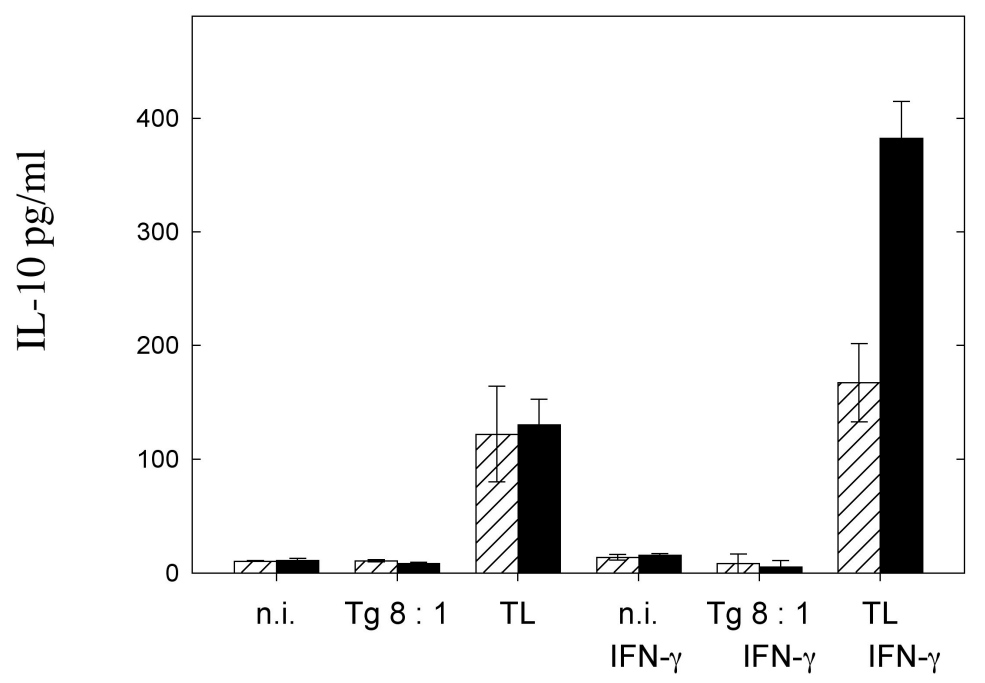

$\nabla / 724$ hours post treatment 48 hours post treatment

Figure 20: $T$. gondii lysate induce the secretion of IL-10 by murine macrophages

BMM from BALB/c mice were infected with viable $T$. gondii at a parasite to host cell ratio of $8: 1$, were incubated with $30 \mu \mathrm{g} / \mathrm{ml}$ parasite lysate or were left uninfected (n.i.). Two to three hours post infection or

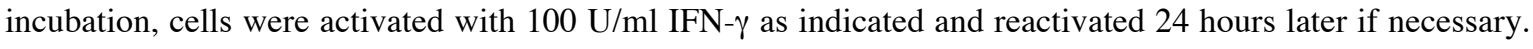
After 24 or 48 hours, supernatants were isolated and analysed for IL-10 using a sandwich ELISA. Bars represent means $+/$ - standard deviation $(n=3)$.

However, after stimulation with IFN- $\gamma$ for 42 hours, expression of the MHC class II molecules I-A/I-E was considerably increased in non-infected cell populations of wildtype and IL-10 KO cells (Figure 21B). In BMM concomitantly infected with viable T. gondii the IFN- $\gamma$-induced up-regulation of MHC class II was abrogated both in wildtype and in IL-10 KO cell populations (Figure 21B). A decrease of the fluorescence intensities after parasitic infection was also observed after staining with an isotype-matched control antibody, however, the differences between infected and non-infected cells were much lower than those observed after staining with the MHC class II-specific antibody. More 
importantly, in both wildtype as well as IL-10 KO cells, the IFN- $\gamma$-induced expression of MHC class II molecules was also considerably diminished after incubation with $T$. gondii lysate compared to untreated control cells (Figure 21C).

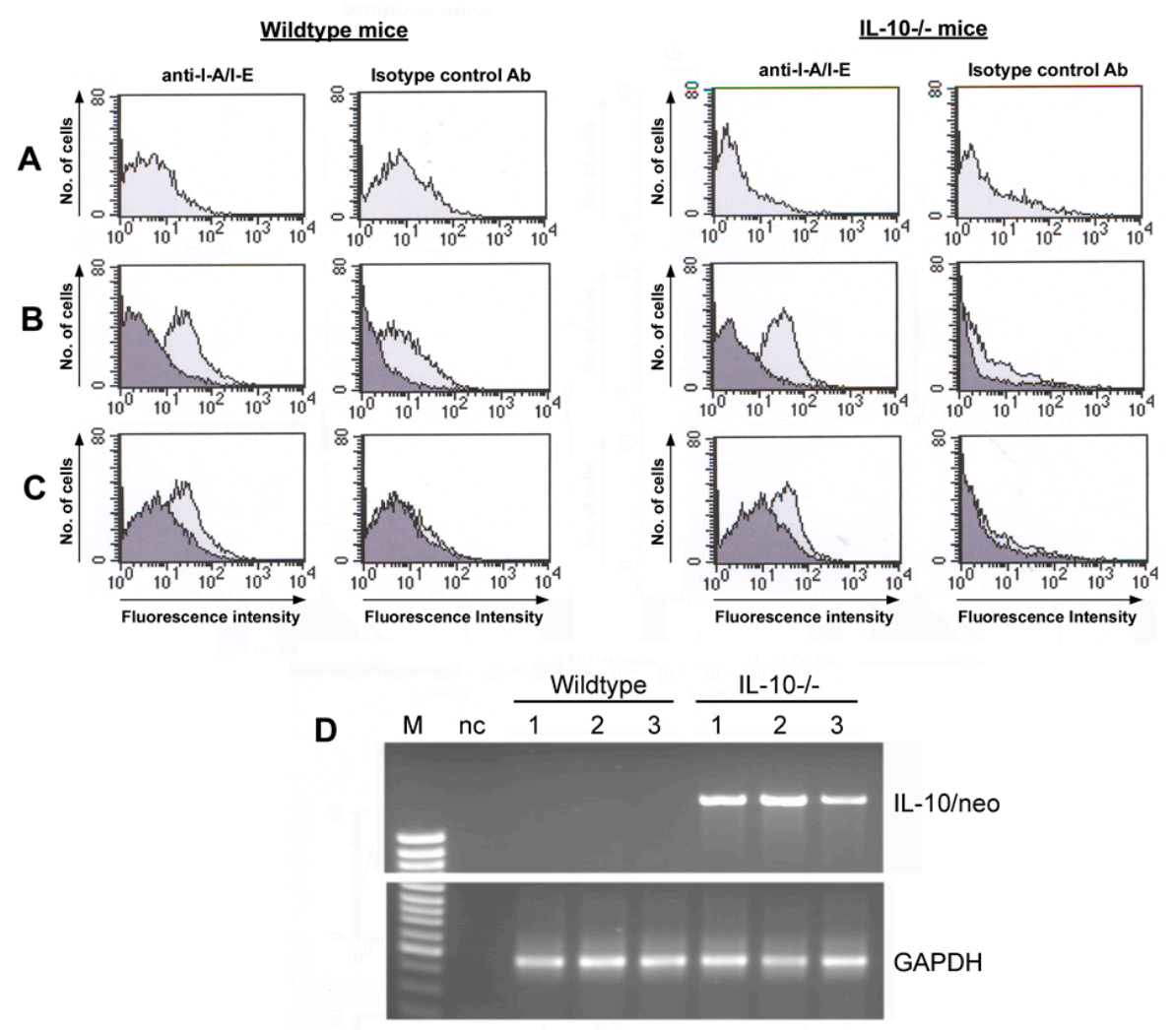

Figure 21: IL-10 secretion by BMM is not involved in interference of $T$. gondii lysate with IFN- $\gamma$ activated MHC class II expression

BMM derived from wildtype mice or IL-10 -/- mice were infected with viable $T$. gondii at a parasite to host cell ratio of 1.5:1 (dark area, B), or were incubated with $30 \mu \mathrm{g} / \mathrm{ml} T$. gondii lysate (dark area, C) or were left uninfected (bright area, A,B,C). Two to three hours post infection, cells were activated with $100 \mathrm{U} / \mathrm{ml} \mathrm{IFN}-\gamma$ (B and C) and reactivated 24 hours post infection or were left unstimulated (A). At 44 hours post infection, surface expression of I-A/I-E (MHC class II) molecules was quantified by flow cytometry, staining with an isotype control antibody was performed in parallel. (D) Chromosomal DNA was isolated from three wild type mice and three IL-10 -/- mice (1-3) and PCR was performed using primer pairs for the neomycin (neo) knock-out cassette within the IL-10 gene. As a control, PCR was performed in parallel with primer pairs specific for GAPDH. PCR products were separated by gelelectrophoresis and visualized by ethidiumbromide staining. Data shown are representative for four independent experiments. 
However, such differences were not observed in cells stained with an isotype control antibody. In order to control the identity of the IL-10 KO mice used for the above experiments, genomic DNA was analysed for the existance of the neomycin knock-out cassette in the IL-10 gene by PCR (Figure $21 \mathrm{C}$ ). The results show, that the IL-10 gene in the IL-10 KO mice was indeed disrupted by the neomycin cassette, the presence of which was not detectable in wildtype control mice.

Taken together, these results show that $T$. gondii lysate induces the secretion of IL-10 by BMM. Nevertheless, IL-10 does not mediate the interference of parasite lysate with IFN- $\gamma$ induced MHC class II expression.

\subsubsection{Kinetics of $\boldsymbol{T}$. gondii-mediated interference with IFN- $\boldsymbol{\gamma}$-mediated signalling}

Viable T. gondii diminished transcript levels of IRF-1, CIITA and consequently H2-Ab (3.3.3). In order to determine the kinetics of the parasite-mediated inhibition of IFN- $\gamma$ induced up-regulation of these mRNA's, total RNA was isolated at 8, 14, 24 and 48 hours post infection and was semiquantitatively analysed by RT-PCR. H2-Ab mRNA was not detectable or only barely detectable in unstimulated cells at all time points investigated (Figure 22). However, activation with IFN- $\gamma$ led to an up-regulation of $\mathrm{H} 2-\mathrm{Ab}$ mRNA levels after 14, 24 and 48 hours but was not yet detectable after 8 hours post infection. Concomitant infection with viable parasites at a parasite to host cell ratio of 8:1 resulted in the inhibition of IFN- $\gamma$-induced up-regulation of $\mathrm{H} 2-\mathrm{Ab}$ transcription, which was already obvious at 14 hours post infection and was similarly observed until 48 hours post infection (Figure 22). Comparable results were obtained for IFN- $\gamma$-induced mRNA levels of CIITA, which were also decreased in cells infected with viable $T$. gondii at time points 14, 24 and 48 hours post infection (Figure 22). In contrast, up-regulation of IRF-1 transcripts in response to IFN- $\gamma$ was already recognized 7 hours post activation and proceeded until the end of observation. Importantly, viable $T$. gondii interfered with this up-regulation during all time points starting as early as 8 hours post infection (Figure 22). 


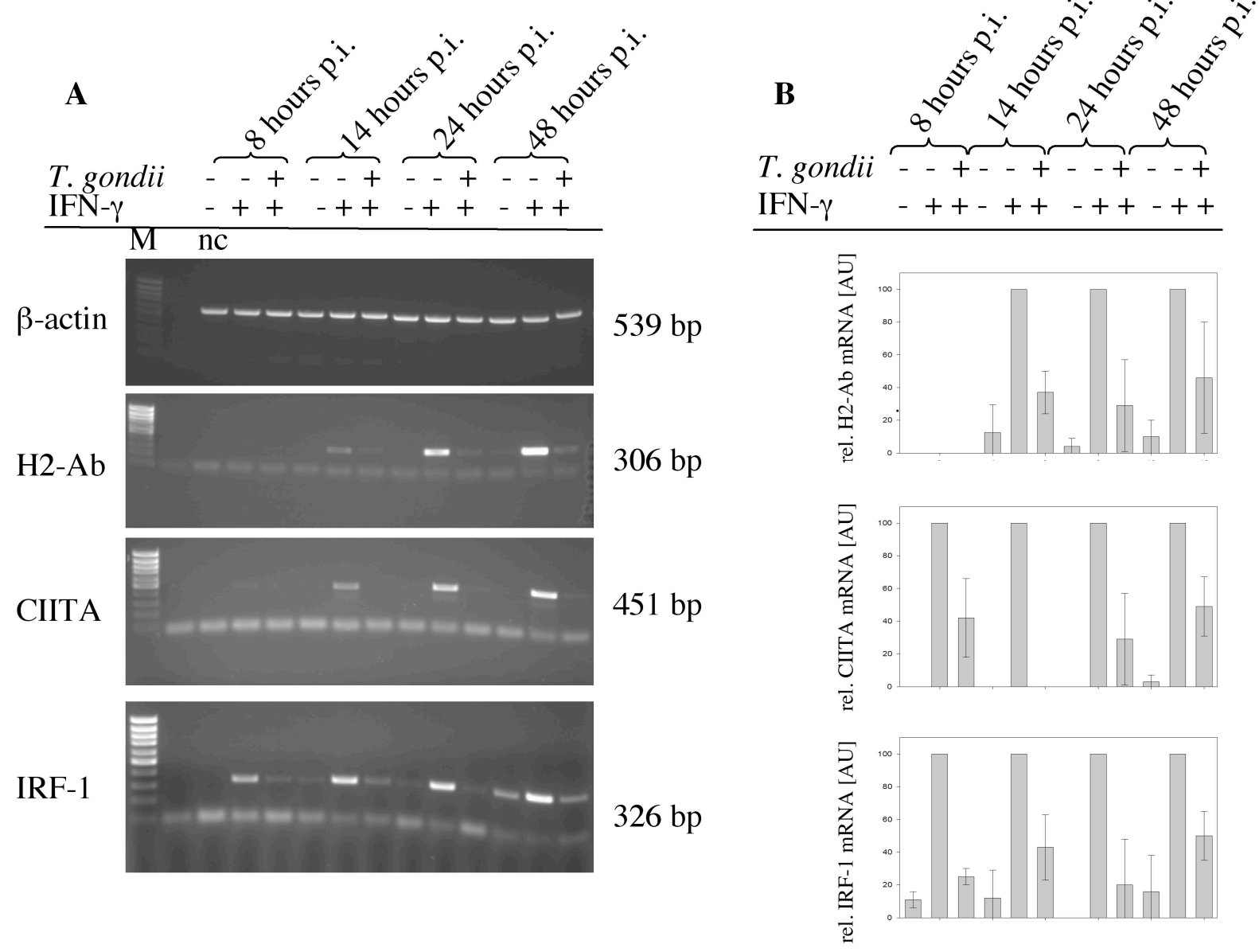

Figure 22: Kinetics of $T$. gondii-mediated interference with IFN- $\gamma$ signalling

RAW 264.7 cells were infected with viable $T$. gondii at a parasite to host cell ratio of 8:1. One hour post infection, cells were activated with $100 \mathrm{U} / \mathrm{ml}$ IFN- $\gamma$ as indicated. Total RNA was isolated at 8 hours, 14 hours, 24 hours and 48 hours after infection, the mRNA was reverse transcribed and cDNA was amplified by PCR using specific primer pairs for $\beta$-actin, H2-Ab, CIITA and IRF-1. The PCR products were separated by agarose gelelectrophoresis (A) and analysed semiquantitatively using a digital imaging system. The relative intensities of the amplicons were calculated $(\mathrm{H} 2-\mathrm{Ab} / \beta$-actin $\times 100, \mathrm{CIITA} / \beta$-actin $\mathrm{x} 100$, IRF- $1 / \beta$-actin $\mathrm{x}$ 100). For each time point, the value for the non-infected, IFN- $\gamma$ activated sample was defined as $100 \%$, the other values of the same time point were calculated relative to the intensity of this sample (B). Bars represent means $+/$ - standard deviation $(\mathrm{n}=2)$.

\subsubsection{Viable $T$. gondii modulate DNA-binding of GAF but induce a second GAS- binding complex}

The transcriptional activation of most IFN- $\gamma$-responsive genes depends on binding of activated Stat $1 \alpha$ dimers (GAF) to their specific DNA-binding site, the GAS sequence. To analyse the effect of $T$. gondii on the DNA-binding activity of GAF, electrophoretic 
mobility shift assays (EMSA) were performed using the GAS-sequence of the Fcy-receptor 1 (Greenlund et al., 1994).

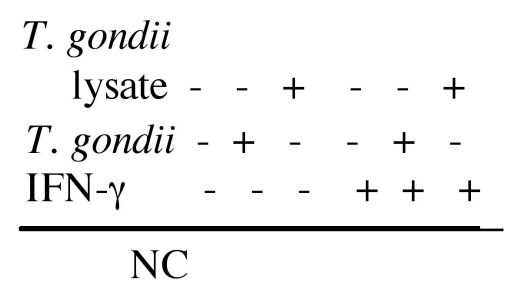

\section{$\Longleftarrow$ second complex}

$\Leftarrow \mathrm{GAF}$

Figure 23: Viable $T$. gondii modulate the DNA-binding activity of nuclear extracts to GAS-containing oligonulceotides

Primary bone marrow-derived macrophages (BMM) from BALB/c mice were infected with viable $T$. gondii at a parasite to host cell ratio of $6: 1$, incubated with $30 \mu \mathrm{g} / \mathrm{ml} T$. gondii lysate or were left uninfected. After 24 hours, cells were activated for 30 minutes with $300 \mathrm{U} / \mathrm{ml} \mathrm{IFN- \gamma}$ as indicated. Thereafter, the DNA-binding activity of nuclear extracts from the different samples to the GAS-sequence of the Fc $\gamma \mathrm{R} 1$ gene were compared by electrophoretic mobility shift assay (EMSA). For this, radioactively labelled GAS-containing oligonucleotides were incubated with nuclear extracts of the different samples and separated by native acrylamide gelelectrophoresis. Oligonucleotide-bound complexes were visualized by autoradiography. The results shown are representative for three independent experiments.

After stimulation of cells with $300 \mathrm{U} / \mathrm{ml} \mathrm{IFN}-\gamma$ for 30 minutes, binding of radioactively labelled GAS-containing oligonucleotides was strongly induced in nuclear extracts of 
uninfected BMM compared to unstimulated control cells (Figure 23). However, such GASbinding activity was significantly diminished in nuclear extracts from cells infected with viable $T$. gondii, but not in those incubated with $T$. gondii lysate. Importantly, viable parasites induced a second GAS-binding complex of lower electromobility, which was not observed with nuclear extracts from uninfected cells or BMM incubated with parasite lysate (Figure 23). This second GAS-binding complex was also detectable in nuclear extracts from $T$. gondii-infected unstimulated cells, i.e. those cells cultured in the absence of exogenous IFN- $\gamma$ (Figure 23).

Since this modulation of GAS-binding might be involved in the interference of $T$. gondii with IFN- $\gamma$-induced MHC class II expression, the composition of the parasite-induced GAS-binding complex was of major interest. Therefore, a series of supershift experiments using specific antibodies were employed. The IFN- $\gamma$-induced as well as the $T$. gondiispecific GAS-binding complex was completely supershifted with anti-Stat $1 \alpha$ antibodies, but not with normal rabbit IgG, clearly indicating that both complexes contain Stat $1 \alpha$ (Figure 24). The lower electromobility of the parasite-induced complex in comparison to the IFN- $\gamma$-induced complex could be due to the secretion of type I interferons by murine macrophages in response to infection by the parasite. IFN- $\alpha$ and IFN- $\beta$ activate a signal transduction cascade leading to formation of Stat1:Stat2 heterodimers, which translocate into the nucleus and form together with p48 the interferon-stimulated gene factor 3 (ISGF3) (Fu et al., 1990). However, supershifts performed with nuclear extracts from $T$. gondii-infected BMM or from uninfected control cells incubated with GAS-containing oligonucleotides and antibodies against Stat2 or p48 did neither alter the electromobility of the IFN- $\gamma$-induced nor that of the second parasite-induced GAS-binding complex (Figure 24). Furthermore, activation of non-infected BMM with IFN- $\beta$ alone or in combination with IFN- $\gamma$ did not result in the formation of a comparable complex as induced by T. gondii (data not shown).

Stat1 is also able to form heterodimers with other members of the Stat-family in response to different stimuli. Therefore, EMSA's were performed incubating nuclear extracts from BMM infected with $T$. gondii or from uninfected control cells with radioactively labelled GAS-containing oligonucleotides with or without antibodies directed against Stat3, Stat4, Stat5b or Stat6. However, none of these antibodies supershifted the $T$. gondii-induced second GAS-binding complex (Figure 25). 


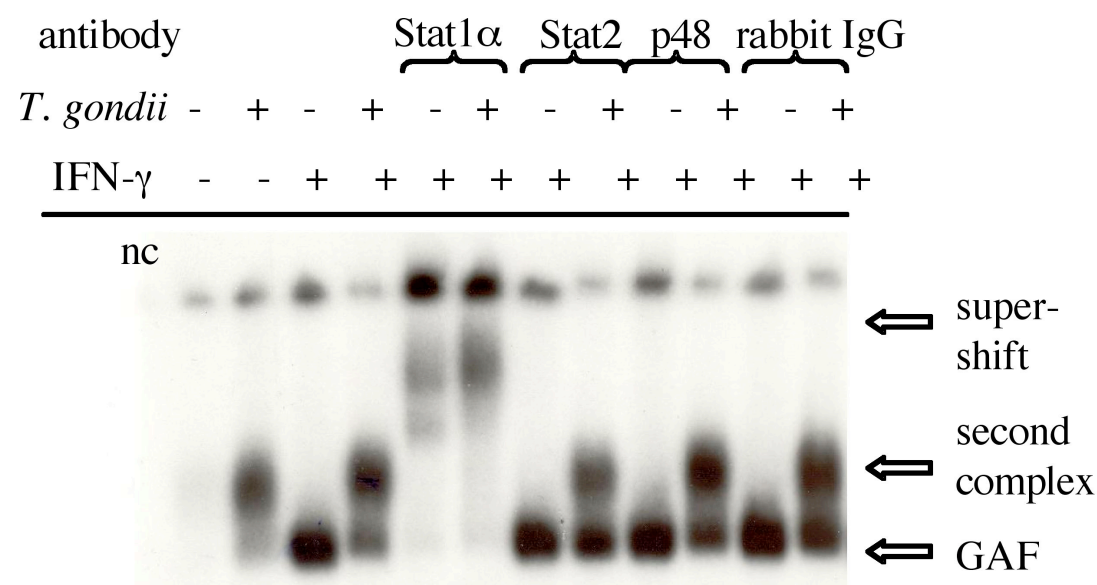

$\Longleftarrow$ Probe

Figure 24: Characterisation of GAS-binding complexes after activation of macrophages with IFN- $\gamma$ or after infection with $T$. gondii

Primary bone marrow-derived macrophages (BMM) from BALB/c mice were infected with viable $T$. gondii at a parasite to host cell ratio of $6: 1$ or were left uninfected. Twenty-four hours post infection, cells were activated for 30 minutes with $300 \mathrm{U} / \mathrm{ml} \mathrm{IFN-} \gamma$ as indicated. The DNA-binding activity of nuclear extracts to GAS-containing oligonucleotides of the $\mathrm{Fc} \gamma \mathrm{R} 1$ gene were compared by EMSA as described in figure legend 23. Supershift assays were performed using anti-Stat1 $\alpha$, anti-Stat2, anti-p48, or normal rabbit IgG antibodies as indicated. Oligonucleotide-bound complexes were visualized by autoradiography. The results shown are representative for two independent experiments.

Taken together, these results indicate, that neither parasite lysate nor viable $T$. gondii interfere with the total binding of GAF to the GAS-sequence in response to IFN- $\gamma$. However, viable $T$. gondii clearly modulate GAS-binding activity of Stat $1 \alpha$ resulting in the formation of a second GAS-binding complex of lower electromobility. According to the 
supershift analysis described above, this $T$. gondii-specific complex contains Stat1 $\alpha$, but not p48, Stat2, Stat3, Stat4, Stat5b or Stat6.

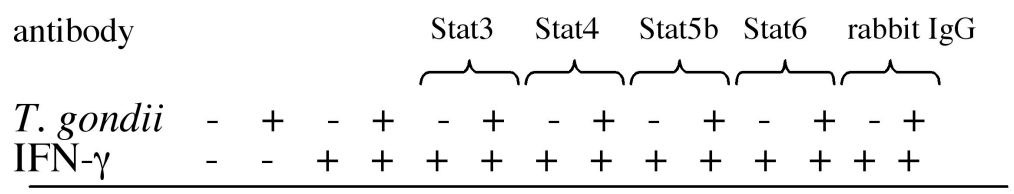
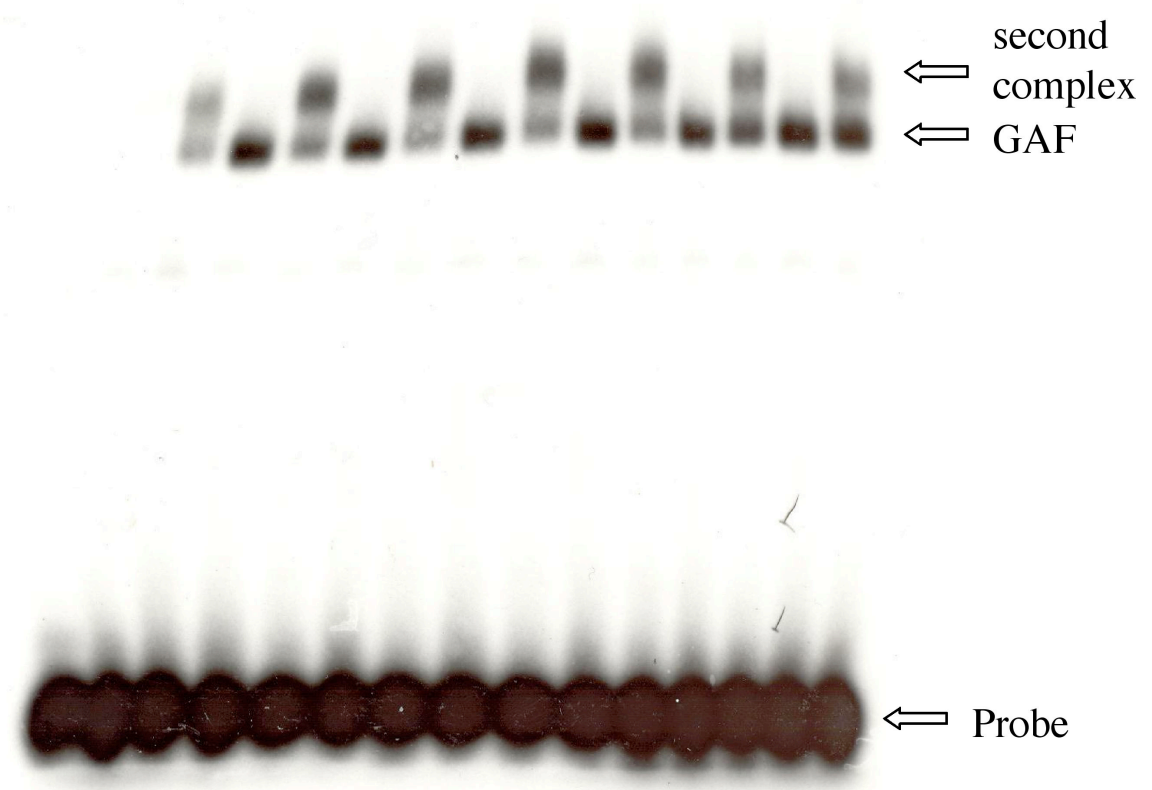

Figure 25: The $T$. gondii-induced second GAS-binding complex does not contain other members of the Stat family

BMM were infected with viable $T$. gondii at a parasite to host cell ratio of 6:1 or were left uninfected. Twenty-four hours post infection, cells were activated for 30 minutes with $300 \mathrm{U} / \mathrm{ml} \mathrm{IFN}-\gamma$ as indicated. The DNA-binding activity of nuclear extracts to the GAS-sequence of the Fc $\gamma \mathrm{R} 1$ gene were analysed by EMSA as described in figure legend 23. Supershift assays were performed by additionally incubating the samples with anti-Stat3, anti-Stat4, anti-Stat5b, anti-Stat6, or normal rabbit IgG antibodies as indicated. Oligonucleotide-bound complexes were visualized by autoradiography. The results shown are representative for two independent experiments. 


\subsubsection{Recruitment of $\beta$-actin to GAS-containing oligonucleotides is reduced in cells infected with $T$. gondii}

Transcriptional activation of most IFN- $\gamma$-responsive genes is dependent on binding of Stat $1 \alpha$ dimers to the GAS-sequence and association of cofactors linking GAF to the basal transcription machinery and RNA polymerase II.

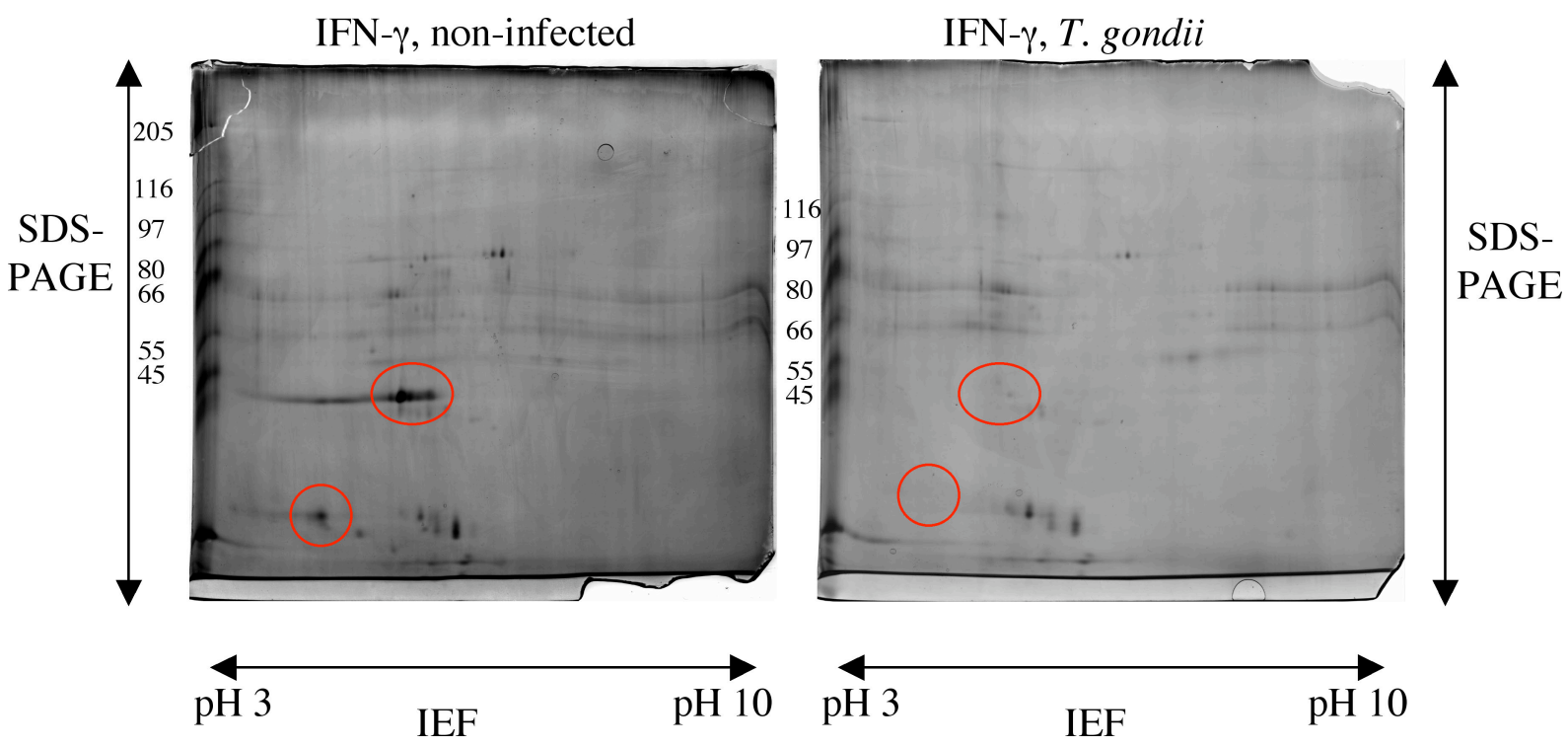

Figure 26: Two-dimensional gelelectrophoresis of proteins pulled-down from cell lysates of T. gondiiinfected or non-infected RAW 264.7 cells using GAS-containing oligonucleotides

RAW 264.7 cells were infected with viable $T$. gondii at a parasite to host cell ratio of 6:1 or were left uninfected as indicated. Twenty-four hours post infection cells were activated for 30 minutes with $300 \mathrm{U} / \mathrm{ml}$ IFN- $\gamma$. Thereafter, complete cell lysates were prepared and precipitated using biotin-labelled GAS-containing oligonucleotides and streptavidin-agarose. Precipitates were separated by isoelectric focussing (IEF) and SDS-PAGE and proteins were visualized by silverstaining. Major differences in the oligoprecipitated proteom are marked. The results shown are representative for three independent experiments.

In order to determine the influence of $T$. gondii on the association of such cofactors with Stat $1 \alpha$, protein extracts of parasite infected and non-infected RAW 264.7 cells were incubated with GAS-containing oligonucleotides to pull-down Stat $1 \alpha$ and associated cofactors. The resulting precipitates were separated by two-dimensional gelelectrophoresis (2D) and proteins were visualized by silverstaining (Figure 26). A variety of protein spots 
were detected which were pulled-down both from non-infected, IFN- $\gamma$-stimulated cells as well as $T$. gondii-infected, IFN- $\gamma$-stimulated cells. In addition, distinctive spots were detected, that were only present in the pull-down from non-infected cells and not in that from T. gondii-infected ones (Figure 26). For further analyses, the oligoprecipitation of non-infected cell lysates was repeated, the 2D gel was stained with colloidal coomassie (Figure 27) and the four marked protein spots were then cut out of the gel and analysed by MALDI-Tof (kindly perfomed by H. Dihazi, Göttingen) (Table 5). Spot number 1 was identified as tropomyosin 5 on the basis of the highest probability scores (Table 5). Spot number 2 was characterized as $\beta$-actin with a probability score of 76 or $\gamma$-actin with a score of 74 , while spot 3 was identified as gamma-actin-like protein or $\beta$-actin. Spot 4 was again identified as mouse $\beta$-actin or $\gamma$-actin (Table 5). In addition, $\gamma$-actin from humans and $\beta$ actin from chicken were found to match with the MALDI-Tof results, however, since mouse cells were used for the experiments, these results were unlikely. It was recently published that $\beta$-actin is involved in the formation of the basal transcription machinery and in the recruitment of RNA polymerase II (Hofmann et al., 2004). Therefore, the following experiments were performed to verify the interference of $T$. gondii with the binding of $\beta$ actin to GAS-containing oligonucleotides as was suggested by 2D gelelectrophosesis. For this, precipitates from complete RAW 264.7 lysates obtained by GAS-oligonucleotide pulldown assay were separated by one-dimensional SDS-PAGE and analysed by immunoblot experiments using $\beta$-actin-specific antibodies (Figure 28A). Binding of $\beta$-actin to the oligonucleotides was observed independently of stimulation of macrophages with IFN- $\gamma$. In accordance with this, binding of $\beta$-actin also occured to be independent of binding of Stat $1 \alpha$ to the GAS-sequence as revealed by parallel staining with anti-Stat $1 \alpha$ antibodies (Figure 28B). Importantly, however, interaction of $\beta$-actin with GAS-containing oligonucleotide was considerably reduced in cells infected with T. gondii, irrespective whether the cell had been activated with IFN- $\gamma$ or not (Figure 28A). In contrast, total binding of Stat $1 \alpha$ to the oligonucleotide was not diminished after infection of IFN- $\gamma$ activated RAW 264.7 cells with viable $T$. gondii (Figure 28B). Attempts to perform similar experiments using nuclear extracts of infected and non-infected RAW 264.7 cells did not lead to conclusive results, which might be due to the high salt concentration in the buffer used for the preparation of the nuclear extracts (data not shown). The presence of $\beta$-actin in the nucleus and the subcellular distribution in infected and non-infected macrophages was analysed by SDS-PAGE and immunoblotting (Figure 28C) as well as by double immunofluorescence staining (Figure 29). 


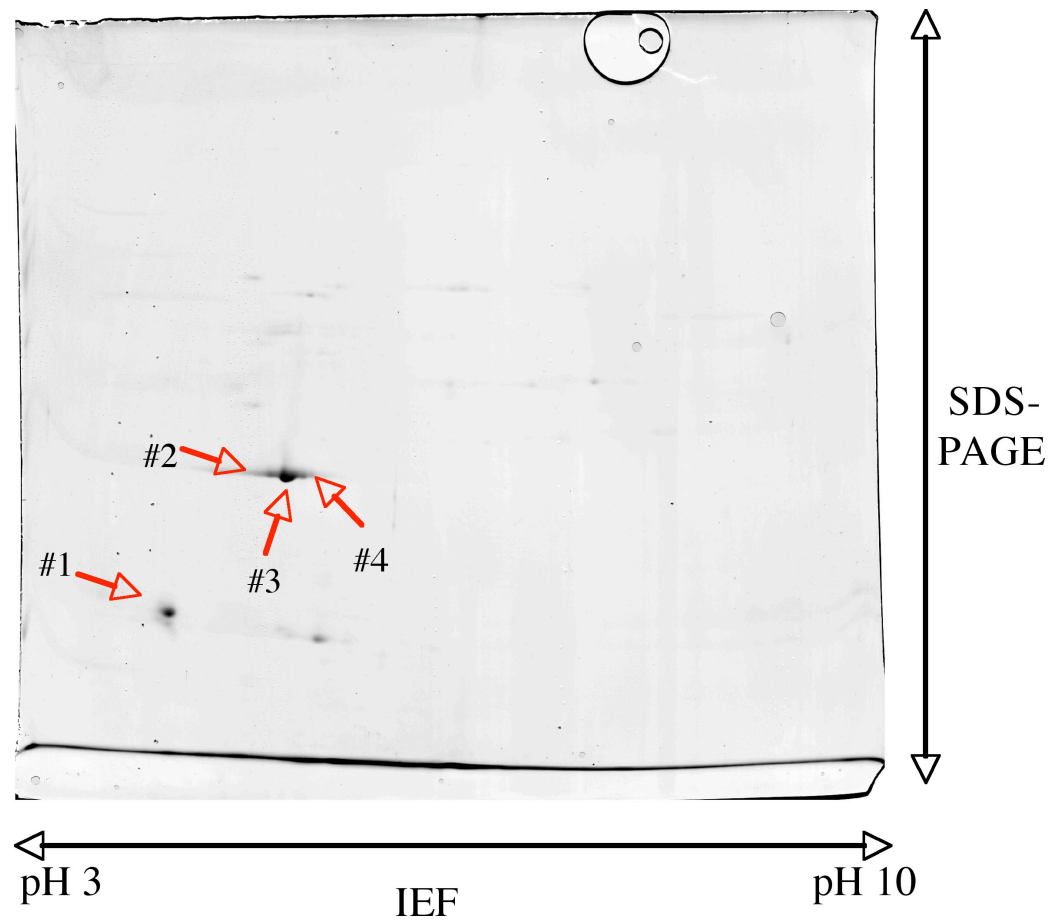

Figure 27: Two-dimensional gelelectrophoresis and coomassie staining of proteins pulled-down from non-infected RAW 264.7 cells using GAS-containing oligonucleotides

Uninfected RAW 264.7 cells were activated with $300 \mathrm{U} / \mathrm{ml}$ IFN- $\gamma$ for 30 minutes. Thereafter, complete cell lysates were prepared and oligoprecipitated using GAS-containing oligonucleotides as described in figure legend 26. Precipitates were separated by two-dimensional gelelectrophoresis and proteins were visualized by colloidal coomassie staining. Spots 1-4 were analysed by MALDI-Tof (see table 5).

Table 5: Results from MALDI-Tof analysis

\begin{tabular}{|l|l|l|l|l|}
\hline $\begin{array}{l}\text { Spot } \\
\text { number }\end{array}$ & protein & $\begin{array}{l}\text { accession } \\
\text { number }\end{array}$ & propability & $\begin{array}{l}\text { molecular } \\
\text { mass }\end{array}$ \\
\hline 1 & $\begin{array}{l}\text { tropomyosin 5 } \\
\text { (mouse) }\end{array}$ & S11390 & 176 & 29003 \\
\hline & $\begin{array}{l}\text { 2 days neonate } \\
\text { thymus thymic } \\
\text { cells cDNA } \\
\text { (mouse) }\end{array}$ & Q87C3 & 171 & 28879 \\
\hline & $\begin{array}{l}\text { tropomyosin 3, } \\
\text { gamma (mouse) }\end{array}$ & Q8K0Z5 & 139 & 33129 \\
\hline
\end{tabular}




\begin{tabular}{|c|c|c|c|c|}
\hline \multirow[t]{3}{*}{2} & $\begin{array}{l}\text { MMACTBR2 } \\
\text { NID ( } \beta \text {-actin) } \\
\text { (mouse) }\end{array}$ & CAA27396 & 76 & 39161 \\
\hline & $\begin{array}{l}\text { MMGACTR } \\
\text { NID }(\gamma \text {-actin) } \\
\text { (mouse) }\end{array}$ & CAA31455 & 74 & 40992 \\
\hline & $\begin{array}{l}\text { actin beta } \\
\text { (chicken) }\end{array}$ & ATCHB & 73 & 41710 \\
\hline \multirow[t]{3}{*}{3} & $\begin{array}{l}\text { actin gamma } 1 \\
\text { (human) }\end{array}$ & ATHUG & 114 & 41766 \\
\hline & $\begin{array}{l}\text { gamma actin- } \\
\text { like protein } \\
\text { (mouse) }\end{array}$ & Q9QZ83 & 111 & 43572 \\
\hline & $\begin{array}{l}\text { MMACTBR2 } \\
\text { NID }(\beta \text {-actin) } \\
\text { (mouse) }\end{array}$ & CAA27396 & 108 & 39161 \\
\hline \multirow[t]{3}{*}{4} & $\begin{array}{l}\text { MMACTBR2 } \\
\text { NID ( } \beta \text {-actin) } \\
\text { (mouse) }\end{array}$ & CAA27396 & 70 & 39161 \\
\hline & $\begin{array}{l}\text { MMGACTR } \\
\text { NID ( } \gamma \text {-actin) } \\
\text { (mouse) }\end{array}$ & CAA31455 & 67 & 40992 \\
\hline & $\begin{array}{l}\text { actin gamma } 1 \\
\text { (human) }\end{array}$ & ATHUG & 66 & 41766 \\
\hline
\end{tabular}

Results obtained from MATRIX SCIENCE Mascot Search. Shown are first three results with the highest probability, scores greater than 61 are significant, molecular mass as depicted in the database.

According to these experiments, $\beta$-actin was clearly present in the cytosol and the nucleus of the cells irrespective of treatment with IFN- $\gamma$ (Figure 28C). Confocal microscopy revealed that $\beta$-actin was most prominently present in the cytoplasm adjacent to the plasma membrane but was also clearly detected in the perinucleus and the nucleus itself (Figure 29). Importantly, Western blotting as well as confocal microscopy showed that $T$. gondii 
did neither interfere with the total amount nor with the subcellular distribution of $\beta$-actin as compared to uninfected control cells (Figures 28C and 29).

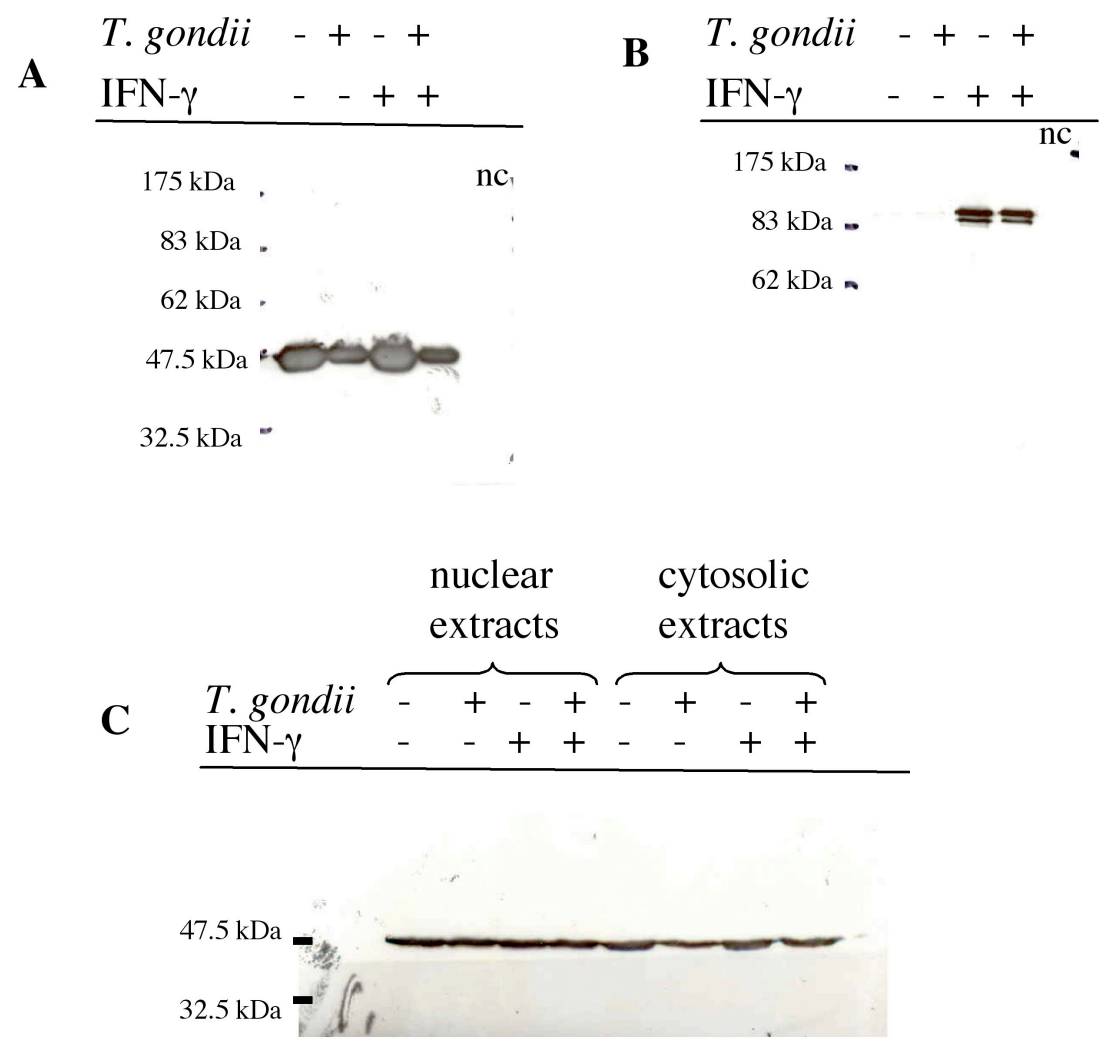

Figure 28: $T$. gondii diminishes recruitment of $\beta$-actin to GAS-containing oligonucleotides

RAW 264.7 cells were infected with viable parasites at a parasite to host cell ratio of 6:1 or were left uninfected. 24 hours after infection, cells were activated with $300 \mathrm{U} / \mathrm{ml} \mathrm{IFN}-\gamma$ for 30 minutes as indicated. Thereafter, complete cell lysates (A and B) or cytosolic and nuclear extracts were prepared (C). The complete cell lysates were subjected to a pull-down assay using biotin-labelled GAS-containing oligonucleotides and streptavidin-agarose. Pull-down assays with cell lysates from non-infected, IFN- $\gamma$-stimulated cells but without oligonucleotides were performed in parallel as a negative control (nc). Precipitates were then separated by SDS-PAGE and analysed by immunoblot using anti- $\beta$-actin (A) or anti-Stat1 $\alpha$ (B) antibodies. Nuclear and cytosolic extracts were directly separated by SDS-PAGE and thereafter analysed by immunoblot using anti- $\beta$-actin antibodies (C).

In conclusion, these results suggest that $T$. gondii interfere with the binding of $\beta$-actin to GAS-containing oligonucleotides while the total cellular content or the subcellular distribution of $\beta$-actin is not altered by the parasite. Since it was shown recently that $\beta$ actin is required for recruitment of RNA polymerase II to the basal transcription machinery 
(Hofmann et al., 2004) the parasite-mediated inhibition of $\beta$-actin binding to the GAScontaining oligonucleotides might be involved in the interference of $T$. gondii with the transcription of IFN- $\gamma$-responsive genes.

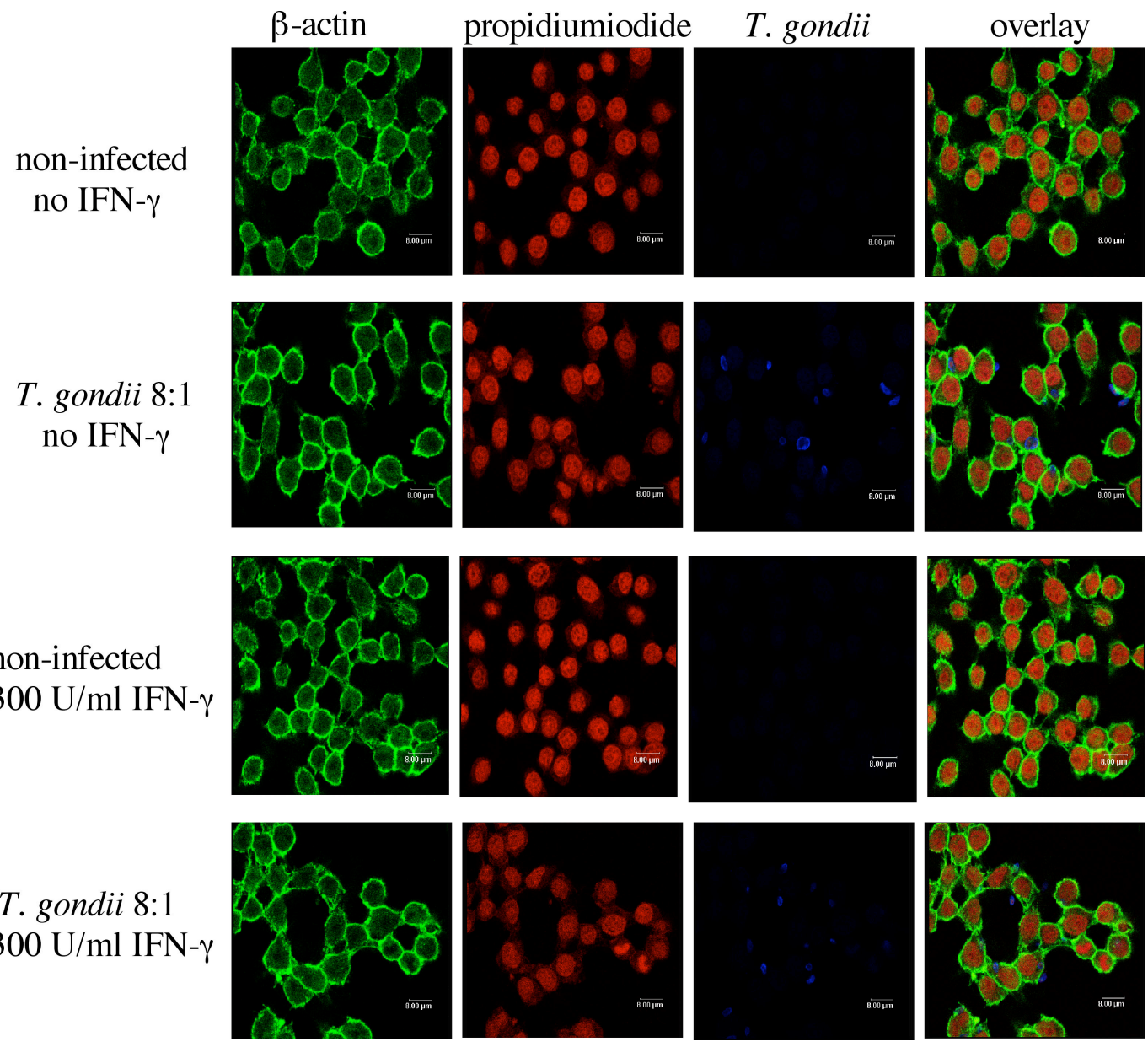

Figure 29: Subcellular distribution of $\beta$-actin is not changed after infection with $T$. gondii

RAW 264.7 cells were infected with viable $T$. gondii at a parasite to host cell ratio of 8:1 or were left uninfected. Twenty-four hours post infection, cells were activated for 30 minutes with $300 \mathrm{U} / \mathrm{ml} \mathrm{IFN}-\gamma$ or were left unstimulated. Thereafter, cells were fixed and analysed by double immunofluorescence staining. $T$. gondii were immunolabelled with anti-Toxoplasma serum (blue), $\beta$-actin with polyclonal anti- $\beta$-actin antibodies (green) and nucleic acids were unspecifically stained with propidiumiodide (red) in order to visualize nuclei. Representative images of each fluorescence was obtained simultaneously by confocal laser scanning microscopy and were superimposed. The results shown are representative for two independent experiments. 


\subsubsection{T. gondii interferes with the acetylation of histone 4 on the CIITA promoter IV}

The acetylation and deacetylation of histones is an important mechanism involved in transcriptional regulation. It results in chromatin-remodelling allowing or inhibiting the access of the transcriptional machinery to the promoter region of specific genes (Eberharter and Becker, 2002). To determine the influence of T. gondii on acetylation of histones at the CIITA promoter IV, a ChIP assay using anti-acetyl H4-specific antibodies was performed.

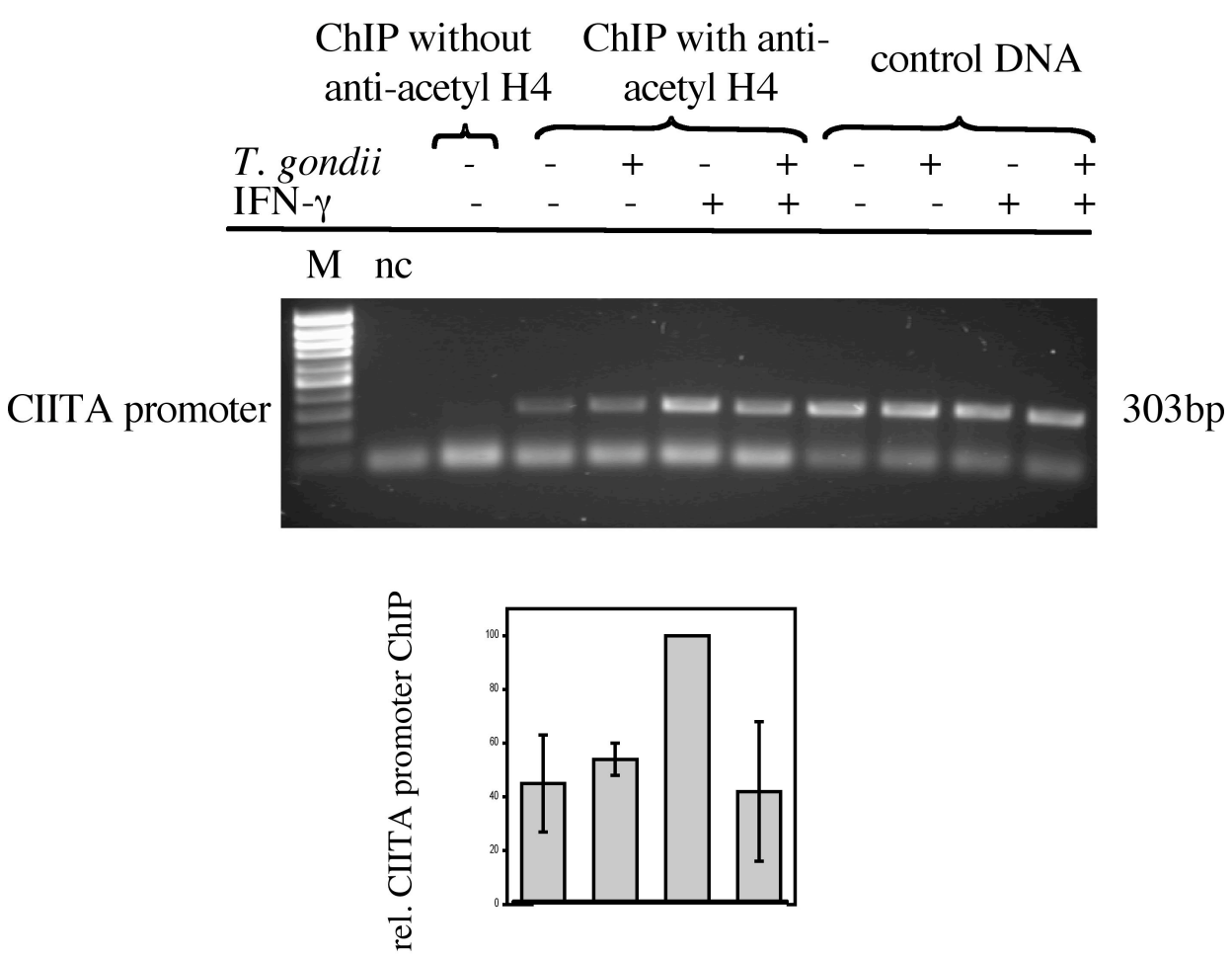

Figure 30: $T$. gondii interferes with IFN- $\gamma$-induced acetylation of histone 4 on the CIITA promoter IV

RAW 264.7 were infected with $T$. gondii at a parasite to host cell ratio of 6:1 or were left uninfected. Twenty-four hours post infection, cells were activated with $300 \mathrm{U} / \mathrm{ml}$ IFN- $\gamma$ for two hours as indicated. Thereafter, proteins and DNA were cross-linked and equal amounts of cells per sample were lysed. DNA was sheared and ChIP assay was performed with specific anti-acetyl H4-specific antibodies. After reversion of DNA-protein linkages, DNA was isolated from the precipitates and PCR was performed using specific primer pairs for the promoter region of CIITA. As a control, PCR was performed with DNA from the original sheared DNA for comparison of the total amount of DNA in each sample (control DNA). ChIP was also performed with one sample without adding the anti-acetyl H4-specific antibody. The PCR products were separated by agarose gelelectrophoresis, visualized by ethidiumbromide staining and the band intensities were analysed semiquantitatively using a digital imaging system. The relative intensities of the amplicons were calculated (ChIP product/control DNA x 100). The value for the non-infected, IFN- $\gamma$ activated sample was defined as $100 \%$, the other values were calculated relative to the intensity of this sample. Bars represent means $+/$ - standard deviation $(\mathrm{n}=3)$. 
After activation with IFN- $\gamma$, the coprecipitation of CIITA promoter-specific DNA with an anti-acetyl H4 antibody increased two-fold compared to unstimulated RAW 264.7 cells as revealed by semiquantitative RT-PCR (Figure 30). In cells that were concomitantly infected with $T$. gondii, however, the coprecipitation of CIITA promoter-specific DNA with the antibody did not increase in response to IFN- $\gamma$ (Figure 30). Control amplifications of the input DNA using CIITA promoter-specific primer pairs revealed that similar amounts of DNA from the different samples were used for the ChIP assay.

Therefore, viable $T$. gondii inhibit the acetylation of Histone 4 on the CIITA promoter IV, which might interfere with transcriptional activation in response to IFN- $\gamma$. 


\section{Discussion}

\subsection{Immune evasion strategies of $T$. gondii and parasite-mediated interference with antigen presentation via inhibition of MHC class II}

T. gondii is able to establish chronic infections within a broad range of warm-blooded hosts including humans. The ability to establish and maintain persistant infections is facilitated by a number of immune evasion strategies of the parasite. Host cell invasion by the parasite plays a critical role for evasion of the humoral immune response. $T$. gondii actively invades the host cell, leading to the formation of a fusion-incompetent parasitophorous vacuole in which the parasite can safely reside and replicate (Joiner and Dubremetz, 1993; Dubremetz et al., 1998; Sibely et al., 2003). Parasite-derived proteins are inserted into the membrane of the parasitophorous vacuole (PVM) or might even be translocated into the cytosol of the host cell possibly in order to assure supply with nutritions and growth factors and to alter the host cell physiology (Joiner and Dubremetz, 1993; Smith, 1995; Sibely et al., 2003; Carey et al., 2004). The latter may also be involved in the parasite's interference with defence reactions of the host cell against intracellular pathogens. For example, T. gondii does not cause an oxidative burst upon host cell entry (Bogdan and Röllinghoff, 1999) and interferes with the production of nitric oxide in infected cells (Lüder et al., 2003). In order to ensure intracellular survival, T. gondii also inhibits the induction of apoptosis in its host cell (Nash et al., 1998; Goebel et al., 2001; Sinai et al., 2004). Additionally, T. gondii was found to interfere with antigen presentation of the host cell to CD4-positive T cells via inhibiting the expression of MHC class II molecules in infected primary bone marrow-derived macrophages (BMM) (Lüder et al., 1998; Lüder et al., 2001; reviewed by Lüder and Seeber, 2001). Since T. gondii predominantly abrogates the IFN- $\gamma$-induced MHC class II expression, it is thought that the parasite interferes with the Jak-Stat signalling cascade or with activation of IFN- $\gamma$ responsive promoters (Lüder et al., 2001). In previous studies it was described that $T$. gondii inhibits the nuclear translocation of Stat $1 \alpha$ in IFN- $\gamma$-stimulated cells concomitantly infected with the parasite (Lüder et al., 2001) resulting in decreased transcript levels of IFN- $\gamma$-responsive genes. However, the exact mechanism of $T$. gondii-mediated inhibition of MHC class II expression has not been elucidated so far, and little is known about the parasite-derived factor involved in this parasite-host interaction. 
Therefore, the specific aim of the present work was to characterise the mechanisms employed by $T$. gondii to interfere with the IFN- $\gamma$-induced MHC class II expression and to elucidate the parasite-derived factor involved in this evasion strategy.

\subsection{T. gondii interferes with IFN- $\gamma$-induced MHC class II expression in different cell types}

As described before, $T$. gondii tachyzoites inhibit IFN- $\gamma$-induced MHC class II expression in BMM (Lüder et al., 1998). In order to facilitate further analyses, the parasites' ability to interfere with IFN- $\gamma$-mediated expression in the monocyte/macrophage tumor cell line RAW 264.7 was determined in the present study. The experiments revealed, that $T$. gondii is also able to abrogate MHC class II expression on the cell surface of infected RAW 264.7 cells. In addition, experiments with the mutant mouse cell lines NIH/3T3 IRF-1/hER (3.3.2) or NIH/3T3 Stat-GFP (data not shown) revealed, that the parasite also diminishes IFN- $\gamma$-induced transcript levels of MHC class II in murine fibroblasts. Furthermore, cytokine-induced MHC class II expression is also inhibited in T. gondii-infected primary murine peritoneal macrophages as well as in the murine B cell line A20 (Ö. Dirik and C. Lüder, personal communication). In addition, $T$. gondii diminishes the IFN- $\gamma$-induced MHC class II expression in the human glioblastoma cell lines 86HG39 and 87HG31 as well as in rat-derived primary astrocytes and microglia (Lüder et al., 2003).

Therefore, $T$. gondii tachyzoites interfere with IFN- $\gamma$-induced MHC class II expression in a number of different cell types derived from mice as well as in cells derived from humans and rats, suggesting a critical role of this immune evasion strategy for survival of the parasite in different intermediate hosts.

\subsection{T. gondii-mediated interference with IFN- $\gamma$-responsive genes in murine macrophages}

As mentioned above, $T$. gondii interferes with IFN- $\gamma$-induced expression of MHC class II molecules in murine macrophages and other cell types. However, more than 200 other genes are known to be regulated by IFN- $\gamma$ and this number is supposed to be even much higher (Boehm et al., 1997). In order to determine whether T. gondii influences the expression of IFN- $\gamma$-responsive genes in RAW 264.7 cells in general, mRNA levels of H2$\mathrm{Ab}$ (MHC class II), intercellular adhesion molecule-1 (ICAM-1), interferon-inducible 
GTP-binding protein (IGTP), inducible nitric oxide synthase (iNOS), indolamine 2,3dioxygenase (INDO), transporters associated with antigen processing-1 (TAP1), IgG Fc receptor type I (Fc $\gamma \mathrm{R} 1)$ and c-myc in $T$. gondii-infected cells were compared to noninfected control cells. Except for c-myc, these molecules play a role in a variety of different immune functions including defence mechanisms against intracellular pathogens (Look et al., 1994; Chon et al., 1996; Seliger et al., 1997; Ganster et al., 2001; Collazo et al., 2002). Therefore, interference of $T$. gondii with the expression of such genes may help to avoid potentially effective anti-parasitic immune functions. The results indicate, that $T$. gondii differentially interferes with the transcriptional activation of the IFN- $\gamma$-responsive genes analysed. The parasite was able to inhibit the IFN- $\gamma$-induced up-regulation of ICAM1, iNOS, IGTP, Fc $\gamma$ R1, and, as expected, H2-Ab. Fc $\gamma$ R1 and INDO are constitutively expressed in RAW 264.7 cells, however, T. gondii only inhibited the IFN- $\gamma$-induced expression of these genes. Thus, $T$. gondii not only interfered with IFN- $\gamma$-mediated MHC class II expression, but also with a variety of other IFN- $\gamma$-regulated genes. In contrast, the parasite did not inhibit the mRNA levels of TAP1 in response to IFN- $\gamma$. Furthermore, the expression of c-myc was even up-regulated in $T$. gondii-infected RAW 264.7 cell populations. Therefore, the parasite clearly interferes with the expression of the majority but not all IFN- $\gamma$-responsive genes analysed. Although, the genes examined are thought to be regulated via the IFN- $\gamma$-induced Jak-Stat signalling cascade (Look et al., 1994; Paquette et al., 1995; Chon et al., 1996; Seliger et al., 1997; Ganster et al., 2001; Collazo et al., 2002), the mRNA levels of TAP1 and c-myc are not down-regulated by $T$. gondii. This might be due to the involvement of alternative Stat-independent signalling pathways (Gil et al., 2001) with which the parasite does not interfere. Alternatively, it might also be explained by the involvement of other transcription factors possibly up-regulated in $T$. gondii-infected cells thereby compensating the interference of the parasite with IFN- $\gamma$ regulated signalling. This possibly results in a balanced interaction between the parasite and the host leading to a partial inhibition of the immune system of infected individuals by T. gondii thereby allowing parasite survival on the one hand and adequate immune response on the other hand in order to guarantee host survival. Nevertheless, $T$. gondii is clearly able to successfully interfere with most of the IFN- $\gamma$-responsive genes analysed. Since IFN- $\gamma$ plays a crucial role for the control of the acute and chronic toxoplasmosis in infected individuals by inducing a number of anti-parasitic effector mechanisms (Murray and Cohn, 1979; Suzuki et al., 1988; Adams et al., 1990; Gazzinelli et al., 1992; Däubener 
et al., 1996), interference with the expression of such genes may facilitate the establishment and maintenance of a persisting infection by $T$. gondii.

\subsection{Parasite requirements for inhibition of IFN- $\gamma$-induced MHC class II expression}

T. gondii secretes a variety of proteins into the PV, which are at least partially targeted to the PVM (Sibley, 2003). However, the function of most of these proteins still remains unknown, even though it is thought that some parasite-derived molecules are involved in altering the host cell physiology (Sibley, 2003; Sinai and Joiner, 2001). The T. gondiiderived molecule(s) directly or indirectly interfering with the IFN- $\gamma$-induced MHC class II expression has not been identified so far. During recent years, however, molecules involved in the interference with MHC class II expression were discovered for a number of other pathogens. A $19 \mathrm{kDa}$ lipoprotein from Mycobacterium tuberculosis mediates the interference with the MHC class II expression by a Toll-like receptor 2-dependent mechanism (Pai et al., 2003, Gehring et al., 2003) and the Sendai virus protein C was identified to induce ubiquitination and subsequently degradation of Stat $1 \alpha$ (Garcin et al., 2002). Furthermore, the human cytomegalovirus protein US2 induces the degradation of HLA-DR and -DM (Tomazin et al., 1999), whereas the VH1 phosphatase from the vaccinia virus was found to dephosphorylate Stat1, thereby inhibiting IFN- $\gamma$-induced MHC class II expression (Najarro et al., 2001). Some pathogen-derived molecules interfering with MHC class II expression have also been identified for eukaryotic parasites. A $35 \mathrm{kDa}$ protein derived from Leishmania amazonensis was found to interact directly with MHC class II, resulting in the degradation of MHC-containing protein complexes (Huynh and Andrews, 2000). Furthermore, the malaria pigment hemazoin derived from the apicomplexan parasite Plasmodium spec. is able to interfere with the MHC class II expression by decreasing the corresponding mRNA levels (Schwarzer et al., 1998).

In order to characterize the $T$. gondii-derived molecule(s) involved in the interference with MHC class II expression in murine macrophages, parasites were UV-irradiated or heatinactivated. UV-irradiated $T$. gondii still invade the host cell but are not able to replicate anymore as reported previously (Endo et al., 1981) and as confirmed by immunofluorescence staining in this study. Heat-inactivated $T$. gondii, however, do not enter the host cell anymore (Sibley et al., 1983) and this has also been shown within this study. Murine macrophages that were infected with UV-irradiated parasites were unable to up-regulate MHC class II transcripts in response to IFN- $\gamma$ stimulation similarly as cells 
infected with untreated parasites. Thus, replication of $T$. gondii within the host cell is not required for interference with MHC class II expression. However, heat-inactivated $T$. gondii did not abrogate the MHC class II transcript up-regulation, indicating that host cell invasion or at least parasite viability is required in order to inhibit MHC class II transcription. $T$. gondii might therefore secrete the molecule interfering with MHC class II expression during or after the process of host cell invasion. As mentioned before, $T$. gondii actively invades its host cell ending up in a parasitophorous vacuole (Sibley et al., 1985). This active invasion process employed by the parasite might also alter the host cell physiology leading to the inhibition of IFN- $\gamma$-regulated gene expression.

Further experiments showed, that crude extracts prepared from $T$. gondii tachyzoites mimic the effect of viable parasites on MHC class II expression on protein and mRNA levels. This is the first report of a $T$. gondii lysate interfering with IFN- $\gamma$-induced gene expression of its host cell. However, relative high concentrations of the parasite lysate were required to interfere with the expression of MHC class II molecules in vitro. Therefore, questions may arise about the importance of the observations described herein for the course of infection in vivo. Indeed, it appears rather unlikely, that concentrations as required for a substantial inhibition of MHC class II expression occurs in vivo throughout the intermediate hosts' organism. Locally, however, such concentrations might be reached due to $T$. gondii-derived debris thereby effecting adjacent cells. Further experiments are clearly required to determine the effect of isolated parasite molecules or parasite debris on the expression of MHC class II molecules. The effector molecule of the parasite lysate appears to be hydrophilic, since it was present in the PBS soluble fraction of the T. gondii-lysate. In addition, digestion with the protease pronase resulted in partial abrogation of lysatemediated interference with IFN- $\gamma$-induced MHC class II expression. This partial abrogation might be due to insufficient concentration of the pronase or the involvement of additional pronase-resistant effector molecules present in the crude extract of $T$. gondii tachyzoites. Nevertheless, the sensitivity of the effector molecules to treatment with pronase strongly suggests the involvement of a parasite protein within the lysate. Importantly, this protein obviously interferes with IFN- $\gamma$-induced MHC class II expression even though applied extracellularly. As described before, experiments using differentially treated parasites indicated that host cell entry appears to be crucial for parasite-mediated inhibition of MHC class II expression. The reason for this discrepancy is probably explained by further experiments of this study, which revealed that viable $T$. gondii and the parasite lysate differentially interfere with IFN- $\gamma$-mediated signalling. This also indicates the involvement 
of distinct molecules of viable $T$. gondii and $T$. gondii lysate in the inhibition of MHC class II expression. Therefore the effector molecule of the parasite lysate either somehow gains access to the cytosol of the host cell or binds to a membrane-anchored receptor resulting in the modification of the host cell physiology. Concerning the first possibility, it is unlikely that the parasite-derived protein is taken up by classical pinocytosis, since such molecules are usually degraded by lysosomal proteins. However, it has been described, that exogenous proteins can gain access from endosomal compartments to the cytosol of the cell leading to their presentation on the cell surface by MHC class I molecules (Kovacsovics-Bankowski et al., 1993, Kovacsovics-Bankowski and Rock 1995). Furthermore, some proteins containing a distinct domain, the protein transduction domain (PTD), were found to be able to translocate through the plasma membrane via an unknown mechanism, which do not depend on transporters, receptors or endocytosis (Wadia and Dowdy, 2002). Such domains were for example identified in the HIV-1 transcription factor Tat, as well as in the Drosophila homeotic protein antennapedia (Wadia and Dowdy, 2002). As mentioned before, the effector molecule of the parasite lysate might also bind to a receptor on the host cell surface which possibly belongs to the so called pattern recognition receptors also including Toll-like receptors (Gordon, 2002). The binding of $T$. gondii lysate-derived molecules to such receptors might induce a signal transduction cascade resulting in the inhibition of MHC class II expression.

Since the results described above indicated the involvement of a parasite protein in the inhibition of MHC class II molecules by $T$. gondii, expression of a $T$. gondii cDNA library in mutant RAW 264.7 macrophages expressing an IFN- $\gamma$-responsive selectable marker would be a valuable strategy. However, such an experimental approach requires a macrophage population in which nearly all cells express MHC class II molecules in response to IFN- $\gamma$. Usually only a subset of macrophages can be activated by IFN- $\gamma$, the reason of which is not known. Therefore, attempts were undertaken to increase the percentage of RAW 264.7 cells that can be activated by IFN- $\gamma$ employing magnetic associated cell sorting (MACS). However, these exeriments did not result in a stable increase of MHC class II-positive cells in IFN- $\gamma$-activated cell populations. Therefore, a genetic approach to identify the parasite molecules interfering with MHC class II expression appeared unfeasible and was not further followed. 


\subsection{Possible involvement of ESA's in parasite-mediated inhibition of MHC class II expression}

T. gondii possess three excreted/secreted organelles namely the micronemes, rhoptries and dense granules, which play an important role during the process of host cell invasion and the establishment of intracellular infection (Cesbron-Delauw, 1994; Carruthers et al., 1999). In order to characterise whether the $T$. gondii-derived molecule interfering with IFN- $\gamma$-induced MHC class II expression might be secreted by the parasite, murine macrophages were incubated with parasites separated from the host cells by a semipermeable membrane. The results revealed, that $T$. gondii tachyzoites are indeed able to interfere with MHC class II expression of host cells, even though they are not able to infect the cell. These results supported that a parasite-derived protein, which either gains access to the cytosol, inserts into the plasma membrane of the host cell or interacts with a receptor of the host cell might be involved, thereby interfering directly and indirectly with MHC class II expression. However, even though T. gondii appeared to secrete the effector molecule, different preparations of excreted/secreted antigens (ESA's) did not abrogate the IFN- $\gamma$-induced up-regulation of MHC class II expression in murine macrophages. Furthermore, highly concentrated ESA preparations kindly provided by V. Carruthers, Baltimore did not result in inhibition of MHC class II transcription. However, this does not exclude the possibility that molecules derived from the excretory/secretory organelles of the parasite are nevertheless involved in the inhibition of MHC class II molecules, since not all ESA's might be excreted/secreted under the in vitro conditions chosen.

\subsection{Interference of $T$. gondii with IFN- $\gamma$-mediated signalling}

Different pathogens have evolved distinct mechanisms to interfere with the IFN- $\gamma$ regulated Jak-Stat signalling cascade. The human cytomegalovirus interferes with MHC class II expression by inducing the degradation of Jak1 (Miller et al., 1998), the Sendai virus protein $C$ induces the degradation of Stat $1 \alpha$ (Garcin et al., 2002), and the VaricellaZoster virus interferes with Jak1, Jak2 and Stat1 $\alpha$ (Accola et al., 2001). Less is known about the exact mechanisms of bacterial and parasitic pathogens interfering with IFN- $\gamma$ induced signalling. It was shown for Mycobacterium tuberculosis and Chlamydia trachomatis, however, that phosphorylation and dimerization as well as nuclear translocation and DNA-binding of Stat1 $\alpha$ was still intact in infected cells, but that the pathogen nevertheless disrupts the transcriptional activation of IFN- $\gamma$-responsive genes 
(Ting et al., 1999; Zhong et al., 1999). During recent years, a number of experiments have been performed to elucidate the mechanism of $T$. gondii-mediated inhibition of IFN- $\gamma-$ induced MHC class II gene expression. The expression of IFN- $\gamma$-receptors (IFN- $\gamma-\mathrm{R}$ ) is not changed in infected cells (Lüder et al., 2001). Additionally, T. gondii does not interfere with the phosphorylation of the IFN- $\gamma-\mathrm{R}$ or Stat1 $\alpha$ (Lüder et al., 2001). It has however been suggested that $T$. gondii interferes with the Jak-Stat signalling cascade via inhibiting the nuclear translocation of activated Stat $1 \alpha$ in response to IFN- $\gamma$ (Lüder et al., 2001). This was an attractive explanation for the parasite-mediated inhibition of IFN- $\gamma$-regulated gene expression, since it was in accordance with reports that $T$. gondii also inhibits nuclear

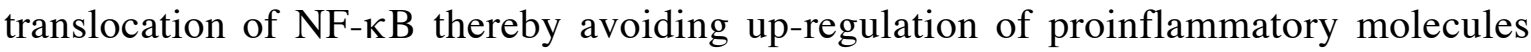
(Butcher et al., 2001; Dobbin et al., 2003). However, careful analyses performed within this study now clearly revealed that other mechanisms account for the inhibition of MHC class II expression after infection with $T$. gondii or after incubation with parasite lysate. In order to elucidate the interference of $T$. gondii with the Jak-Stat signalling cascade, the nuclear translocation of Stat $1 \alpha$ in response to IFN- $\gamma$ was analysed in RAW 264.7 cells by Western blot and immunostaining as well as by double immunofluorescence staining. It revealed, that the parasite does not interfere with the transport of Stat $1 \alpha$ into the nucleus. It can be excluded that this represents a peculiar feature of RAW 264.7 cells since this was also confirmed using primary bone marrow-derived macrophages (data not shown). Furthermore, this was also clearly confirmed by experiments performed with mouse fibroblasts expressing a Stat-GFP fusion protein. As observed with primary macrophages and in the permanent macrophage cell line RAW 264.7, the nuclear translocation of StatGFP was still detectable in cells infected with viable parasites as well as in cells incubated with the parasite lysate. In addition, $T$. gondii is also able to abrogate the estradiol-induced transcriptional activation of $\mathrm{H} 2-\mathrm{Ab}$ in cells expressing IRF-1 fused to the estradiol receptor. In these cells, the activation with estradiol results in the translocation of the IRF1/hER fusion protein into the nucleus allowing IRF-1-binding to DNA, which finally results in transcriptional activation of MHC class II genes. Since T. gondii is able to interfere with such estradiol-activated transcription of $\mathrm{H} 2-\mathrm{Ab}$ in these cells, the hypothesis that $T$. gondii interferes with the IFN- $\gamma$-mediated signalling downstream of the nuclear translocation of activated Stat $1 \alpha$ is further supported. The reason for the discrepancy concerning the nuclear translocation of Stat $1 \alpha$ between the results described herein and those previously reported are yet unknown. Differences in the parasite strain can be excluded since the NTE strain of T. gondii (Gross et al., 1991) was used in both studies. 
Furthermore, the different cell types used in both studies do also not account for this discrepancy, since the current results were confirmed in different cell types and also in primary bone marrow-derived macrophages, i.e. those cells employed in the former study (Lüder et al., 2001). Thus, the reason for this discrepancy remains elusive. On the basis of the current experiments it is, however, concluded that inhibition of nuclear translocation of Stat $1 \alpha$ after infection with $T$. gondii does not account for the inhibition of IFN- $\gamma$-regulated MHC class II expression.

In order to futher determine at which step the parasite interferes with IFN- $\gamma$-induced signalling, expression of IRF-1 and CIITA were analysed in cells infected with viable parasites or incubated with $T$. gondii-lysate. The transcription of IRF-1 depends on binding of activated Stat1 $\alpha$ to the GAS-sequence in the promoter region of IRF-1 (Boehm et al., 1997). Expression of IRF-1 as well as activated Stat $1 \alpha$ are then required for transcriptional activation of the CIITA promoter (Muhlethaler-Mottet et al., 1997). Furthermore, the expression of MHC class II genes directly depends on the presence of CIITA (Steimle et al., 1994; Boehm et al., 1997; Otten et al., 1998). Experiments revealed, that viable $T$. gondii interfere with the IFN- $\gamma$-induced transcript levels of IRF-1 and CIITA resulting in the abrogation of MHC class II expression. In contrast, $T$. gondii-lysate does not interfere with the transcriptional activation of IRF-1 but diminishes IFN- $\gamma$-induced expression of CIITA and MHC class II. These results clearly indicated, that viable

parasites and $T$. gondii-lysate differentially interfere with IFN- $\gamma$-induced signalling of host cells. The different mechanisms employed by viable parasites and parasite lysate interfering with MHC class II expression might also indicate the involvement of different parasite molecules. It could be hypothesized that the effector molecule of the parasite lysate binds to a membrane-anchored receptor of the host cell inducing a signalling cascade that interferes with the IFN- $\gamma$-induced MHC class II expression, whereas the molecule derived from viable intracellular parasites might directly or indirectly interfere with IFN- $\gamma$-mediated signalling.

\subsection{Inhibition of transcriptional activation of IFN- $\gamma$-responsive promoters mediated}

\section{by $T$. gondii}

Analyses of the ability of viable $T$. gondii and $T$. gondii lysate to interfere with the activity of IFN- $\gamma$-regulated promoters were performed using the CIITA promoter IV. Reporter assays revealed that viable $T$. gondii as well as parasite lysate both interfere with the 
transcriptional activation of the CIITA promoter IV. This clearly shows, that the decrease of CIITA mRNA in cells infected with viable $T$. gondii or incubated with $T$. gondii lysate is not due to an increased instability of CIITA mRNA, but that the transcriptional activation of this promoter is considerably diminished. Importantly, only viable parasites and not parasite lysate were found to inhibit the transcriptional activity of a minimal GAScontaining pomoter driving luciferase. These results further support the hypothesis that parasite lysate employs a different mechanism interfering with the MHC class II expression than viable parasites. It also suggests that viable parasites either interfere with Stat $1 \alpha$ and/or its DNA-binding sequence or with the recruitment of the basal transcription machinery to IFN- $\gamma$-responsive promoters, since a minimal GAS-containing promoter is sufficient for the inhibition of IFN- $\gamma$-mediated transcriptional activation by $T$. gondii. However, the inhibition of reporter activity by viable $T$. gondii with minimal GAScontaining promoters is less efficient than that observed with the complex CIITA promoter IV. This difference could be due to the additive effect of parasite-mediated interference with IRF-1 expression plus interference with GAS-dependent transcriptional activation. Alternatively, cofactors of Stat $1 \alpha /$ GAS-mediated transcriptional activity like CBP/p300 (Korzus et al., 1998) or Nmi (Zhu et al., 1999) might also be targeted by T. gondii after infection. In contrast to this, parasite lysate modulates transcriptional activity of the CIITA promoter independently of Stat1 or its DNA consensus sequence. One possibility is that $T$. gondii lysate leads to an altered DNA-binding activity of USF-1 or even induces the degradation of USF-1, as described for Chlamydia trachomatis thereby interfering with MHC class II expression of the host cell (Zhong et al., 1999). Alternatively, disturbance of Stat $1 \alpha$-IRF-1 interaction on the promoter IV of CIITA could also lead to the abrogation of transcription, a mechanism employed by the adenovirus protein E1A (Chatterjee et al., 2000). Mycobacterium tuberculosis was also found to be unable to inhibit IFN- $\gamma$-induced gene expression of a minimal GAS-containing promoter (Kincaid and Ernst, 2003). Thus, similar mechanisms are possibly employed by $M$. tuberculosis and by $T$. gondii lysate. The ability of viable $T$. gondii but not of parasite lysate to interfere with a minimal GAScontaining promoter is in accordance with the observation that only viable $T$. gondii interfere with the transcript levels of both CIITA and IRF-1, whereas parasite lysate diminishes CIITA mRNA levels only. Since the IRF-1 promoter contains a Stat1 $\alpha$ consensus sequence, but not several other binding sites modulating CIITA promoter activity, viable parasites may block IFN- $\gamma$-regulated IRF-1 expression via interference with Stat $1 \alpha$-induced promoter activation. In contrast, $T$. gondii lysate modulates transcriptional 
activity of the CIITA promoter via a region different from the GAS-sequence and this region might not be present within the IRF-1 promoter.

\subsection{Mechanism of $T$. gondii lysate-mediated interference with MHC class II expression}

As previously described, viable $T$. gondii and parasite lysate differentially interfere with IFN- $\gamma$-induced signalling. In contrast to viable parasites, the $T$. gondii lysate does not interfere with transcript levels of IRF-1 and is not able to abrogate the transcriptional activation of a minimal GAS-containing promoter. However, the parasite lysate clearly inhibits the expression of CIITA and MHC class II. This indicates, that T. gondii lysate interferes with IFN- $\gamma$-induced MHC class II expression on the level of CIITA transcription. T. gondii is known to induce the secretion of IL-10 in infected mice (Gazzinelli et al., 1996; Rozenfeld et al., 2003). Furthermore, IL-10 interferes with the IFN- $\gamma$-induced MHC class II transcription (de Waal Malefyt et al., 1991) via inhibiting CIITA expression (O'Keefe et al., 1999). In order to determine the effect of $T$. gondii lysate on the autocrine secretion of IL-10 in murine macrophages, IL-10 ELISA was performed. It revealed that only parasite lysate, but not viable $T$. gondii induce considerable secretion of IL-10. Therefore, T. gondii lysate might indeed interfere with IFN- $\gamma$-activated signalling by inducing the autocrine secretion of IL-10. The exact mechanism of IL-10-mediated interference with MHC class II expression is yet unknown. However, it was shown that the anti-inflammatory effect of IL-10 is transduced through Jak-Stat signalling inducing the formation of Stat1:Stat3 heterodimers (Riley et al., 1999; Williams et al., 2004). Furthermore, IL-10 has been shown to induce the expression of suppressors of cytokine signalling (SOCS) (Donnelly et al., 1999; Berlato et al., 2002; Herrero et al., 2003). In order to analyse the importance of IL-10 for $T$. gondii lysate-mediated interference with MHC class II expression, the presence of MHC class II molecules on the surface of parasite lysate-incubated cell populations derived from IL-10 -/- mice was analysed. The results revealed, that IL-10 -/- macrophages incubated with $T$. gondii lysate were unable to up-regulate MHC class II expression in response to IFN- $\gamma$ to a similar extent as observed in wildtype control macrophages. Therefore, parasite lysate-mediated interference with MHC class II expression is clearly independent of autocrine IL-10 secretion. An alternative mechanism of $T$. gondii lysate to interfere with IFN- $\gamma$-mediated signalling could involve IL-6, which was shown to be secreted by macrophages infected with M. tuberculosis and to 
interfere with IFN- $\gamma$-responsive genes without inhibiting Stat1 activation or function (Nagabushanam et al., 2003). Therefore, analysis of the involvement of IL-6 in interference of $T$. gondii lysate with IFN- $\gamma$-mediated signalling would be a promising attempt to elucidate the mechanism of lysate-mediated inhibition of MHC class II expression.

\subsection{T. gondii-induced modulation of GAS-binding complexes}

As described above, viable $T$. gondii tachyzoites interfere with a minimal GAS-containing promoter. This interference might directly involve parasite-derived interaction with Stat $1 \alpha$ or GAS. In order to analyse whether the DNA-binding activity of Stat1 $\alpha$ is abrogated in cells infected with viable parasites, EMSA's were performed. The results revealed that viable parasites indeed alter the IFN- $\gamma$-induced binding of GAF, i.e. Stat $1 \alpha$ dimers, to the GAS-sequence, while this is not the case in cells incubated with parasite lysate. This again confirms that viable $T$. gondii and parasite lysate differentially interfere with IFN- $\gamma$ induced signalling. Importantly, only viable $T$. gondii were found to induce the formation of an additional complex with GAS-binding activity. This protein-DNA complex contains Stat $1 \alpha$ as shown by supershift analyses, however, it clearly differs from the regular IFN- $\gamma$ induced complex by a considerably lower electromobility. It can therefore be concluded, that viable parasites, although not diminishing the overall DNA-binding activity of Stat $1 \alpha$, nevertheless clearly modulates the Stat1-GAS-complex. In contrast, parasite lysate do neither alter DNA-binding of Stat $1 \alpha$ nor the Stat $1 \alpha-G A S-c o m p l e x$.

The exact composition of the GAS-binding complex only induced in cells infected with viable $T$. gondii was of major interest because the molecules additionally associated with Stat1 $\alpha$ may be involved in the interference of $T$. gondii with Stat $1 \alpha$-dependent transcriptional activation. One possible explanation for the parasite-induced GAS-binding complex could be type I interferons, i.e. IFN- $\alpha$ and/or IFN- $\beta$, the autocrine secretion of which may be induced by $T$. gondii in murine macrophages. Such type I interferons induce the formation of the so called interferon-stimulated gene factor 3 (ISGF3), which is composed out of Stat1:Stat2 heterodimers and p48 (Fu et al., 1990). Furthermore, other members of the Stat family might be involved, the dimer-formation of which result from different stimuli (Akira, 1999). However, supershift analysis revealed that neither members of the Stat family, distinct from Stat1, nor p48 participate in the formation of the parasitemodulated GAS-binding complex. In addition, the stimulation of murine macrophages with 
IFN- $\beta$ alone or in combination with IFN- $\gamma$ do not result in the formation of a complex comparable to that observed after infection of macrophages with viable $T$. gondii. These results suggest that modulation of the Stat $1 \alpha$-GAS-complex as observed after infection with viable $T$. gondii is not due to type I interferons or other stimuli resulting in the interaction of GAF with other members of the Stat family. The lower electromobility of the parasite-modulated GAS-binding complex could also be due to the direct binding of a $T$. gondii-derived molecule interfering with transcriptional activation of IFN- $\gamma$-dependent genes. However, incubation of nuclear extracts from infected cells with GAS-containing oligonucleotides and anti-Toxoplasma serum do not lead to a supershift of the parasiteinduced complex (data not shown). However, this does not exclude a direct interaction of parasite-derived molecules with GAF-GAS complexes, since a parasite molecule could be involved that is not recognized by the polyclonal anti-Toxoplasma serum. Alternatively, a host cell-derived molecule might interact with Stat $1 \alpha$ and/or GAS, the activation of which might be directly or indirectly initiated by $T$. gondii. The exact composition of the parasiteinduced complex therefore remains unknown, but identification of the involved molecules might help to elucidate the mechanism employed by $T$. gondii interfering with the IFN- $\gamma$ induced transcriptional activation of IFN- $\gamma$ responsive genes.

As described above, viable $T$. gondii tachyzoites modulate Stat $1 \alpha$-GAS-complexes and this may diminish the transcription of Stat $1 \alpha$-dependent genes in response to IFN- $\gamma$. In order to determine whether T. gondii inhibits the association of Stat $1 \alpha$ with the GAS sequence or the association Stat $1 \alpha$-GAS-complex with other proteins involved in the activation of transcription, precipitation with GAS-containing oligonucleotides was performed. Analyses of the oligonucleotide-bound proteins by two-dimensional gelelectrophoresis revealed four distinctive spots that could only be detected in noninfected samples. These spots were identified as $\beta$ - or $\gamma$-actin and as tropomyosin 5 or 3 by MALDI-Tof analysis. Precipitation of $\beta$-actin with GAS-containing oligonucleotides is independent of IFN- $\gamma$ stimulation and therefore of Stat $1 \alpha$-binding to the GAS-sequence. This indicates a direct or indirect but constitutive interaction of $\beta$-actin with GAScontaining DNA. However, significantly less $\beta$-actin is pulled-down with GAS-containing oligonucleotides from $T$. gondii-infected cells compared to non-infected control cells. Further experiments revealed that the subcellular distribution of $\beta$-actin is not altered by viable $T$. gondii, indicating an interference with recruitment of $\beta$-actin to GAS-containing oligonucleotides. It was shown recently that $\beta$-actin is part of the basal transcription machinery, that it is required for the recruitment of polymerase II to the promoter and that 
it has crucial functions in RNA-polymerase II-based transcription (Franke, 2004; Hofmann et al., 2004). Therefore, interference of $T$. gondii with the association of $\beta$-actin to GAScontaining promoters might result in the abrogation of IFN- $\gamma$-induced transcriptional initiation in $T$. gondii-infected cells. This is the first report of a pathogen interfering with the recruitment of $\beta$-actin to the promoter region and possibly therefore diminishing the transcriptional activation of the distinctive gene. As described above, the precipitation of tropomyosin 3/5 with GAS-containing nucleotides is also abrogated in T. gondii-infected cell extracts. Tropomyosin binds actin (Perry, 2001) and the association with GAScontaining oligonulceotides might therefore only be due to the presence of $\beta$-actin in the precipitated complex. However, myosin-actin complexes were shown to be involved in transcription of RNA polymerase I (Fomproix and Percipalle, 2004; Philimonenko et al., 2004). Therefore, it might be speculated that tropomyosin bound to $\beta$-actin is also involved in transcriptional initiation and RNA polymerase II-mediated transcription. This would have to be further investigated in order to elucidate the involvement of tropomyosin and its role in $T$. gondii-mediated inhibition of transcriptional activation of GAS-containing promoters.

The histones $\mathrm{H} 3$ and $\mathrm{H} 4$ possess a highly conserved amino acid sequence at their $\mathrm{N}$ termini, the post-translational modification of which includes phosporylation, methylation and acetylation (Grunstein, 1997; Howe et al., 1999; Jenuwein and Allis 2001). Particularly, acetylation and deacetylation of histones are crucial for transcriptional activation of genes resulting in the remodelling of chromatin allowing or restricting access of the basal transcription machinery to the promoter region of specific genes (Eberharter and Becker 2002). The influence of viable $T$. gondii on the acetylation status of histone $\mathrm{H} 4$ on the CIITA promoter IV was analysed by ChIP. The results indicate, that $T$. gondii indeed inhibit the acetylation of histone 4 in response to IFN- $\gamma$ in infected cells. Importantly, this is the first report of a pathogen interfering with the acetylation status of H4. Comparable experiments were performed for M. tuberculosis, however, the bacterium was found not to inhibit acetylation of $\mathrm{H} 3$ and $\mathrm{H} 4$. According to the results described above, it can be hypothesized that $T$. gondii interferes with the transcriptional initiation of Stat $1 \alpha$-dependent promoters possibly by inhibiting chromatin remodelling in response to IFN- $\gamma$, thereby abrogating the access of the basal transcription machinery to the promoter region. The binding of Stat $1 \alpha$ to the GAS-sequence is accompanied by acetylation of $\mathrm{H} 3$ and $\mathrm{H} 4$ and is an early process during CIITA promoter IV assembly (Morris et al., 2002). 
Since T. gondii interferes with acetylation of $\mathrm{H} 4$ in response to IFN- $\gamma$ stimulation, the parasite appears to target the assembly of the transcription machinery at an early stage.

Taken together, these experiments reveal that $T$. gondii does not abrogate but modulate the DNA-binding of Stat1 $\alpha$ to its DNA consensus sequence. Furthermore, the recruitment of the preinitiation complex to the promoter region of distinctive genes is disturbed in infected cells. This may be due to the reduced acetylation of histone 4 as well as reduced association of $\beta$-actin being crucial for transcriptional initiation. Whether these two processes are linked or act independently should remain in the focus of further investigations. Importantly, such modifications of promoters mediated by $T$. gondii tachyzoites might not be limited to GAS-containing promoters but might be a more general effect of the parasite on gene expression of specific target genes altering the host cell physiology. For example, the inhibition of NF-кB-dependent expression by $T$. gondii (Butcher and Denkers, 2002; Dobbin et al., 2002) might also be partially due to reduced histone acetylation and/or interference with the assembly of the preinitiation complex on respective promoters. This would further underline the importance of this newly described parasite-host interaction for the course of infection. 


\section{Summary and Conclusion}

Viable $T$. gondii are able to interfere with the IFN- $\gamma$-induced up-regulation of MHC class II molecules and antigen presentation (Lüder et al., 2001) thereby partially evading an effective immune response of the host. In the present study, the mechanisms of the parasite-mediated inhibition of MHC class II expression in murine macrophages were analysed. Specifically, the parasite requirements as well as the mechanisms of interference with IFN- $\gamma$-mediated host cell signalling were characterized. The results show that viable T. gondii abrogate IFN- $\gamma$-induced expression of MHC class II molecules on the surface of the murine monocyte/macrophage tumor cell line RAW 264.7. Importantly, viable parasites not only diminish IFN- $\gamma$-mediated MHC class II expression but also interfere with a variety but not with all IFN- $\gamma$-responsive genes analysed. Concerning the parasite requirements for interference with IFN- $\gamma$-mediated gene expression, host cell invasion but not intracellular replication by $T$. gondii is required for the down-regulation of MHC class II expression. In addition, a crude $T$. gondii lysate is able to mimic the effect of viable parasites on MHC class II expression. However, the mechanisms employed by viable $T$. gondii or exerted by incubation with parasite lysate to inhibit IFN- $\gamma$-induced MHC class II expression clearly differ (see below). Thus, T. gondii or parasite-derived molecules exert diverse effects on IFN- $\gamma$-regulated gene expression. Since the inhibitory effect of the parasite lysate is partially abrogated after treatment with pronase, a parasite protein appears to be involved. Transwell experiments with isolated parasites separated from the macrophages by a semipermeable membrane suggest that the effector molecule is also released by extracellular parasites. However, different preparations of excretory/secretory antigens (ESA's) derived from the three ES organelles of $T$. gondii namely the rhoptries, the micronemes and the dense granules, did not interfere with IFN- $\gamma$-induced up-regulation of MHC class II genes.

As already mentioned above, analyses of the mechanisms of $T$. gondii-mediated inhibition of MHC class II expression revealed, that viable $T$. gondii and parasite lysate differentially interfere with IFN- $\gamma$-mediated signalling of host cells. While neither viable parasites nor parasite lysate interfere with nuclear translocation of Stat $1 \alpha$ in response to IFN- $\gamma$, only viable parasites decrease the transcript levels of both IRF-1 and CIITA. In contrast, $T$. gondii lysate only diminishes mRNA levels of CIITA. Reporter assays revealed that viable T. gondii and parasite lysate are both able to interfere with transcriptional activation of a luciferase reporter gene under the control of the CIITA promoter IV. However, only viable 
T. gondii interfere with the transcriptional activation of a minimal GAS-containing promoter driving luciferase. This further supports the finding of differential effects of viable parasites and parasite lysate on IFN- $\gamma$-induced signal transduction. Furthermore, $T$. gondii but not parasite lysate clearly diminish the formation of the IFN- $\gamma$-induced Stat $1 \alpha$ GAS complex. Importantly, however, viable parasites induce the formation of a GASbinding complex with lower electromobility containing Stat $1 \alpha$ and other unknown molecules. This clearly indicates that viable $T$. gondii, but not parasite lysate modulate the protein assembly at GAS-containing DNA-oligonucleotides. Analyses of proteins bound to GAS-containing sequences by 2D-gelelectrophoresis and MALDI-Tof revealed that viable T. gondii inhibit the direct or indirect recruitment of $\beta$-actin to the oligonucleotides. Importantly, $\beta$-actin was shown to be involved in the recruitment of the basal transcription machinery and of RNA polymerase II to the promoter region (Hofmann et al., 2004). Therefore, the inhibition of $\beta$-actin-binding to GAS-containing DNA by $T$. gondii may be involved in the parasite-mediated interference with IFN- $\gamma$-activated transcription. In addition, $T$. gondii also interferes with the acetylation of histone $\mathrm{H} 4$ on the CIITA promoter IV. This suggests that $T$. gondii interferes with chromatin remodelling as a crucial prerequisite for the recruitment of the basal transcription machinery to the CIITA promoter IV. This may then lead to a diminished transcriptional activity and reduced expression of CIITA, the lack of which block IFN- $\gamma$-induced up-regulation of MHC class II genes.

In conclusion, the results obtained in this study further characterize the complex interaction of $T$. gondii with its host. Since IFN- $\gamma$ is the major mediator involved in the immune response of the host in order to control $T$. gondii-infection, it is not surprising, that $T$. gondii inhibits IFN- $\gamma$-mediated signalling. It appears that $T$. gondii differentially interfere with IFN- $\gamma$-induced gene expression probably leading to a delicate balance between suppression of host immune mechanisms in order to support establishment of infection on the one hand and an adequate immune response to guarantee host survival on the other hand. Importantly, according to results obtained in this study concerning the mechanism of parasite-mediated inhibition of IFN- $\gamma$-induced transcriptional activation, it can be hypothesized that $T$. gondii interfere with the histone modifications of, but not necessarily limited to, GAS-containing promoters responsive to stimulation with IFN- $\gamma$. This interference may result in diminished chromatin remodelling thereby successfully inhibiting the assembly of the basal transcription machinery and transcriptional activation by $T$. gondii. In addition, alteration of the assembly of the preinitiation comples as a 
prerequisite for transcriptional activation may also occur independently of a disturbed histone modification in $T$. gondii-infected cells. As a consequence, this may then lead to a diminished activation-induced expression of IFN- $\gamma$-responsive but possibly also other genes.

Further experiments are clearly needed to dissect the exact mechanisms of viable $T$. gondii interfering with the transcriptional activation of GAS-containing promoters. Nevertheless, within this study, the principal target of $T$. gondii to down-regulate IFN- $\gamma$-regulated MHC class II expression, i.e. chromatin remodelling and assembly of the machinery required for initiation of transcription has been determined. The identification of the composition of the parasite-induced GAS-binding complex might not only elucidate the cell biological mechanisms of interference of $T$. gondii with the assembly of transcription-activating factors at GAS-containing promoters but will possibly also identify parasite molecules involved in this process. Knowledge of the parasite factors responsible for this interaction will then possibly allow elucidation of the impact of this evasion strategy for the parasitehost interaction. Since transfection of $T$. gondii is well established, targeted disruption of the respective parasitic gene is clearly feasible. Another important field of further investigations is the effect of $T$. gondii on chromatin modification and transcription initiation at other promoters than those containing GAS-sequences. It is, for example known that $T$. gondii also partially blocks the NF-кB-mediated up-regulation of proinflammatory genes. Therefore, it will be interesting to elucidate whether chromatin modification and initiation of transcription is also targeted at promoters others than those containing GAS sequences. Such information will certainly give further insights into the general effect of $T$. gondii on the transcription machinery of the host cell. 


\section{References}

Accolla, R. S., De Lerma Barbaro, A., Mazza, S., Casoli, C., De Maria, A. and Tosi, G. (2001). "The MHC class II transactivator: prey and hunter in infectious diseases." Trends Immunol 22(10): 560-3.

Adams, L. B., Hibbs, J. B., Jr., Taintor, R. R. and Krahenbuhl, J. L. (1990).

"Microbiostatic effect of murine-activated macrophages for Toxoplasma gondii. Role for synthesis of inorganic nitrogen oxides from L-arginine." J Immunol 144(7): 2725-9.

Akira, S. (1999). "Functional roles of STAT family proteins: lessons from knockout mice." Stem Cells 17(3): 138-46.

Ambroise-Thomas, P. and Pelloux, H. (1993). "Toxoplasmosis - congenital and in immunocompromised patients: A parallel." Parasitol Today 9(2): 61-3.

Bach, E. A., Aguet, M. and Schreiber, R. D. (1997). "The IFN gamma receptor: a paradigm for cytokine receptor signaling." Annu Rev Immunol 15: 563-91.

Berger, S. L. (2001). "An embarrassment of niches: the many covalent modifications of histones in transcriptional regulation." Oncogene 20(24): 3007-13.

Berlato, C., Cassatella, M. A., Kinjyo, I., Gatto, L., Yoshimura, A. and Bazzoni, F. (2002). "Involvement of suppressor of cytokine signaling-3 as a mediator of the inhibitory effects of IL-10 on lipopolysaccharide-induced macrophage activation." J Immunol 168(12): 6404-11.

Bliss, S. K., Zhang, Y. and Denkers, E. Y. (1999). "Murine neutrophil stimulation by Toxoplasma gondii antigen drives high level production of IFN-gamma-independent IL12." J Immunol 163(4): 2081-8.

Boehm, U., Klamp, T., Groot, M. and Howard, J. C. (1997). "Cellular responses to interferon-gamma." Annu Rev Immunol 15: 749-95.

Bogdan, C. and Rollinghoff, M. (1999). "How do protozoan parasites survive inside macrophages?" Parasitol Today 15(1): 22-8.

Bohne, W., Holpert, M. and Gross, U. (1999). "Stage differentiation of the protozoan parasite Toxoplasma gondii." Immunobiology 201(2): 248-54.

Boss, J. M. (1997). "Regulation of transcription of MHC class II genes." Curr Opin Immunol 9(1): 107-13.

Brodsky, F. M. and Guagliardi, L. E. (1991). "The cell biology of antigen processing and presentation." Annu Rev Immunol 9: 707-44.

Carey, K. L., Jongco, A. M., Kim, K. and Ward, G. E. (2004). "The Toxoplasma gondii rhoptry protein ROP4 is secreted into the parasitophorous vacuole and becomes phosphorylated in infected cells." Eukaryot Cell 3(5): 1320-30. 
Carruthers, V. B., Moreno, S. N. and Sibley, L. D. (1999). "Ethanol and acetaldehyde elevate intracellular [Ca2+] and stimulate microneme discharge in Toxoplasma gondii." Biochem J 342 ( Pt 2): 379-86.

Cesbron-Delauw, M. F. and Capron, A. (1993). "Excreted/secreted antigens of Toxoplasma gondii--their origin and role in the host-parasite interaction." Res Immunol 144(1): 41-4.

Cesbron-Delauw, M. F. (1994). "Dense-granule organelles of Toxoplasma gondii: Their role in the host-parasite relationship." Parasitol Today 10(8): 293-6.

Chao, C. C., Gekker, G., Hu, S. and Peterson, P. K. (1994). "Human microglial cell defense against Toxoplasma gondii. The role of cytokines." J Immunol 152(3): 1246-52.

Chatterjee-Kishore, M., Van Den Akker, F. and Stark, G. R. (2000). "Adenovirus E1A down-regulates LMP2 transcription by interfering with the binding of stat1 to IRF1." J Biol Chem 275(27): 20406-11.

Chitnis, C. E. and Blackman, M. J. (2000). "Host cell invasion by malaria parasites." Parasitol Today 16(10): 411-5.

Chon, S. Y., Hassanain, H. H. and Gupta, S. L. (1996). "Cooperative role of interferon regulatory factor 1 and p91 (STAT1) response elements in interferon-gamma-inducible expression of human indoleamine 2,3-dioxygenase gene." J Biol Chem 271(29): 17247-52.

Collazo, C. M., Yap, G. S., Hieny, S., Caspar, P., Feng, C. G., Taylor, G. A. and Sher, A. (2002). "The function of gamma interferon-inducible GTP-binding protein IGTP in host resistance to Toxoplasma gondii is Stat1 dependent and requires expression in both hematopoietic and nonhematopoietic cellular compartments." Infect Immun 70(12): 69339 .

Daubener, W., Remscheid, C., Nockemann, S., Pilz, K., Seghrouchni, S., Mackenzie, C. and Hadding, U. (1996). "Anti-parasitic effector mechanisms in human brain tumor cells: role of interferon-gamma and tumor necrosis factor-alpha." Eur J Immunol 26(2): 487-92.

De Souza Leao, S., Lang, T., Prina, E., Hellio, R. and Antoine, J. C. (1995). "Intracellular Leishmania amazonensis amastigotes internalize and degrade MHC class II molecules of their host cells." J Cell Sci 108 ( Pt 10): 3219-31.

De Waal Malefyt, R., Haanen, J., Spits, H., Roncarolo, M. G., Te Velde, A., Figdor, C., Johnson, K., Kastelein, R., Yssel, H. and De Vries, J. E. (1991). "Interleukin 10 (IL-10) and viral IL-10 strongly reduce antigen-specific human T cell proliferation by diminishing the antigen-presenting capacity of monocytes via downregulation of class II major histocompatibility complex expression." J Exp Med 174(4): 915-24.

Decker, T., Kovarik, P. and Meinke, A. (1997). "GAS elements: a few nucleotides with a major impact on cytokine-induced gene expression." J Interferon Cytokine Res 17(3): 12134.

Denkers, E. Y. and Gazzinelli, R. T. (1998). "Regulation and function of T-cell-mediated immunity during Toxoplasma gondii infection." Clin Microbiol Rev 11(4): 569-88. 
Dobrowolski, J. M. and Sibley, L. D. (1996). "Toxoplasma invasion of mammalian cells is powered by the actin cytoskeleton of the parasite." Cell 84(6): 933-9.

Donnelly, R. P., Dickensheets, H. and Finbloom, D. S. (1999). "The interleukin-10 signal transduction pathway and regulation of gene expression in mononuclear phagocytes." $\mathrm{J}$ Interferon Cytokine Res 19(6): 563-73.

Dubey, J. P. (1998). "Advances in the life cycle of Toxoplasma gondii." Int J Parasitol 28(7): 1019-24.

Dubremetz, J. F. (1998). "Host cell invasion by Toxoplasma gondii." Trends Microbiol 6(1): 27-30.

Dubremetz, J. F., Garcia-Reguet, N., Conseil, V. and Fourmaux, M. N. (1998). "Apical organelles and host-cell invasion by Apicomplexa." Int J Parasitol 28(7): 1007-13.

Eberharter, A. and Becker, P. B. (2002). "Histone acetylation: a switch between repressive and permissive chromatin. Second in review series on chromatin dynamics." EMBO Rep 3(3): 224-9.

Endo, T., Pelster, B. and Piekarski, G. (1981). "Infection of murine peritoneal macrophages with Toxoplasma gondii exposed to ultraviolet light." Z Parasitenkd 65(2): 121-9.

Everett, H. and Mcfadden, G. (1999). "Apoptosis: an innate immune response to virus infection." Trends Microbiol 7(4): 160-5.

Fagerlund, R., Melen, K., Kinnunen, L. and Julkunen, I. (2002). "Arginine/lysine-rich nuclear localization signals mediate interactions between dimeric STATs and importin alpha 5." J Biol Chem 277(33): 30072-8.

Ferreira, M. S. and Borges, A. S. (2002). "Some aspects of protozoan infections in immunocompromised patients- a review." Mem Inst Oswaldo Cruz 97(4): 443-57.

Fomproix, N. and Percipalle, P. (2004). "An actin-myosin complex on actively transcribing genes." Exp Cell Res 294(1): 140-8.

Franke, W. W. (2004). "Actin's many actions start at the genes." Nat Cell Biol 6(11): 10134.

Frenkel, J. K., Dubey, J. P. and Miller, N. L. (1970). "Toxoplasma gondii in cats: fecal stages identified as coccidian oocysts." Science 167(919): 893-6.

Frenkel, J. K. (1988). "Pathophysiology of toxoplasmosis." Parasitol Today 4(10): 273-8.

Fruth, U., Solioz, N. and Louis, J. A. (1993). "Leishmania major interferes with antigen presentation by infected macrophages." J Immunol 150(5): 1857-64.

Fu, X. Y., Kessler, D. S., Veals, S. A., Levy, D. E. and Darnell, J. E., Jr. (1990). "ISGF3, the transcriptional activator induced by interferon alpha, consists of multiple interacting polypeptide chains." Proc Natl Acad Sci U S A 87(21): 8555-9. 
Ganster, R. W., Taylor, B. S., Shao, L. and Geller, D. A. (2001). "Complex regulation of human inducible nitric oxide synthase gene transcription by Stat 1 and NF-kappa B." Proc Natl Acad Sci U S A 98(15): 8638-43.

Garcin, D., Marq, J. B., Strahle, L., Le Mercier, P. and Kolakofsky, D. (2002). "All four Sendai Virus C proteins bind Stat1, but only the larger forms also induce its monoubiquitination and degradation." Virology 295(2): 256-65.

Gazzinelli, R. T., Hakim, F. T., Hieny, S., Shearer, G. M. and Sher, A. (1991). "Synergistic role of CD4+ and CD8+ T lymphocytes in IFN-gamma production and protective immunity induced by an attenuated Toxoplasma gondii vaccine." J Immunol 146(1): 28692.

Gazzinelli, R., Xu, Y., Hieny, S., Cheever, A. and Sher, A. (1992). "Simultaneous depletion of CD4+ and CD8+ T lymphocytes is required to reactivate chronic infection with Toxoplasma gondii." J Immunol 149(1): 175-80.

Gazzinelli, R. T., Hieny, S., Wynn, T. A., Wolf, S. and Sher, A. (1993). "Interleukin 12 is required for the T-lymphocyte-independent induction of interferon gamma by an intracellular parasite and induces resistance in T-cell-deficient hosts." Proc Natl Acad Sci U S A 90(13): 6115-9.

Gazzinelli, R. T., Wysocka, M., Hayashi, S., Denkers, E. Y., Hieny, S., Caspar, P., Trinchieri, G. and Sher, A. (1994). "Parasite-induced IL-12 stimulates early IFN-gamma synthesis and resistance during acute infection with Toxoplasma gondii." J Immunol 153(6): 2533-43.

Gazzinelli, R. T., Wysocka, M., Hieny, S., Scharton-Kersten, T., Cheever, A., Kuhn, R., Muller, W., Trinchieri, G. and Sher, A. (1996). "In the absence of endogenous IL-10, mice acutely infected with Toxoplasma gondii succumb to a lethal immune response dependent on CD4+ T cells and accompanied by overproduction of IL-12, IFN-gamma and TNFalpha." J Immunol 157(2): 798-805.

Gehring, A. J., Rojas, R. E., Canaday, D. H., Lakey, D. L., Harding, C. V. and Boom, W. H. (2003). "The Mycobacterium tuberculosis 19-kilodalton lipoprotein inhibits gamma interferon-regulated HLA-DR and Fc gamma R1 on human macrophages through Toll-like receptor 2." Infect Immun 71(8): 4487-97.

Goebel, S., Gross, U. and Luder, C. G. (2001). "Inhibition of host cell apoptosis by Toxoplasma gondii is accompanied by reduced activation of the caspase cascade and alterations of poly(ADP-ribose) polymerase expression." J Cell Sci 114(Pt 19): 3495-505.

Greenlund, A. C., Farrar, M. A., Viviano, B. L. and Schreiber, R. D. (1994). "Ligandinduced IFN gamma receptor tyrosine phosphorylation couples the receptor to its signal transduction system (p91)." Embo J 13(7): 1591-600. 
Gross, U., Muller, W. A., Knapp, S. and Heesemann, J. (1991). "Identification of a virulence-associated antigen of Toxoplasma gondii by use of a mouse monoclonal antibody." Infect Immun 59(12): 4511-6.

Gross, U. and Bohne, W. (1994). "Toxoplasma gondii: strain- and host cell-dependent induction of stage differentiation." J Eukaryot Microbiol 41(5): 10S-11S.

Grunstein, M. (1997). "Histone acetylation in chromatin structure and transcription." Nature 389(6649): 349-52.

Halonen, S. K., Chiu, F. and Weiss, L. M. (1998). "Effect of cytokines on growth of Toxoplasma gondii in murine astrocytes." Infect Immun 66(10): 4989-93.

Haspel, R. L. and Darnell, J. E., Jr. (1999). "A nuclear protein tyrosine phosphatase is required for the inactivation of Stat1." Proc Natl Acad Sci U S A 96(18): 10188-93.

Heemels, M. T. and Ploegh, H. (1995). "Generation, translocation, and presentation of MHC class I-restricted peptides." Annu Rev Biochem 64: 463-91.

Herrero, C., Hu, X., Li, W. P., Samuels, S., Sharif, M. N., Kotenko, S. and Ivashkiv, L. B. (2003). "Reprogramming of IL-10 activity and signaling by IFN-gamma." J Immunol 171(10): 5034-41.

Heussler, V. T., Kuenzi, P. and Rottenberg, S. (2001). "Inhibition of apoptosis by intracellular protozoan parasites." Int J Parasitol 31(11): 1166-76.

Hofmann, W. A., Stojiljkovic, L., Fuchsova, B., Vargas, G. M., Mavrommatis, E., Philimonenko, V., Kysela, K., Goodrich, J. A., Lessard, J. L., Hope, T. J., Hozak, P. and De Lanerolle, P. (2004). "Actin is part of pre-initiation complexes and is necessary for transcription by RNA polymerase II." Nat Cell Biol 6(11): 1094-101.

Howe, L., Brown, C. E., Lechner, T. and Workman, J. L. (1999). "Histone acetyltransferase complexes and their link to transcription." Crit Rev Eukaryot Gene Expr 9(3-4): 231-43.

Jenuwein, T. and Allis, C. D. (2001). "Translating the histone code." Science 293(5532): 1074-80.

Joiner, K. A., Fuhrman, S. A., Miettinen, H. M., Kasper, L. H. and Mellman, I. (1990). "Toxoplasma gondii: fusion competence of parasitophorous vacuoles in Fc receptortransfected fibroblasts." Science 249(4969): 641-6.

Joiner, K. A. and Dubremetz, J. F. (1993). "Toxoplasma gondii: a protozoan for the nineties." Infect Immun 61(4): 1169-72.

Jones, T. C. and Hirsch, J. G. (1972). "The interaction between Toxoplasma gondii and mammalian cells. II. The absence of lysosomal fusion with phagocytic vacuoles containing living parasites." J Exp Med 136(5): 1173-94.

Jones, E. Y. (1997). "MHC class I and class II structures." Curr Opin Immunol 9(1): 75-9. 
Keating, S., Prince, S., Jones, M. and Rowe, M. (2002). "The lytic cycle of Epstein-Barr virus is associated with decreased expression of cell surface major histocompatibility complex class I and class II molecules." J Virol 76(16): 8179-88.

Kincaid, E. Z. and Ernst, J. D. (2003). "Mycobacterium tuberculosis exerts gene-selective inhibition of transcriptional responses to IFN-gamma without inhibiting STAT1 function." J Immunol 171(4): 2042-9.

Korzus, E., Torchia, J., Rose, D. W., Xu, L., Kurokawa, R., Mcinerney, E. M., Mullen, T. M., Glass, C. K. and Rosenfeld, M. G. (1998). "Transcription factor-specific requirements for coactivators and their acetyltransferase functions." Science 279(5351): 703-7.

Koster, M. and Hauser, H. (1999). "Dynamic redistribution of STAT1 protein in IFN signaling visualized by GFP fusion proteins." Eur J Biochem 260(1): 137-44.

Kovacsovics-Bankowski, M., Clark, K., Benacerraf, B. and Rock, K. L. (1993). "Efficient major histocompatibility complex class I presentation of exogenous antigen upon phagocytosis by macrophages." Proc Natl Acad Sci U S A 90(11): 4942-6.

Kovacsovics-Bankowski, M. and Rock, K. L. (1995). "A phagosome-to-cytosol pathway for exogenous antigens presented on MHC class I molecules." Science 267(5195): 243-6.

Kroger, A., Ortmann, D., Krohne, T. U., Mohr, L., Blum, H. E., Hauser, H. and Geissler, M. (2001). "Growth suppression of the hepatocellular carcinoma cell line Hepa1-6 by an activatable interferon regulatory factor-1 in mice." Cancer Res 61(6): 2609-17.

Kuhn, R., Lohler, J., Rennick, D., Rajewsky, K. and Muller, W. (1993). "Interleukin-10deficient mice develop chronic enterocolitis." Cell 75(2): 263-74.

Langermans, J. A., Van Der Hulst, M. E., Nibbering, P. H. and Van Furth, R. (1992). "Endogenous tumor necrosis factor alpha is required for enhanced antimicrobial activity against Toxoplasma gondii and Listeria monocytogenes in recombinant gamma interferontreated mice." Infect Immun 60(12): 5107-12.

Look, D. C., Pelletier, M. R. and Holtzman, M. J. (1994). "Selective interaction of a subset of interferon-gamma response element-binding proteins with the intercellular adhesion molecule-1 (ICAM-1) gene promoter controls the pattern of expression on epithelial cells." J Biol Chem 269(12): 8952-8.

Luder, C. G., Lang, T., Beuerle, B. and Gross, U. (1998). "Down-regulation of MHC class II molecules and inability to up-regulate class I molecules in murine macrophages after infection with Toxoplasma gondii." Clin Exp Immunol 112(2): 308-16.

Luder, C. G., Walter, W., Beuerle, B., Maeurer, M. J. and Gross, U. (2001). "Toxoplasma gondii down-regulates MHC class II gene expression and antigen presentation by murine macrophages via interference with nuclear translocation of STAT1alpha." Eur J Immunol 31(5): 1475-84.

Luder, C. G. and Seeber, F. (2001). "Toxoplasma gondii and MHC-restricted antigen presentation: on degradation, transport and modulation." Int J Parasitol 31(12): 1355-69. 
Luder, C. G., Lang, C., Giraldo-Velasquez, M., Algner, M., Gerdes, J. and Gross, U. (2003). "Toxoplasma gondii inhibits MHC class II expression in neural antigen-presenting cells by down-regulating the class II transactivator CIITA." J Neuroimmunol 134(1-2): 1224.

Luder, C. G., Algner, M., Lang, C., Bleicher, N. and Gross, U. (2003). "Reduced expression of the inducible nitric oxide synthase after infection with Toxoplasma gondii facilitates parasite replication in activated murine macrophages." Int J Parasitol 33(8): 83344.

Masternak, K. and Reith, W. (2002). "Promoter-specific functions of CIITA and the MHC class II enhanceosome in transcriptional activation." Embo J 21(6): 1379-88.

Mcbride, K. M., Mcdonald, C. and Reich, N. C. (2000). "Nuclear export signal located within theDNA-binding domain of the STAT1transcription factor." Embo J 19(22): 6196206.

Mcbride, K. M., Banninger, G., Mcdonald, C. and Reich, N. C. (2002). "Regulated nuclear import of the STAT1 transcription factor by direct binding of importin-alpha." Embo J 21(7): 1754-63.

McGavin D.D.M..'Ophthalmology in the topics and subtopics; in: Manson's tropical diseases"; ed. Cook,G.C.; WB Saunders Company, London 2996;278.

Melen, K., Kinnunen, L. and Julkunen, I. (2001). "Arginine/lysine-rich structural element is involved in interferon-induced nuclear import of STATs." J Biol Chem 276(19): 1644755.

Meyer, T., Marg, A., Lemke, P., Wiesner, B. and Vinkemeier, U. (2003). "DNA binding controls inactivation and nuclear accumulation of the transcription factor Stat1." Genes Dev 17(16): 1992-2005.

Miller, D. M., Rahill, B. M., Boss, J. M., Lairmore, M. D., Durbin, J. E., Waldman, J. W. and Sedmak, D. D. (1998). "Human cytomegalovirus inhibits major histocompatibility complex class II expression by disruption of the Jak/Stat pathway." J Exp Med 187(5): 675-83.

Mordue, D. G., Desai, N., Dustin, M. and Sibley, L. D. (1999). "Invasion by Toxoplasma gondii establishes a moving junction that selectively excludes host cell plasma membrane proteins on the basis of their membrane anchoring." J Exp Med 190(12): 1783-92.

Morris, A. C., Beresford, G. W., Mooney, M. R. and Boss, J. M. (2002). "Kinetics of a gamma interferon response: expression and assembly of CIITA promoter IV and inhibition by methylation." Mol Cell Biol 22(13): 4781-91.

Muhlethaler-Mottet, A., Otten, L. A., Steimle, V. and Mach, B. (1997). "Expression of MHC class II molecules in different cellular and functional compartments is controlled by differential usage of multiple promoters of the transactivator CIITA." Embo J 16(10): 2851-60. 
Murray, H. W., Juangbhanich, C. W., Nathan, C. F. and Cohn, Z. A. (1979). "Macrophage oxygen-dependent antimicrobial activity. II. The role of oxygen intermediates." J Exp Med 150(4): 950-64.

Nagabhushanam, V., Solache, A., Ting, L. M., Escaron, C. J., Zhang, J. Y. and Ernst, J. D. (2003). "Innate inhibition of adaptive immunity: Mycobacterium tuberculosis-induced IL-6 inhibits macrophage responses to IFN-gamma." J Immunol 171(9): 4750-7.

Najarro, P., Traktman, P. and Lewis, J. A. (2001). "Vaccinia virus blocks gamma interferon signal transduction: viral VH1 phosphatase reverses Stat1 activation." J Virol 75(7): 3185-96.

Nash, P. B., Purner, M. B., Leon, R. P., Clarke, P., Duke, R. C. and Curiel, T. J. (1998). "Toxoplasma gondii-infected cells are resistant to multiple inducers of apoptosis." J Immunol 160(4): 1824-30.

O'keefe, G. M., Nguyen, V. T. and Benveniste, E. N. (1999). "Class II transactivator and class II MHC gene expression in microglia: modulation by the cytokines TGF-beta, IL-4, IL-13 and IL-10." Eur J Immunol 29(4): 1275-85.

Otten, L. A., Steimle, V., Bontron, S. and Mach, B. (1998). "Quantitative control of MHC class II expression by the transactivator CIITA." Eur J Immunol 28(2): 473-8.

Pai, R. K., Askew, D., Boom, W. H. and Harding, C. V. (2002). "Regulation of class II MHC expression in APCs: roles of types I, III, and IV class II transactivator." J Immunol 169(3): 1326-33.

Pai, R. K., Convery, M., Hamilton, T. A., Boom, W. H. and Harding, C. V. (2003). "Inhibition of IFN-gamma-induced class II transactivator expression by a 19-kDa lipoprotein from Mycobacterium tuberculosis: a potential mechanism for immune evasion." J Immunol 171(1): 175-84.

Paquette, R. L., Minosa, M. R., Verma, M. C., Nimer, S. D. and Koeffler, H. P. (1995). "An interferon-gamma activation sequence mediates the transcriptional regulation of the IgG Fc receptor type IC gene by interferon-gamma." Mol Immunol 32(12): 841-51.

Philimonenko, V. V., Zhao, J., Iben, S., Dingova, H., Kysela, K., Kahle, M., Zentgraf, H., Hofmann, W. A., De Lanerolle, P., Hozak, P. and Grummt, I. (2004). "Nuclear actin and myosin I are required for RNA polymerase I transcription." Nat Cell Biol 6(12): 1165-72.

Popkin, D. L., Watson, M. A., Karaskov, E., Dunn, G. P., Bremner, R. and Virgin, H. W. T. (2003). "Murine cytomegalovirus paralyzes macrophages by blocking IFN gammainduced promoter assembly." Proc Natl Acad Sci U S A 100(24): 14309-14.

Ramana, C. V., Grammatikakis, N., Chernov, M., Nguyen, H., Goh, K. C., Williams, B. R. and Stark, G. R. (2000). "Regulation of c-myc expression by IFN-gamma through Stat1dependent and -independent pathways." Embo J 19(2): 263-72. 
Reiner, N. E., Ng, W. and Mcmaster, W. R. (1987). "Parasite-accessory cell interactions in murine leishmaniasis. II. Leishmania donovani suppresses macrophage expression of class I and class II major histocompatibility complex gene products." J Immunol 138(6): 192632.

Reis E Sousa, C., Hieny, S., Scharton-Kersten, T., Jankovic, D., Charest, H., Germain, R. N. and Sher, A. (1997). "In vivo microbial stimulation induces rapid CD40 ligandindependent production of interleukin 12 by dendritic cells and their redistribution to $\mathrm{T}$ cell areas." J Exp Med 186(11): 1819-29.

Riley, J. K., Takeda, K., Akira, S. and Schreiber, R. D. (1999). "Interleukin-10 receptor signaling through the JAK-STAT pathway. Requirement for two distinct receptor-derived signals for anti-inflammatory action." J Biol Chem 274(23): 16513-21.

Rozenfeld, C., Martinez, R., Figueiredo, R. T., Bozza, M. T., Lima, F. R., Pires, A. L., Silva, P. M., Bonomo, A., Lannes-Vieira, J., De Souza, W. and Moura-Neto, V. (2003). "Soluble factors released by Toxoplasma gondii-infected astrocytes down-modulate nitric oxide production by gamma interferon-activated microglia and prevent neuronal degeneration." Infect Immun 71(4): 2047-57.

Schwab, J. C., Beckers, C. J. and Joiner, K. A. (1994). "The parasitophorous vacuole membrane surrounding intracellular Toxoplasma gondii functions as a molecular sieve." Proc Natl Acad Sci U S A 91(2): 509-13.

Schwarzer, E., Alessio, M., Ulliers, D. and Arese, P. (1998). "Phagocytosis of the malarial pigment, hemozoin, impairs expression of major histocompatibility complex class II antigen, CD54, and CD11c in human monocytes." Infect Immun 66(4): 1601-6.

Sekimoto, T., Imamoto, N., Nakajima, K., Hirano, T. and Yoneda, Y. (1997). "Extracellular signal-dependent nuclear import of Stat1 is mediated by nuclear poretargeting complex formation with NPI-1, but not Rch1." Embo J 16(23): 7067-77.

Seliger, B., Hammers, S., Hohne, A., Zeidler, R., Knuth, A., Gerharz, C. D. and Huber, C. (1997). "IFN-gamma-mediated coordinated transcriptional regulation of the human TAP-1 and LMP-2 genes in human renal cell carcinoma." Clin Cancer Res 3(4): 573-8.

Sher, A., Oswald, I. P., Hieny, S. and Gazzinelli, R. T. (1993). "Toxoplasma gondii induces a T-independent IFN-gamma response in natural killer cells that requires both adherent accessory cells and tumor necrosis factor-alpha." J Immunol 150(9): 3982-9.

Sibley, L. D., Weidner, E. and Krahenbuhl, J. L. (1985). "Phagosome acidification blocked by intracellular Toxoplasma gondii." Nature 315(6018): 416-9.

Sibley, L. D., Adams, L. B., Fukutomi, Y. and Krahenbuhl, J. L. (1991). "Tumor necrosis factor-alpha triggers antitoxoplasmal activity of IFN-gamma primed macrophages." J Immunol 147(7): 2340-5.

Sibley, L. D. (2003). "Toxoplasma gondii: perfecting an intracellular life style." Traffic 4(9): 581-6. 
Sinai, A. P. and Joiner, K. A. (2001). "The Toxoplasma gondii protein ROP2 mediates host organelle association with the parasitophorous vacuole membrane." J Cell Biol 154(1): 95108.

Sinai, A. P., Payne, T. M., Carmen, J. C., Hardi, L., Watson, S. J. and Molestina, R. E. (2004). "Mechanisms underlying the manipulation of host apoptotic pathways by Toxoplasma gondii." Int J Parasitol 34(3): 381-91.

Smith, J. E. (1995). "A ubiquitous intracellular parasite: the cellular biology of Toxoplasma gondii." Int J Parasitol 25(11): 1301-9.

Stafford, J. L., Neumann, N. F. and Belosevic, M. (2002). "Macrophage-mediated innate host defense against protozoan parasites." Crit Rev Microbiol 28(3): 187-248.

Steimle, V., Siegrist, C. A., Mottet, A., Lisowska-Grospierre, B. and Mach, B. (1994). "Regulation of MHC class II expression by interferon-gamma mediated by the transactivator gene CIITA." Science 265(5168): 106-9.

Suzuki, Y. and Remington, J. S. (1988). "Dual regulation of resistance against Toxoplasma gondii infection by Lyt-2+ and Lyt-1+, L3T4+ T cells in mice." J Immunol 140(11): 39436.

Suzuki, Y., Orellana, M. A., Schreiber, R. D. and Remington, J. S. (1988). "Interferongamma: the major mediator of resistance against Toxoplasma gondii." Science 240(4851): 516-8.

Tenter, A. M., Heckeroth, A. R. and Weiss, L. M. (2000). "Toxoplasma gondii: from animals to humans." Int J Parasitol 30(12-13): 1217-58.

Ting, J. P. and Trowsdale, J. (2002). "Genetic control of MHC class II expression." Cell 109 Suppl: S21-33.

Tomazin, R., Boname, J., Hegde, N. R., Lewinsohn, D. M., Altschuler, Y., Jones, T. R., Cresswell, P., Nelson, J. A., Riddell, S. R. and Johnson, D. C. (1999). "Cytomegalovirus US2 destroys two components of the MHC class II pathway, preventing recognition by CD4+ T cells." Nat Med 5(9): 1039-43.

Wadia, J. S. and Dowdy, S. F. (2002). "Protein transduction technology." Curr Opin Biotechnol 13(1): 52-6.

Williams, G. T. (1994). "Programmed cell death: a fundamental protective response to pathogens." Trends Microbiol 2(12): 463-4.

Williams, L., Bradley, L., Smith, A. and Foxwell, B. (2004). "Signal transducer and activator of transcription 3 is the dominant mediator of the anti-inflammatory effects of IL10 in human macrophages." J Immunol 172(1): 567-76.

Woolsey, A. M. and Burleigh, B. A. (2004). "Host cell actin polymerization is required for cellular retention of Trypanosoma cruzi and early association with endosomal/lysosomal compartments." Cell Microbiol 6(9): 829-38. 
Yang, T. H., Aosai, F., Norose, K., Ueda, M. and Yano, A. (1996). "Differential regulation of HLA-DR expression and antigen presentation in Toxoplasma gondii-infected melanoma cells by interleukin 6 and interferon gamma." Microbiol Immunol 40(6): 443-9.

Zhong, G., Fan, T. and Liu, L. (1999). "Chlamydia inhibits interferon gamma-inducible major histocompatibility complex class II expression by degradation of upstream stimulatory factor 1." J Exp Med 189(12): 1931-8.

Zhu, M., John, S., Berg, M. and Leonard, W. J. (1999). "Functional association of Nmi with Stat5 and Stat1 in IL-2- and IFNgamma-mediated signaling." Cell 96(1): 121-30. 


\section{Curriculum vitea}

\section{Personal data}

- Christine Lang

- Rohnsweg 4, D-37085 Göttingen, Germany

- E-mail: clang @stud.uni-goettingen.de

- Phone : +449-551-5177629

- Date \& place of birth : January 26th, 1977 , Göttingen, Germany

\section{School education}

june 1996

july 1996-july 1997

\section{Stay abroad}

\author{
,Abitur' Felix-Klein-Gymnasium \\ Göttingen
}

\section{University}

october 1997 - july 2000

\author{
Georg-August-University Göttingen \\ Basic and main studies in Biology
}

october 2000 -august 2001

International graduate program

Molecular Biology offered by

Georg-August-University Göttingen

and Max-Planck-Research-School

october 2001 - june 2002
Master Thesis : 'Identification of parasite requirements for down-regulation of $\mathrm{MHC}$ 
class II molecules in murine

macrophages by Toxoplasma gondii "

(Göttingen)

since june 2002

Ph.D. studies: ' Interference of

Toxoplasma gondii with IFN- $\gamma$ -

regulated gene expression of its host

cell' (Göttingen).

Financed by the Georg Christoph

Lichtenberg Stipend and DFG

june 2002/ march 2003/

april 2004

november 2002/

october 2003

september 2003-april 2004
Research assistant, University Göttingen:

tutorials for the lecture „Viruses and

Cancer" for Master students (in Englisch)

Method course concerning „SDS-

Page und Western Blot" for

Master students (in Englisch)

Training of apprentice for laboratory

assistant

very good

basic

German: native language 
IT-skills

Basic knowledge in different operating systems (Windows/Mac)

and different software (MS Office, Adobe Photoshop, Netscape...)

\section{Hobbies and special interest}

riding, skiing, jogging, reading, swimming 